\title{
Credit Trading and Wind Power: Issues and Opportunities
}

Resource Document

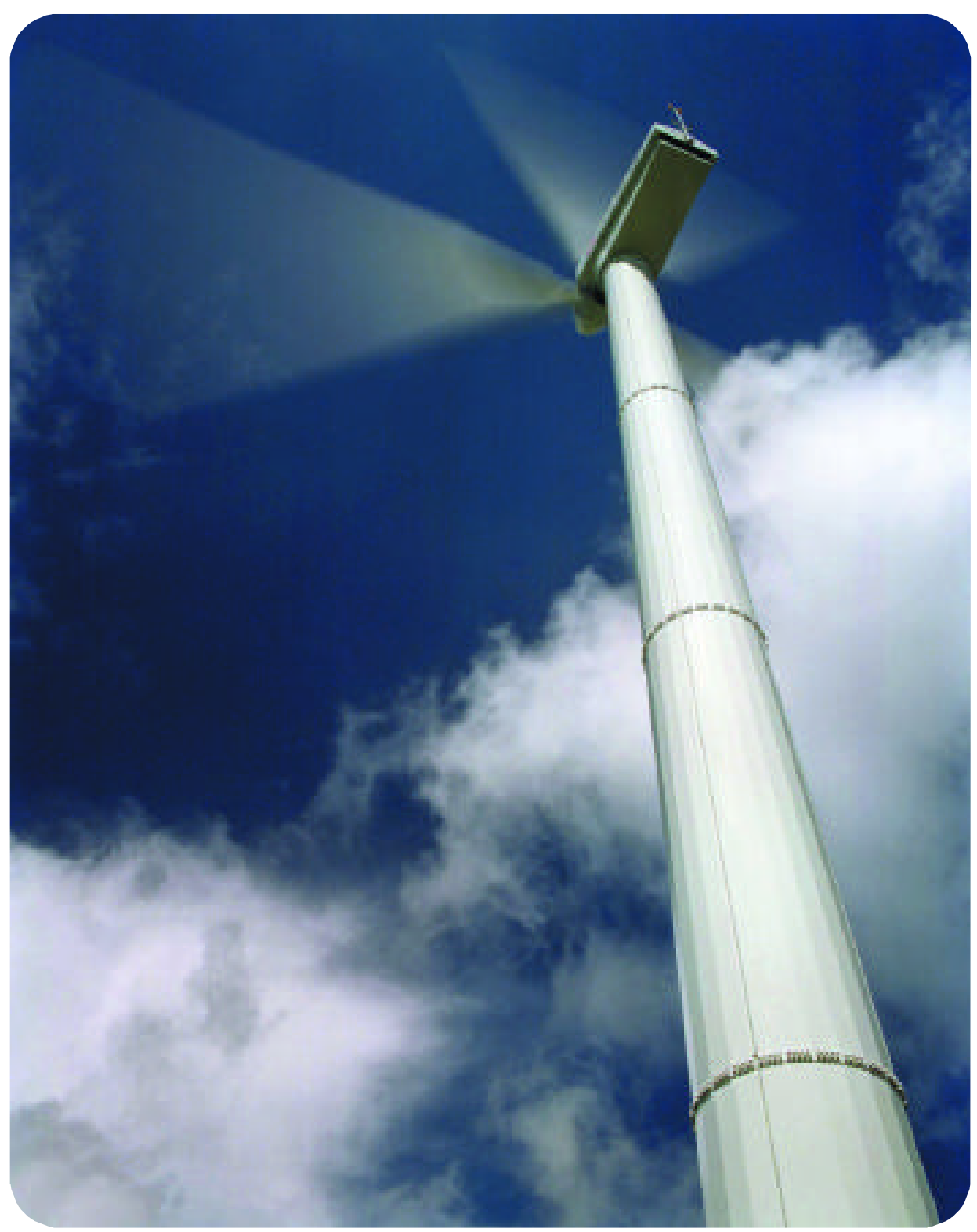

Prepared for the NWCC Credit Trading and Green Power Marketing Working Group

February 2002

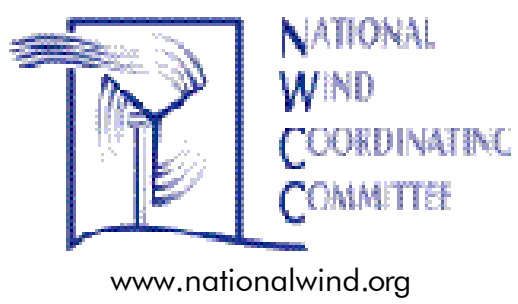




\section{N WC C members include representatives from:}

Alliance of Energy Suppliers

American Electric Power

American Wind Energy Association

Atlantic Renewable Energy Corporation

Bonneville Power Administration

California Energy Commission

Center for Resource Solutions

City of Lake Benton, MN

Community Energy Inc.

CSGServices Inc.

EAPC Architects Engineers

Ed Holt \& Associates

Electric Power Research Institute

Energy and Environmental Research Center

Enron Wind Corporation

Environmental \& Energy Study Institute

Exeter Associates

FPL Energy

Greenmountain Energy Co.

Green Marketer

lowa State Legislature

Kansas Corporation Commission

Kansas State Representative

Land \& Water Fund of the Rockies

Last Mile Electric Co-op

Lincoln County Enterprise Development Corporation

Midwest Renewable Energy Corporation

Minnesota Environmental Quality Board
Montana Public Service Commission

National Association of Regulatory Utility Commissioners

National Association of State Energy Officials

National Conference of State Legislatures

National Renewable Energy Laboratory

North Dakota Office of Community Assistance

North Dakota State Representative

Nebraska Public Power District

NEG Micon USA, Inc.

Oregon Office of the Governor

PacifiCorp

Pennsylvania Public Utilities Commission

Renewable Energy Consulting Services, Inc.

South Dakota Governor's Office

South Dakota Public Utilities Commission

Union of Concerned Scientists

U.S. Department of Agriculture

U.S. Department of Energy

U.S. Department of Interior/ BLM

Utility Wind Interest Group

Vermont Environmental Research Associates, Inc.

Vermont Public Service Board

Western Resources

Wind Management, LLC

Windustry Project

Wyoming Business Council

Xcel Energy

The NWCC is a collaborative endeavor formed in 1994 that includes representatives from electric utilities and their support organizations, state legislatures, state utility commissions, consumer advocacy offices, wind equipment suppliers and develop-

ers, power marketers, environmental organizations, and state and federal agencies. The National Wind Coordinating

Committee identifies issues that affect the use of wind power, establishes dialogue among key stakeholders, and catalyzes

appropriate activities to support the development of an environmentally, economically, and politically sustainable market for

wind power.

For additional information, please contact

Outreach Coordinator

National Wind Coordinating Committee

c/o RESOLVE

1255 23rd Street, Suite 275

Washington, DC 20037

Phone: 202-944-2300 or 888-764-WIND
Fax: 202-338-1264

E-mail: nwcc@resolv.org

This document is available on NWCC's Website:

http://www.nationalwind.org. 


\title{
Credit Trading and Wind Power: Issues and Opportunities
}

\section{National Wind Coordinating Committee (NWCC) Resource Document}

Submitted by

\author{
Econergy International Corporation \\ Kevin Rackstraw \\ John Palmisano
}

\section{Completion Date - January 15, 2001 Published After Editing, May 2002}

This document is being released as a resource document for educational and informational purposes. The document has been reviewed and approved by an NWCC working group with relevant experience. Chapters 6 and 7 represent a consensus of the NWCC (consensus is defined as "all can live with"); however, the rest of the document, by choice of the NWCC, has not been carried through the full NWCC consensus process. Publication does not presume that all members have reviewed the document's content.

This complete document is available on NWCC's Website: www.nationalwind.org 


\section{About the National Wind Coordinating Committee}

The National Wind Coordinating Committee (NWCC), a U.S. consensus-based collaborative formed in 1994, identifies issues that affect the use of wind power, establishes dialogue among key stakeholders, and catalyzes activities to support the development of an environmentally, economically, and politically sustainable commercial market for wind power. NWCC members include representatives from electric utilities and support organizations; wind developers, equipment suppliers, and support organizations; environmental organizations; state legislatures and utility commissions; consumer advocacy offices; green power marketers; local, state, tribal, and federal agencies; and agriculture and economic development organizations. RESOLVE, a nonprofit environmental dispute resolution organization, offers a full range of facilitation services designed to create opportunities for NWCC members and other wind stakeholders to build long-term relationships, and to develop a number of landmark products resulting from significant negotiation and reflecting consensus of the NWCC. More than 2,500 individuals from diverse sectors and wind resource areas across the country have participated in the NWCC's collaborative efforts.

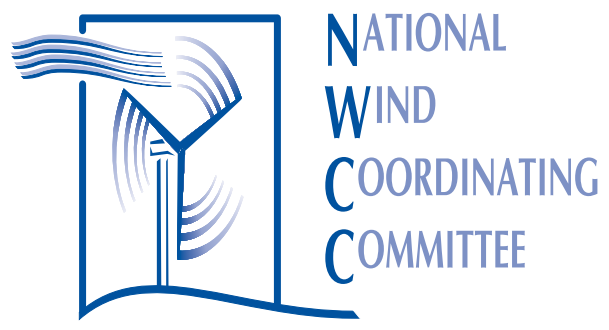

c/o RESOLVE

1255 23rd Street, N.W., Suite 275

Washington, DC 20037

Phone: (202)965-6398 or (888)764-WIND

Fax: 202/338-1264

e-mail: nwcc@resolv.org

www.nationalwind.org 


\section{Table of Contents}

\section{EXECUTIVE SUMMARY}

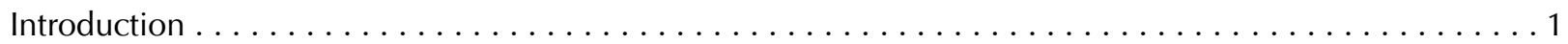

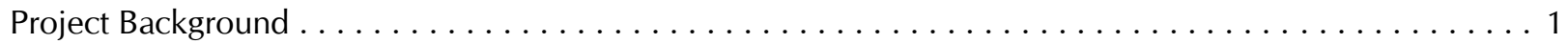

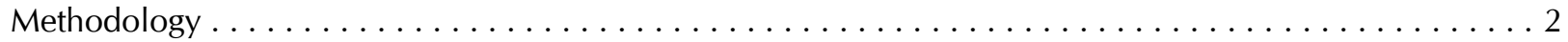

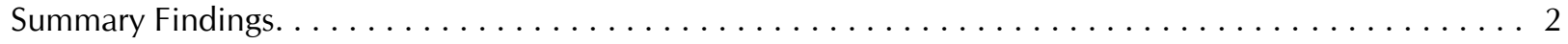

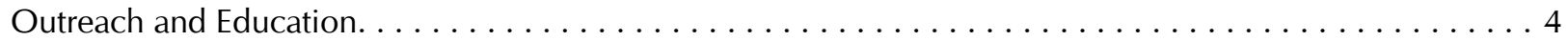

CHAPTER 1 - INTRODUCTION

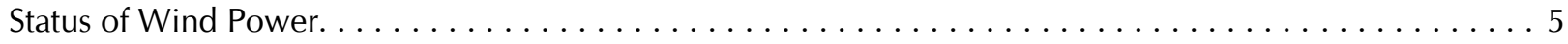

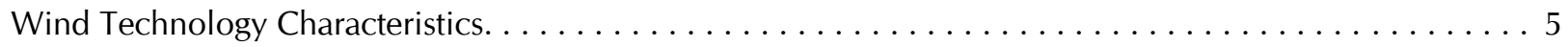

\section{CHAPTER 2 - CREDIT TRADING 101}

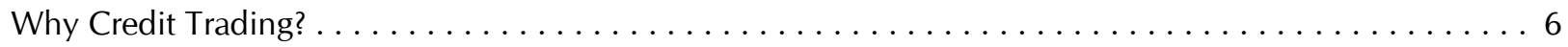

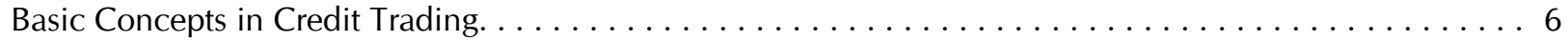

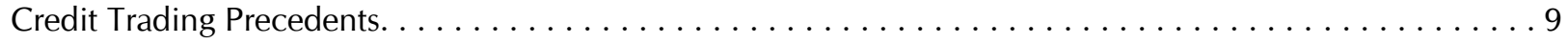

Greenhouse Gas Trading Under the Kyoto Protocol and Related Commitments . . . . . . . . . 10

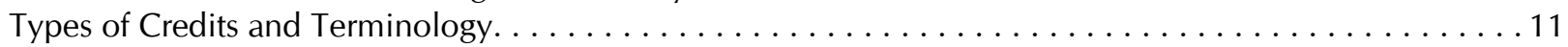

Credits Arising From Mandated Markets. . . . . . . . . . . . . . . . . . . . . . . 11

Credits Arising From Private or Voluntary Markets, or Both. . . . . . . . . . . . . . . . 11

Other Venues in Which Credits Could Be Applied. . . . . . . . . . . . . . . . . . . . . . 12

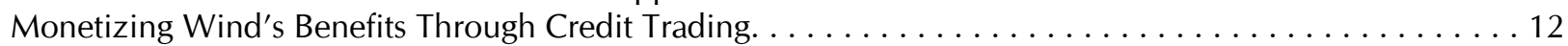

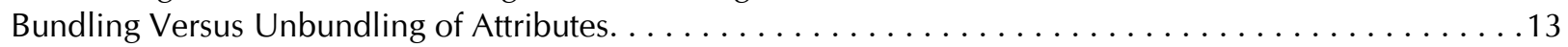

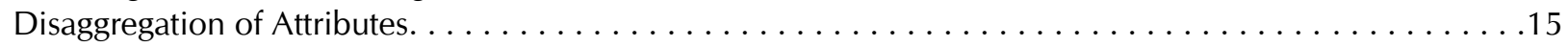

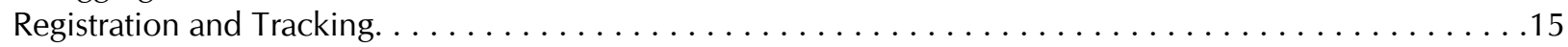

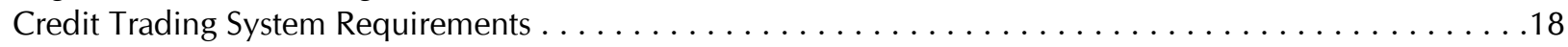

\section{CHAPTER 3 - DISCUSSION OF ISSUES}

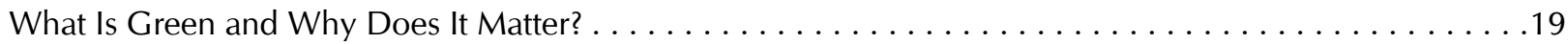

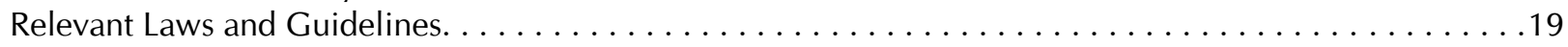

When Green Is No Longer Really Green. . . . . . . . . . . . . . . . . . . . . . . . . 20

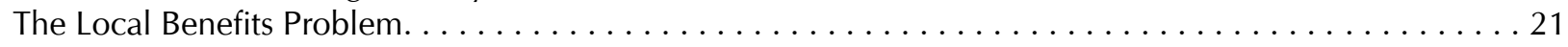

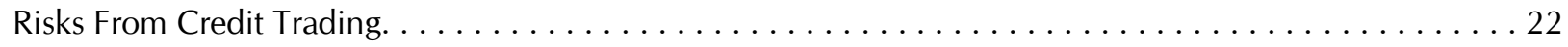

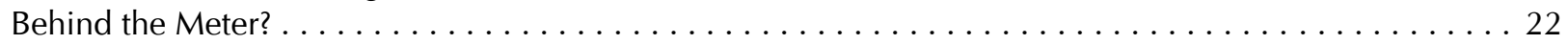

\section{CHAPTER 4 - BARRIERS AND OPPORTUNITIES}

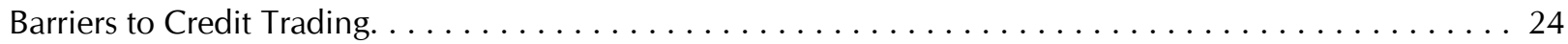

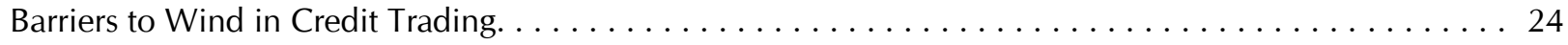

Consequences of Prohibiting Disaggregation of Attributes in Consumer Markets . . . . . . . . 26

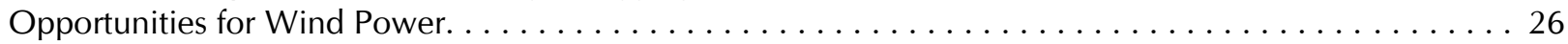

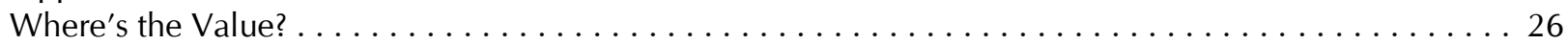

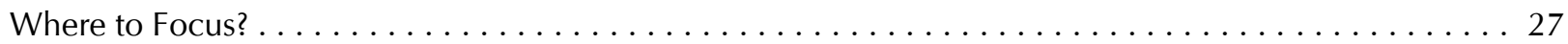

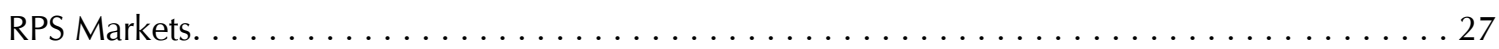

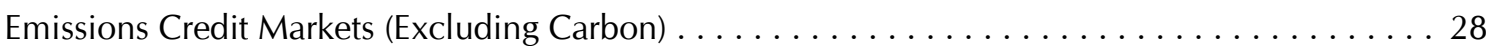

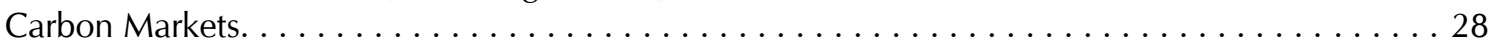

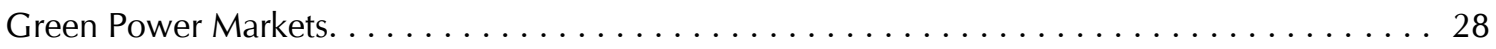

System Benefits Charges. . . . . . . . . . . . . . . . . . . . . . . . . . . . . . 29 


\section{CHAPTER 6 - OPPORTUNITIES}

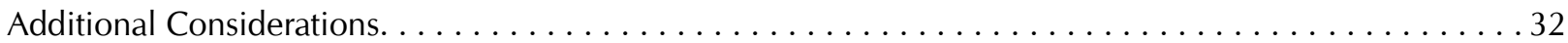

\section{CHAPTER 7 - CREDIT TRADING GUIDELINES}

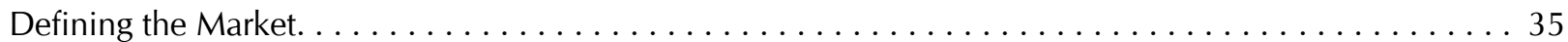

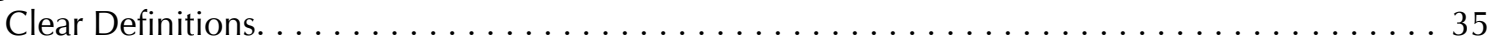

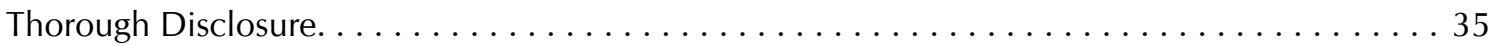

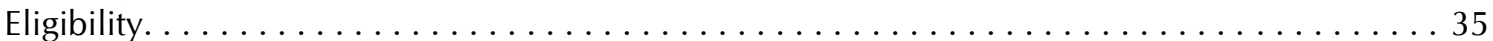

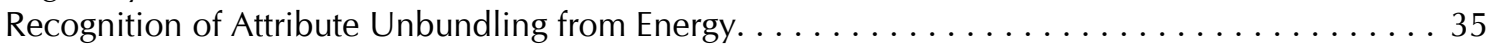

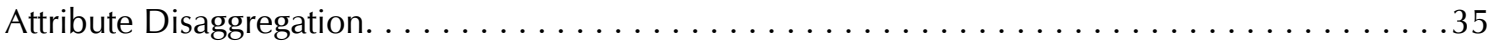

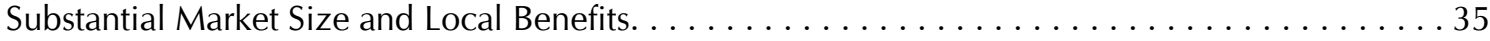

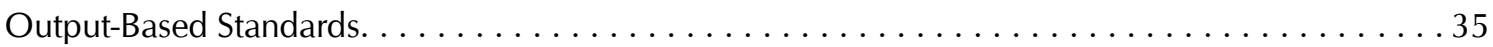

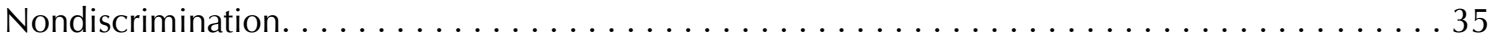

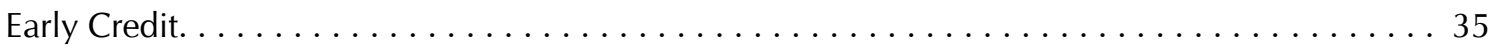

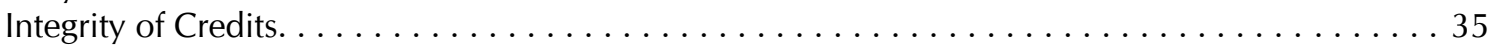

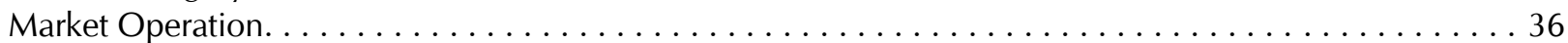

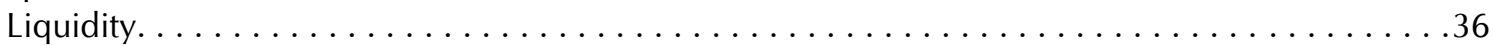

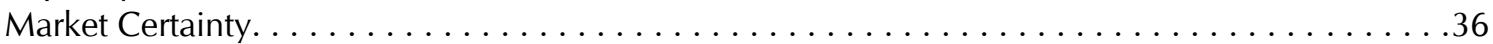

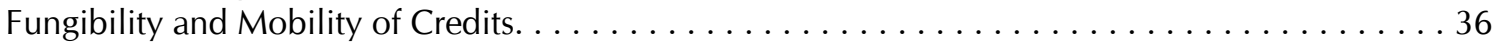

Disconnection of Credit Trading from Time of Delivery Requirements. . . . . . . . . . . 36

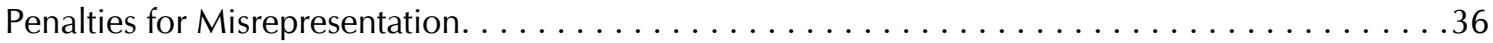

Administration of Regulatory Noncompliance Penalties and Mitigation Activities. . . . . . . . . 36

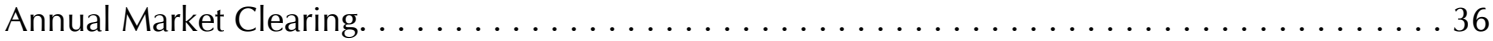

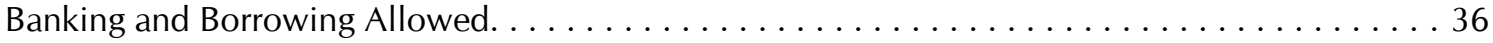

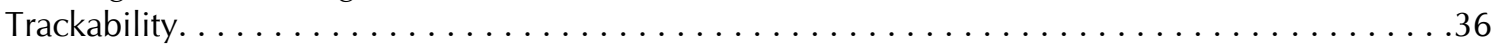

\section{CHAPTER 8 - CASE STUDIES}

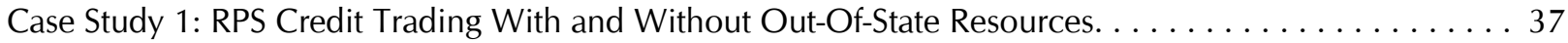

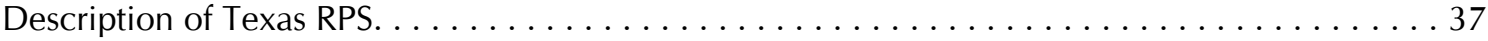

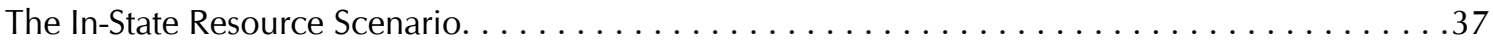

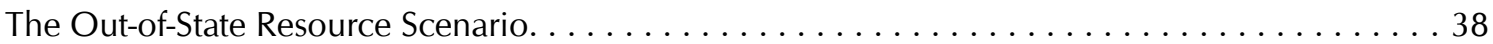

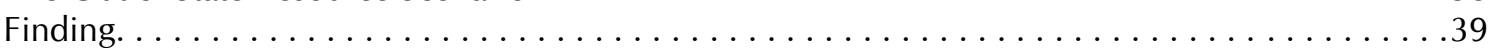

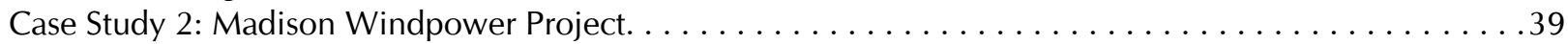

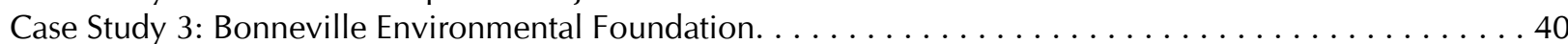

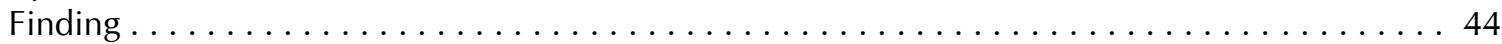

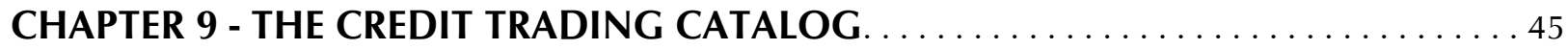

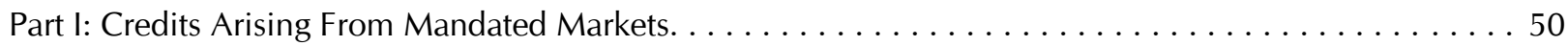

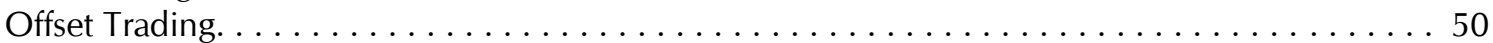

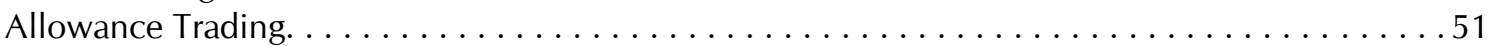

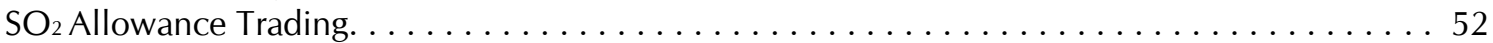

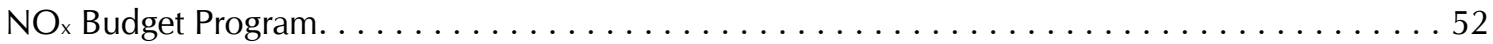

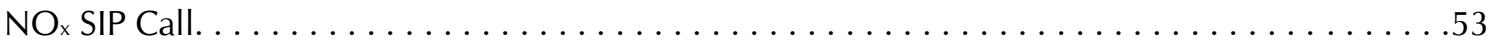

Renewable Energy Set-Asides. . . . . . . . . . . . . . . . . . . . . . . . . . . 53

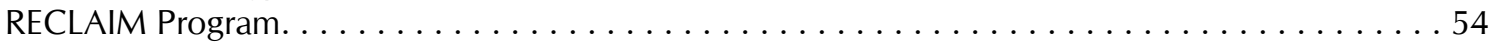

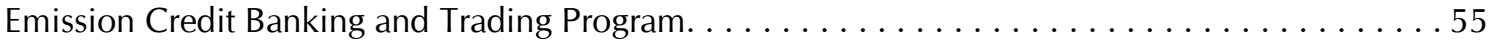

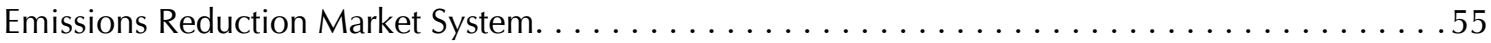

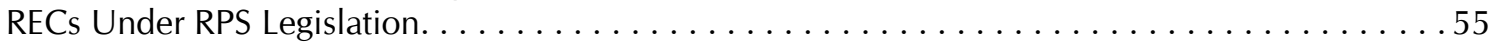

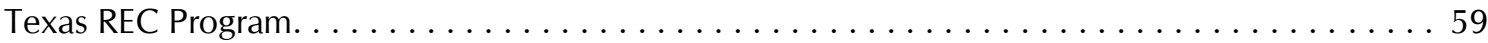

Carbon Credit Trading. . . . . . . . . . . . . . . . . . . . . . . . . . . . . . . 59 
Part II: Credits Arising from Voluntary Markets. . . . . . . . . . . . . . . . . . . 60

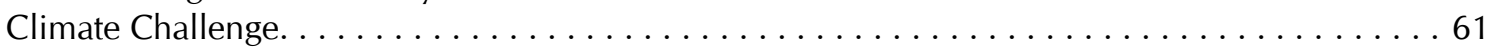

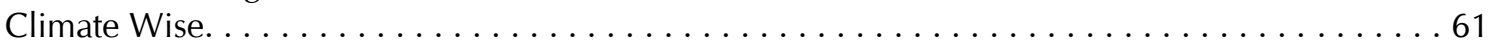

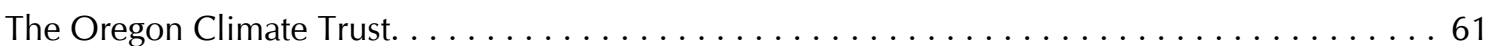

New Jersey's Sustainability Greenhouse Gas Action Plan. . . . . . . . . . . . . . . . . . . . . . . .62

Other Voluntary Emissions Trading Activities. . . . . . . . . . . . . . . . . . . . . . .662

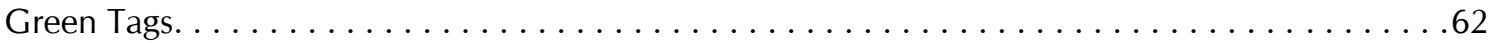

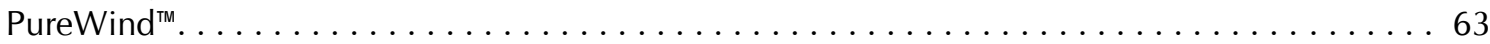

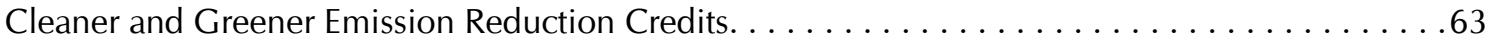

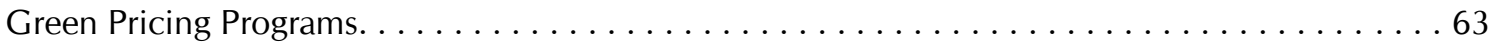

Emission Reduction Credit Registry System. . . . . . . . . . . . . . . . . . . . 64

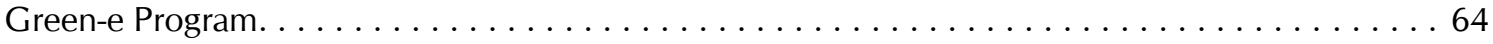

Generation Disclosure. . . . . . . . . . . . . . . . . . . . . . . . . . . 64

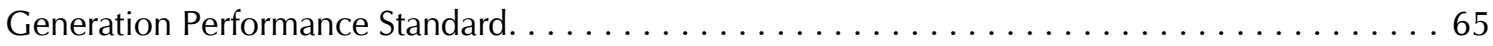

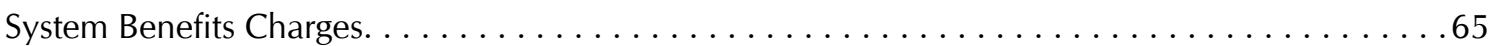

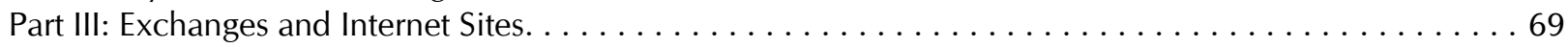

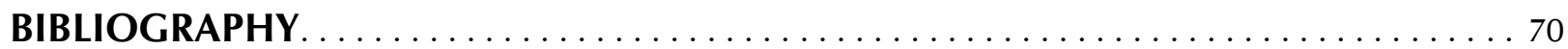

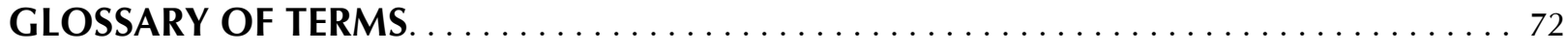

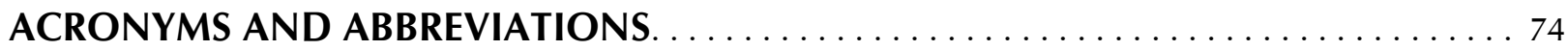

APPENDIX A: SAMPLE DATABASE PRINTOUT $\ldots \ldots \ldots \ldots \ldots$ 


\section{List of Tables}

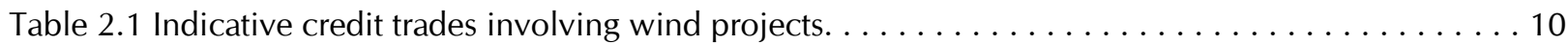

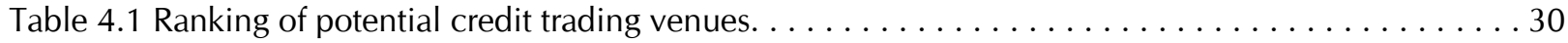

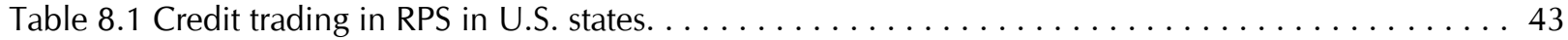

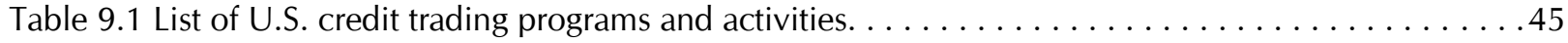

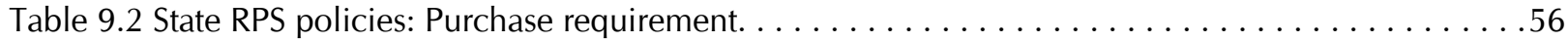

Table 9.3 State RPS policies: Credit multipliers and out-of-state resources $\ldots \ldots \ldots \ldots \ldots \ldots \ldots \ldots \ldots 7$

Table 9.4 State RPS policies: Resource eligibility and credit trading. $\ldots \ldots \ldots \ldots \ldots \ldots \ldots \ldots \ldots \ldots$

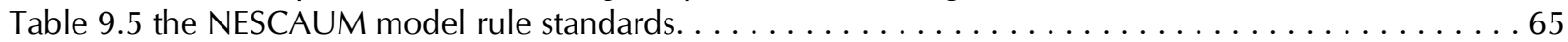

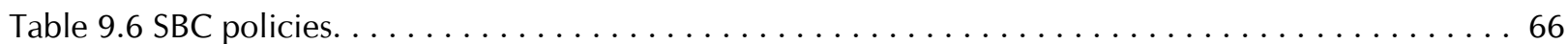

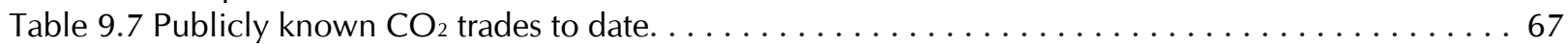

\section{List of Figures}

Figure 2.1 Differentiating characteristics of major credit trading types. $\ldots \ldots \ldots \ldots \ldots \ldots \ldots \ldots \ldots$

Figure 2.2 Bundled transaction with no differentiated environmental attributes $\ldots \ldots \ldots \ldots \ldots \ldots \ldots 12$

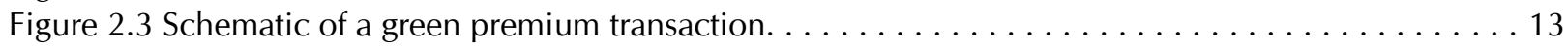

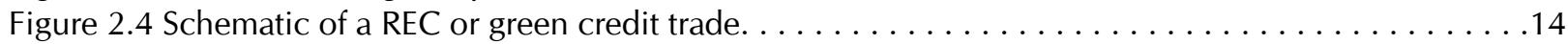

Figure 2.5 Schematic of a renewable energy credit with multiple green attributes $\ldots \ldots \ldots \ldots \ldots \ldots 17$

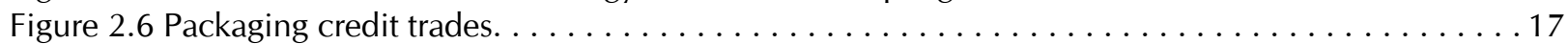

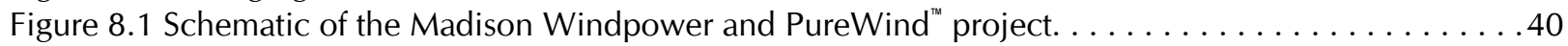

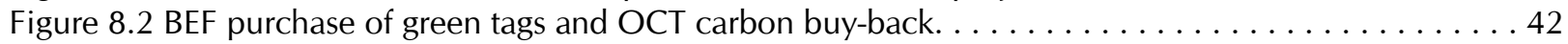




\section{Executive Summary}

\section{INTRODUCTION}

Trading of emissions credits, allowances, and quotas is becoming widely recognized as an effective means of lowering the cost of achieving air pollution control objectives, but the use of credit trading is spreading far beyond emissions trading. Credits are now being developed to convey or represent the environmental and other benefits that flow from the use of renewable energy. This report focuses on credits that are derived from wind energy technology, but the same concepts also apply to other renewable energy technologies. Credit trading, which can be applied to a wide variety of policies, programs, and private market activities, represents a means of tapping into revenue streams that traditionally have largely excluded wind and other renewables. In addition, credit trading can help to create new revenue streams for wind and other renewables by helping to establish new markets.

Depending on how the rules are written, however, credit trading can also create potential liabilities for companies that generate, buy, or sell credits. Wind developers, owners, investors, and lenders in the wind sector need to understand both the potential benefits and the pitfalls of credit trading.

Renewable portfolio standards (RPS), an increasingly popular mechanism for achieving renewable energy and environmental goals at a lower cost, have begun to make use of credit trading. Allowing wind to participate in emissions trading markets based on government-driven pollution control programs gives wind power producers an opportunity to tap into an existing revenue stream associated with efforts to reduce emissions of certain regulated pollutants. With the advent of green power markets and increasing recognition of the environmental benefits provided by renewable energy, there is a greater awareness that credit trading could be applied to some of the green benefits of renewables that are not related to emissions reductions. Credit trading also presents an opportunity for expanding the breadth and speed of green power market growth by making it easier and less expensive for larger numbers of people to choose green options. In some cases, credit trading can help to open up green power markets where none existed before.
These markets represent billions of dollars of potential value for wind power, and including credit trading as a means of lowering costs and increasing choice can be an important part of making a compelling argument for renewable energy policies. This report is intended to help identify and make sense of these opportunities, as well as to make some reasoned judgments about where efforts of the NWCC to encourage wind energy development in the United States might be most effective.

\section{PROJECT BACKGROUND}

The NWCC is a consensus-based collaborative formed in 1994 to encourage the development of a sustainable commercial market for wind power in the United States. The NWCC comprises representatives from the utility, wind industry, environmental, consumer, regulatory, power marketer, agricultural, tribal, state legislator, and state and federal government sectors. This analysis of credit trading is intended to educate NWCC members and others, including air quality regulators, the wind industry, utilities, and the environmental community, about how credit trading may affect wind development in the United States. A team of representatives from Econergy International Corporation (Mike Ashford, Amy Ellsworth, and Rick Renner) and Remote Power Group (Kevin Rackstraw and John Palmisano) carried out this project.

Phases I and II of this project have been combined into a single report to eliminate duplication and reduce the report's length. The first phase of the study is an assessment and review of credit trading opportunities for wind energy, including a ranking and analysis of those opportunities. As part of this assessment, the consultant team assembled a catalog of programs and activities in which credit trading is now being used or could be used in the future. This catalog serves as a reference for the study and for others interested in examining various forms of credit trading. The first phase also looks at the major issues that affect credit trading, particularly in terms of their effects on wind energy markets. The second phase of the study develops a set of guidelines that can help to ensure that credit trading markets develop in a manner that is open and fair to wind energy. 


\section{METHODOLOGY}

This report is based largely on a review of existing programs and activities and the literature developed around these activities, supplemented by discussions with experts and market participants who are involved in credit trading and wind market development. To give the reader a basic understanding of this fast-changing and often confusing arena, the report compares and contrasts several emerging financial, policy, and market concepts that utilize credit trading and attempt to level the playing field for clean energy projects. The catalog is an electronic database of relevant programs and activities, with entries on the program drivers, jurisdictions, general descriptions, and contacts for further information. An abbreviated list of the database records is included in Chapter 9 (Table 9-1), and Appendix A contains a sample printout of one record from the database. In this report, we also present three case studies that look at some of the detailed issues and concerns involved in credit trading. Two of the cases look at particular credit trades involving wind energy projects. The third examines credit trading in the context of states that do and do not allow external renewable generation to satisfy RPS requirements.

\section{SUMMARY FINDINGS}

The work described in this report indicates that wind power stands to benefit from an increase in the use of credit trading, assuming that wind energy is allowed to participate on a fair and equitable basis. These credits derive principally from the environmental benefits of clean energy generation and can be traded separately from that energy. Recent national and international transactions ${ }^{1}$ have already demonstrated how credit sales can generate additional revenue for wind projects, making them more competitive with conventional power generators in an increasingly competitive market. Although today these revenues are relatively small and have failed to encourage substantial new wind development, credit trading represents an opportunity for the wind industry to tap into the large revenue streams associated with existing pollution reduction efforts and the even larger ones that may emerge from the development of private markets, as well as the many new

\footnotetext{
${ }^{1}$ Mostly credits representing carbon dioxide $\left(\mathrm{CO}_{2}\right)$ emission reductions.
}

attempts at the local, state, and federal levels to control emissions and promote clean energy.

Credit trading is increasingly being recognized as a market-oriented mechanism that can help to lower the cost of implementation of various pollution control programs and renewable energy promotion policies (the RPS, for example). If implemented appropriately, credit trading can also help to increase the growth rate and efficiency of green power markets by increasing the options available to consumers.

Because credit markets operate separately from energy markets, credit trading also helps wind relieve-although not eliminate-some of the technical issues that burden wind generation in energy markets. Transmission access becomes less of an issue (although still significant) because energy sales from the wind plant are divorced from the sale of credits. Intermittency also becomes less of an issue (depending on how market rules are structured) because credit markets operate independently of the time-sensitive demands of energy markets.

However, it is by no means certain that wind will be allowed to participate in all credit trading opportunities, especially because the traditional models of pollution regulation consider emitting technologies to be eligible for crediting only through allowance or quota programs. Even where wind has been allowed to participate in regulatory programs in the past, the rules as written have made actual participation infeasible. ${ }^{2}$ The wind industry will therefore be well served to help define the rules and uses of credit trading as they emerge in new, more open markets. The potential economic and financial benefits from credit trading, along with the environmental (and other) benefits accruing to society at large from increased reliance on wind power, justify an engaged and aggressive approach to credit trading on NWCC's part.

Nearly 70 discernable regulatory programs and voluntary activities do or can engender credit

\footnotetext{
${ }^{2}$ Under the EPA's $\mathrm{SO}_{2}$ trading program (combating acid rain), only utilities were eligible to earn credits, and the rate at which wind was allowed to earn $\mathrm{SO}_{2}$ allowances was set very low (one allowance per 500 megawatthours of generation). For further discussion, see Wooley (2000).
} 
trading in some form (see Table 9-1 in Chapter 9), but very few have potential near-term implications for wind. Even those that could benefit wind power are subject to uncertainties such as the recent national elections and the challenges to air pollution regulations that are now in the courts. ${ }^{3}$ Private-market voluntary credit trading has strong potential and is beginning to grow, although uncertainty arises in this area because such trading relies on voluntary behavior (as opposed to markets that result from air pollution regulations, for instance). On the basis of the marketing activities of many green power marketers, it appears that institutional buyers represent a better near-term market than do individual consumers because they are better able to embrace these new concepts. There is also a debate about whether credit trading, particularly with credits separated from energy, is a good thing for consumers and the healthy development of green markets. The concerns range from a belief that consumers will not be able to embrace electricity products that represent abstract environmental benefits, to fear that marketing claims will be difficult to evaluate or enforce, to a belief that credit trading will not result in the promised environmental benefits (at least in locations of concern). Such concerns point out the importance of developing rules or practices that protect consumers and ensure that environmental benefits are indeed realized.

Various government requirements have given rise to a number of opportunities with potential to benefit wind including the oxides of nitrogen $\left(\mathrm{NO}_{\mathrm{x}}\right)$ State Implementation Plan (SIP) Call ${ }^{4}$ programs under the Clean Air Act, proposed new clean air standards, a haze control program being developed by western states, and state-level RPS. The prospects for a multi-pollutant program that integrates and accelerates controls for up to four major pollutants appears to have regained some momentum and may be taken up in the context of restructuring legislation in the next session of Congress. A national RPS would be one of the most

\footnotetext{
${ }^{3}$ Particularly the American Trucking Association v. the U.S. Environmental Protection Agency (EPA) case, which challenges EPA's authority to issue new air standards and a related case about whether cost-benefit analysis is required for many types of environmental regulation. These cases are now before the U.S. Supreme Court.
}

${ }^{4}$ SIP Call: EPA's call for a SIP to meet more stringent standards for $\mathrm{NO}_{\mathrm{x}}$ emissions. powerful tools to boost near-term markets and provide necessary market stability, but the prospects of a meaningful commitment are uncertain at best. An additional category with very good near-term promise is system benefit charges (SBCs), which are already in place or well under development in many states and collectively may represent as much as $\$ 2.8$ billion of clean energy investment over the next 10 years. Although many interests compete for these monies, SBC funds could be used to help jump-start credit trading markets in a number of ways, such as underwriting the cost of credit purchases, helping to put the necessary infrastructure in place for trading, helping to ensure the viability of such markets in their early years (i.e., supporting some minimum level of activity), or educating consumers on the existence and availability of credits.

In Chapter 7, we present a draft set of recommendations and guidelines for engendering credit trading. The guidelines include an emphasis on nondiscriminatory treatment of wind in credit trading activities. In the discussion that accompanies the guidelines, we suggest that the NWCC focus on engendering a market that will be large and robust enough to deliver emission reductions efficiently. The NWCC may also play an important role in ensuring the integrity of credit trading by promoting the setting of standards, harmonizing regulatory eligibility requirements across jurisdictions, and seeking full disclosure and transparency of the environmental characteristics of both generation and subsequent credit trades.

Many of the concepts we cover in this report are new and still evolving in terms of law and market acceptance. The lack of agreed-on definitions creates issues that need to be dealt with-issues that affect consumers, generators, power marketers, financiers, and others in the electric sector. For sizable and liquid credit markets to develop and mature, a common set of terms and practices must be agreed upon. The NWCC can support such activity by including this area in its recommendations and by encouraging its members to participate in the emerging dialogue.

Finally, credit trading can be a confusing and complex topic, and there is some question about buyers' willingness or ability to understand the concept, as well as their willingness to purchase credits separately from energy. Fortunately, there 
are great similarities between the current practice of buying green power, whether in regulated or deregulated markets, and the new practice of buying credits. For instance, a given electricity buyer on a typical grid cannot know the source of the electrons that flow into the buyer's house, even if the buyer is purchasing power from a particular wind plant. This is just the uncertain nature of electron flow on an electric grid. The green premium paid, then, does financially support the wind plant, which does in turn feed the purchased amount of wind-generated electricity into the grid, but the purchase itself is effectively divorced from the actual delivery of electrons to the consumer's home. As long as the delivered energy matches up with the purchased energy at some level, everything is fine. For sophisticated institutional buyers, this is not a significant hurdle. For individual consumers, it can be confusing.

\section{OUTREACH AND EDUCATION}

Credit trading, which already has substantial momentum, will be applied in a variety of venues over the next few years. The NWCC can work with its key stakeholders and target audiences to help establish equitable treatment for wind energy and to allow wind technology to play a central role wherever it can make a significant contribution.
The key stakeholders in wind energy-based credit trading include, but are not limited to, wind energy developers and manufacturers, wind energy consumers, energy system managers and regulatory bodies, environmental regulators, governmental bodies charged with administering renewable energy programs, nonprofit environmental organizations, green power marketers and suppliers, and credit brokers and traders. Many of these groups are also target audiences that need to be reached if wind energy is to succeed in this endeavor. These groups all need to be engaged to various degrees in an effort to structure the rules and application of credit trading so that wind can participate fully and fairly.

A key goal of any group promoting the use of credits will be to educate consumers, politicians, regulators, and other stakeholders to increase acceptance of the concept and practice of buying and selling credits separately from energy. It will also be incumbent on such a group to help ensure that the practice protects consumers from improper claims about the environmental attributes of the credits. Although challenging, finding a balance that protects consumers, promotes the development of healthy green power markets, and encourages innovation is a manageable task. 


\section{Chapter 1 \\ Introduction}

\section{STATUS OF WIND POWER}

The wind power industry has gained considerable experience throughout the past two decades in constructing and operating both individual wind turbines and larger scale wind facilities. In 1999, more than 3,600 megawatts (MW) of new wind energy generating capacity was installed around the globe, bringing total installed capacity to about $13,500 \mathrm{MW}$ by the end of 1999 and approximately $16,500 \mathrm{MW}$ by the end of 2000 (Windpower Monthly, January 2001). Worldwide, this represents a growth rate of $24 \%$ a year.

Financial analysts are broadly positive about wind power shares listed in the world stock markets, predicting world market growth rates in the $18 \%$ $30 \%$ range annually in coming years with no significant alternative energy competitors in sight (Reuters 2000).

\section{WIND TECHNOLOGY CHARACTERISTICS}

Wind energy technology has improved dramatically in the last 20 years in terms of efficiency, availability, and cost. Wind farms today expect $98 \%$ or better availability (the amount of time the turbine is ready to run whether or not the wind is blowing). Turbine sizes are increasing to harvest the economies of scale of large machines, with the latest commercial designs coming in at 1.0 to $1.65 \mathrm{MW}$.

Wind energy's advantages include virtually zero emissions, modular nature, quick construction time, no fuel price risk, and relatively low operations and maintenance costs. Harnessing the wind can provide other benefits as well, including property tax revenue, land-lease payments, and job creation in what are often rural areas with a great need for any kind of development. Wind also helps to provide fuel diversity in a given area, which lessens the area's vulnerability to fuel price or electricity supply and demand shocks. An example of this "hedging" capability was seen in southern California. Electricity prices there rose sharply as a result of both a lack of generation capacity and a doubling of natural gas prices, but customers buying power on a fixed price basis from wind experienced stable pricing that insulated them from the shocks. More offers of flat rates for renewablesbased electricity are coming on the market as customers recognize the value of being insulated from fuel price risks (U.S. Department of Energy [DOE] Efficiency and Renewable Energy Network [EREN] Network News, November 15, 2000).

The disadvantages of wind energy include intermittency, high initial capital costs, and the remote location of many of the excellent wind resources. This remoteness increases the cost of transmission and other costs associated with getting the energy to market. Wind cannot schedule delivery of its power on a basis that fits easily with most market rules, which often prescribe penalties for failure to deliver within certain time constraints. At the least, this means that wind may be at a disadvantage in the energy market if its energy cannot be sold "as available." 


\section{Chapter 2 \\ Credit Trading 101}

\section{WHY CREDIT TRADING?}

Trading of allowances, quotas, and emissions credits is recognized in many countries as a market-oriented and efficient way to reduce harmful pollution. Credit trading harnesses the forces of supply and demand by enabling firm- or individual-level decision-making that steers scarce resources to the greatest marginal benefit at the lowest cost (the "biggest bang for the buck"). Credit trading allows the benefits of renewable energy generation, primarily pollution reduction or other green benefits, to be monetized (brought into the price system). Creating and trading credits allows various specific benefits (e.g., emissions avoidance of a particular pollutant that would have been emitted by conventional technologies) to flow to those that value them most. Finally, credit trading operates independently of energy markets. Credit markets are not tied to the time-sensitive energy markets where time of delivery is of paramount importance in determining what values are earned from energy sales. In addition, because energy does not need to be delivered to the buyer or to the buyer's electric supplier, buyers of credits need not be located on the same grid as the renewable generating plants (subject to certain reasonable constraints about the distance of the plant from the consumer). Transmission remains a significant hurdle for wind in the energy markets, however, because the wind plant still needs to be able to deliver the energy cost-effectively to gridconnected buyers somewhere.

\section{BASIC CONCEPTS IN CREDIT TRADING}

The many terms used in the newly emerging field of credit trading can be confusing. Tags, certificates, credits, and other terms are used frequently and loosely, and sometimes appear to be used interchangeably. Although many of these terms are not well defined, at times simply because they are new and not well understood, for the purposes of this report we will establish certain basic concepts. We do not expect these definitions to be universally accepted. Instead, we are putting them forward to facilitate dialogue.

This report explores the use of trading mechanisms to exchange certain characteristics (primarily the green "benefits") of energy generation from clean sources of energy such as wind energy. We define "credit" as a vehicle (or instrument) for conducting such exchanges. Before the "use" of credits, however, there is the act of recognizing and recording such characteristics, the documented result of which we will call "certificates." Certificates, as a generic term, are a representation of the objective fact that certain basic characteristics exist (the wind farm's location, the amount of generation in a given period, etc.). One can estimate avoided emissions by measuring those "certified" characteristics against a base case, such as an average or marginal emissions rate in a given jurisdiction.

Credit, then, refers to the use of such characteristics (such as in a trade or for compliance). Certificate will be used in a generic sense to refer to the original recognition and documentation of such characteristics. Some specific commercial products in the green power marketplace also use the term certificate, but when we refer to them in this report, we will identify these specific certificate products by their full name (e.g., PureWind certificates). Renewable energy credit (REC) is the generic term used throughout this report to refer to a category of credits derived from renewable energy (such as green tags, green tickets, and green certificates). Green credits can be from renewable energy but could also be from other nonemitting or low-emission sources.

It is also helpful to refer to a narrow but common definition of the term credit as used in the context of market-oriented pollution control. In this context, credit generally refers to a unit created as a representation of emissions avoidance or an offset that results from a specific project activity and is measured against a specific benchmark. This report's use of the term credit will encompass a broader definition, which allows a credit to be seen as a vehicle that can contain or convey a wider variety of elements than just emissions reductions. This way a credit can also convey non-emissionsrelated characteristics such as the general "green" qualities often accorded to generation from renewable energy sources (e.g., the reportedly more sustainable nature of renewables). 
A credit is usually contrasted with an "allowance" (or "quota"), which is not project related but is created by the government as a "right" to emit a certain quantity (usually 1 ton) of a specific regulated pollutant. Allowances are created in the context of a "cap" system, wherein a ceiling is set on a regulated entity's total emissions of a pollutant within a given jurisdiction and then either held constant or gradually reduced. Allowances today typically are tradable commodities (under a cap and trade system), so that if an allowance holder reduces its emissions below its own cap, it can then sell its unused allowances to a regulated party that cannot meet the standard. A cap and trade system is an example of a "closed" trading system, meaning a system that has defined emissions caps and is limited to identified participants (usually regulated major sources of emissions). Greenhouse gas trading as envisioned under the Kyoto Protocol is also a cap and trade system, although no true cap is yet in place. Closed systems can be contrasted with "open" trading systems, which generally are voluntary, in which all (or many) sources can participate, and where credits are earned against benchmarks or historical emissions. Credits can be developed under either open or closed trading systems. In closed trading systems, allowances or quotas can be earned by applying a conversion factor to an eligible project's actual production (e.g., one allowance is earned for a given number of megawatt-hours [MWh] of production) or by measuring reductions (offsets) against some benchmark.

In general, credits can be developed from nearly any activity that produces environmental benefits recognized as having value and measured against some recognized baseline. Some green benefits and their associated credits are not measured quantitatively against a specific baseline but still derive their value from being better (in environmental terms at least) than a more conventional option. In many cases in the emerging private voluntary green power marketplace, and possibly in other markets, these criteria may not be enumerated and may be highly subjective.

Credits must meet some kind of minimum standards, of course, to be considered real and verifiable. In most cases, they also have to be additional or surplus, meaning that they must be beyond what is required (i.e., one generally cannot get credits for meeting a standard that is required by law anyway). This problem, sometimes referred to as "additionality," is a murky area that is often hard to define. Still, there is nothing to prevent someone from paying, voluntarily, for credits that may have been used elsewhere for compliance purposes if the purchaser wishes to provide additional support to an energy technology of choice. The question of whether compliance consumes credits (or the related characteristics) is unsettled, and there are strong opinions on both sides. The issue goes to the heart of the question of whether something can legitimately be used more than once, a subject that we will cover in greater detail later in this report.

Not all credits have to be created or approved by government regulators to be traded or recognized in law. Any contract between two parties can create a credit that can be traded between the two or with any other willing party. Of course, this kind of "private market credit" is more difficult for other players to accept, and certainly professional traders prefer some type of legal sanction behind the credit or the backing of some financially sound entity. Allowances and credits created under regulated allowance programs have much more credibility than most private market credits because there is (usually) a long-term mandate from the government to encourage the behavior that is targeted by the regulatory program (e.g., limiting emissions and maintaining those limits over time). Voluntary agreements that underlie credits have less credibility than binding private contracts for obvious reasons, particularly the fact that a buyer cannot necessarily rely on whether the credit was generated as it was portrayed or that the practice will continue into the future. In general, there is a continuum running from purely voluntary behavior with no consequences to mandatory behavior with high penalties (or other consequences for failure to perform); see Figure 2.1. Credits that would be located near the mandatory end of the spectrum would tend to have higher value and be more easily traded than those toward the voluntary end of the spectrum. 


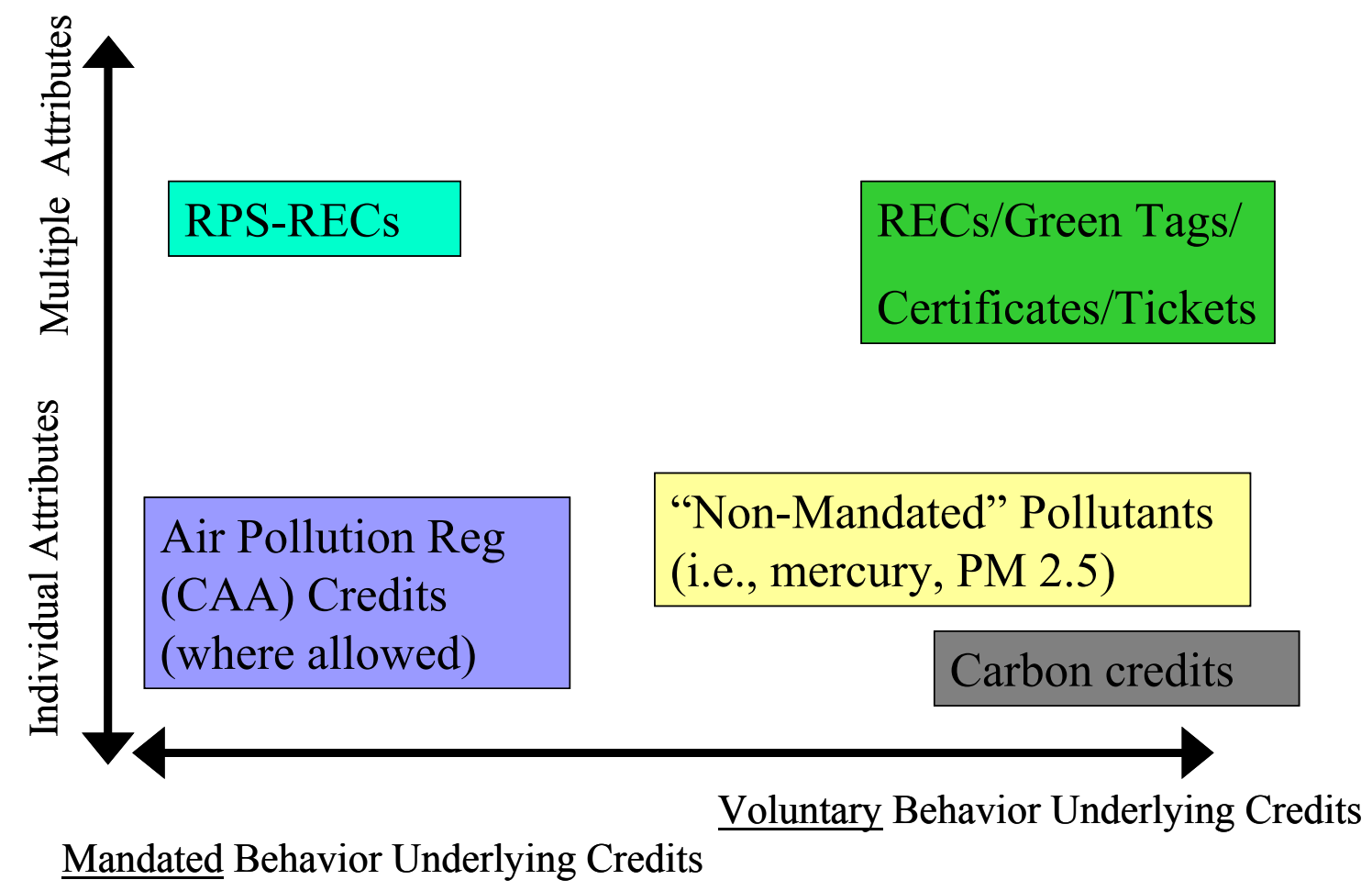

Figure 2.1 Differentiating characteristics of major credit trading types.

Attributes are the descriptive or performance characteristics of a particular generation resource (R.C. Grace, Sustainable Energy Advantage, personal conversations, October 2000). Primary attributes denote basic characteristics such as the type of resource, the date and time of energy generation, the location, and other fundamental characteristics. Secondary attributes include those that are derived from primary attributes, which would include emissions avoidance or other avoided characteristics (e.g., costs to society or a particular group that would have occurred if electricity had been generated from other sources). These secondary attributes result from the interface of primary attributes (e.g., energy production in a given time period) and outside information such as average or marginal emissions in a given jurisdiction or from a specific plant. Not all attributes are tradable, and it is not yet settled which are tradable and which are not. Tradable attributes are relatively straightforward; one can imagine selling an emissions avoidance attribute but not a plant location attribute.
Relating to the concept of attributes is the principle of conservation of attributes, ${ }^{5}$ also termed equivalence of attributes, which states that at some level of aggregation (i.e., a state, trading region, nation, or other larger jurisdiction), energy and attributes should be present in the same proportion to each other as they were when the energy was first generated. As a corollary to this principle, it makes no sense for a wind project to generate energy to produce attributes if that energy is not used somewhere. Particularly when either the attributes or the energy cross jurisdictional borders, some tracking system must ensure that the originating energy is used somewhere or the principle of conservation of attributes is violated. Small, "behind-the-meter" clean generation (such as home wind or photovoltaic systems), for example, would require an alternative method to measure generation. ${ }^{6}$

Ownership of attributes from electricity generation is an emerging area of the law. Depending on the

\footnotetext{
${ }^{5}$ A term coined by Grace, Wiser, and Abbanat (2000).

${ }^{6}$ See Behind the Meter? in Chapter 3 for a fuller treatment.
} 
circumstances, ownership of attributes constitutes a smaller or larger risk to the value of trading and transactions. Which party owns the attributes should be spelled out explicitly in contracts, laws, and regulations. Can these attributes be transferred to another owner? Are contracts between two consenting parties sufficient to protect the value of credit trades? Because only a few recent projects have dealt explicitly with this issue, the matter is unclear in the vast majority of existing wind projects. Buyers of wind-generated electricity might maintain that they should be considered the owners because attributes had not been defined as separate from the energy being purchased. Generators might argue that because attributes had not been explicitly passed on to the buyer, they remain with the generator by default. Consumers might argue that because they paid a premium for the green energy, the attributes should flow to them. In Canada, the government's EcoLogo ${ }^{7}$ program (Canada's main green labeling program) specifically states that all environmental benefits of green power purchased by consumers will be conveyed to those consumers. It is the first case we have come across where the government has specified explicitly how the ownership of green attributes is to be handled in market transactions. Conflicting claims will have to be sorted out before the issue is settled. As tradable attributes come to have more value, or at least are perceived to have future value, this matter will come to a head.

Of course, ownership of attributes presupposes a fairly rigorous set of definitions and agreement on how ownership is created and transferred.

Currently, the definitions of many attributes and the products (or credits) that contain them are so vague that there is confusion about what is being sold or conveyed, or both. This confusion may lead to overlapping claims by different parties on the same attributes or even to the same party transferring what may be the same attribute to different buyers. The latter would constitute "double selling," which may well contravene consumer protection laws even if it is unintentional. Liability may result for wind companies that generate credits or others in the chain of exchange if double selling does occur, whether intentional or not.

\footnotetext{
${ }^{7}$ Entry \#65 in the database table.
}

\section{Credit Trading Precedents}

The most prominent and oldest examples of credit trading are state and regional programs enabled by the 1990 Clean Air Act Amendments (CAAA). They rely heavily on cap and trade market-based approaches to reaching the mandatory reductions in harmful emissions. The cap and trade approach has been quite effective in reducing certain specific pollutants, particularly sulfur dioxide $\left(\mathrm{SO}_{2}\right)$, but the policies to promote renewable energy under the CAAA were not constructed on a basis favorable to renewables and thus have had virtually no effect. ${ }^{8}$ Regulated utilities were able to meet the moderate standards through switching to low-sulfur coal and other conventional means. Despite an allowance set-aside program for renewables, renewable energy projects were not allowed to earn allowances at a favorable rate. ${ }^{9}$ In addition, only utilities were allowed to receive allowances, which made it difficult for generators of renewable energy to participate. Additionally, renewable energy projects cannot earn offsets under the New Source Review process (offsetting incremental emissions from new emitters), effectively closing wind energy out of this opportunity. However, there may be opportunities to introduce more favorable policies for wind in several CAAA programs, particularly at the level of state implementation plans (SIPS). ${ }^{10}$ The various CAAA programs relevant to wind are discussed in greater detail in the catalog (Chapter 9). We will treat the CAAA programs in more depth in the sections of this report that deal with opportunities and guidelines (Chapter 7). Many other types of credit trading have emerged, and the most important of these are discussed in detail in the catalog. To date, however, there are few successful examples of credit trading that have achieved much penetration. Private market credits such as green tags and green tickets have been developed in the United States and overseas, tradable RECs are being tried in a number of U.S. states in relation to renewable portfolio standards

\footnotetext{
${ }^{8}$ For an excellent analysis of the failings of previous CAAA programs, see Wooley 2000 (p. 18).

${ }^{9}$ One allowance (equal to 1 ton of $\mathrm{SO}_{2}$ emissions) for each 500 MWh of production, a rate intentionally set low (Wooley 2000).

${ }^{10}$ Programs with SIPs give the states flexibility to define regulations and activities that are appropriate for their locale, rather than relying on a one-size-fits-all approach. In this report, we will give the most attention to the NOx SIP Call, which requires the states to meet new standards and deadlines for $\mathrm{NO}_{x}$ emissions but allows flexibility in how this is done.
} 
(RPS), and some governments in Europe have begun instituting green credit trading in various forms. The Los Angeles Department of Water and Power has begun to sell "GreenLA" green certificates. In Denmark and the Netherlands, traditional subsidies are giving way to trade in green credits or green certificates as the primary support mechanism for wind. The intention of these programs is that eventually the purchase of certificates will be fully voluntary. Similar programs are in pilot phases or under development in the United Kingdom, Ireland, Belgium, and other countries. Harmonization of trade in green certificates across Europe and beyond is the aim of a European Renewable Energy Certificate Trading Project (ECerT) initiative. ECerT is also expected to offer certificates over the Internet. Other similar but smaller efforts include InTraCert, which is led by the Netherlands Energy Research Foundation (ECN), and ELGREEN, which is led by the Technical University of Vienna. Europe has moved aggressively to implement tradable green credits of various types, but because of delays in developing rules, definitions, and procedures, this initiative has thus far not yielded benefits to wind markets in many of the countries it was intended to help (Windpower Monthly, April and May 2000). The harmonization project will be a model from which other countries can learn about the difficulties of moving credits across borders.

\section{Greenhouse Gas Trading under the Kyoto Protocol and Related Commitments}

A recent and highly uncertain opportunity for credit trading is through programs developed under the Kyoto Protocol of the United Nations Framework Convention on Climate Change (UNFCCC). The Kyoto Protocol lays out the framework for international trading of $\mathrm{CO}_{2}$ reduction credits (measured in tonnes of $\mathrm{CO}_{2}$ but also referred to in its reduced form as "carbon") under the so-called "flexibility mechanisms" of the agreement. Trading may also apply to other greenhouse gases (GHGs) but $\mathrm{CO}_{2}$ accounts for the large majority of emissions by weight. None of these programs is clearly defined yet because international negotiations are ongoing. Despite the regulatory uncertainties, a number of international carbon transactions have been carried out, including some related to wind power projects. Table 2.1 lists the publicly known trades involving wind, most of which have specifically targeted carbon. The programs and activities that create or support carbon transactions are described in more detail in the catalog in Chapter 9.

Table 2.1 Indicative credit trades involving wind projects.

\begin{tabular}{|l|l|l|}
\hline Name of transaction & Credit type & Relevant market or regulatory driver \\
\hline $\begin{array}{l}\text { Bonneville Environment } \\
\text { Foundation wind project, } \\
\text { Oregon, to EPA Region 10 } \\
\text { and CH2M HILL }\end{array}$ & $\begin{array}{l}\text { Green tags and carbon } \\
\text { credits }\end{array}$ & $\begin{array}{l}\text { Open market and Oregon state law on new power } \\
\text { plant siting; Executive Order 13123 encouraging } \\
\text { federal agencies to increase use of renewables }\end{array}$ \\
\hline $\begin{array}{l}\text { SeaWest solicitation, } \\
\text { California }\end{array}$ & $\begin{array}{l}\text { All associated emission } \\
\text { benefits }\end{array}$ & Market activity (not regulated) \\
\hline $\begin{array}{l}\text { Madison Wind Power, } \\
\text { New York }\end{array}$ & $\begin{array}{l}\text { All associated emission } \\
\text { benefits (wind certificate) }\end{array}$ & Market activity (not regulated) \\
\hline $\begin{array}{l}\text { Vision Quest Windelectric, } \\
\text { Canada }\end{array}$ & $\begin{array}{l}\text { Carbon credits (verified } \\
\text { emission reductions or } \\
\text { VERs) }\end{array}$ & $\begin{array}{l}\text { Canada's Voluntary Challenge Registry; also open } \\
\text { market because VERs are sold to businesses wishing for } \\
\text { offsets as well as to individuals }\end{array}$ \\
\hline $\begin{array}{l}\text { TransAlta to Hamburgische } \\
\text { Electricitats-Werke AG } \\
\text { (HEW) } \\
\text { wind credit trade, Germany }\end{array}$ & $\begin{array}{l}\text { Carbon credit } \\
\text { Panadian government GHG reduction laws and Kyoto } \\
\text { Protocol }\end{array}$ \\
\hline $\begin{array}{l}\text { TXU wind power bid, } \\
\text { Green Mountain (Vermont } \\
\text { utility) to EPA Northeast } \\
\text { Region; Pacific Gas and } \\
\text { Electric (PG\&E) to U.S. } \\
\text { Environmental Protection } \\
\text { Agency (EPA) }\end{array}$ & $\begin{array}{l}\text { Renewable certificates, } \\
\text { green tags }\end{array}$ & $\begin{array}{l}\text { Executive Order 13123 encouraging federal agencies to } \\
\text { increase use of renewables }\end{array}$ \\
\hline
\end{tabular}




\section{TYPES OF CREDITS AND TERMINOLOGY}

Many different types of credits have been used, or at least conceived. Some are sanctioned through government regulations or legislation and some are created through the actions of private markets. Many of these are emissions credits, a term that is sometimes used synonymously with credit trading. Not all credit trades today are emissions trades, however, because credits can represent nonemissions characteristics as well. An indicative list of different types of credits, grouped by their legal basis for creation, follows. We should note that wind projects are not currently eligible to earn credits under most of these programs. The credits are presented in two categories reflecting the strength of the driver behind them (mandated versus voluntary).

\section{Credits Arising from Mandated Markets}

- Cap and trade or allowance or quota trading ( $\mathrm{SO}_{2}$ and $\mathrm{NO} \times$ allowances and related credits);

- Title 1 offsets and regulation-based Emission Reduction Credits (ERCs) ( $\mathrm{NO}_{x}, \mathrm{SO}_{2}$, carbon monoxide [CO], volatile organic compounds [VOCs] used for all criteria pollutants but primarily in the context of plant shutdowns);

- Renewable Energy Credits based on Renewable Portfolio Standards (RPS-RECs-a specific kind of REC). ${ }^{11}$

\section{Credits Arising from Private or Voluntary Markets, or Both}

- GHG credits (mainly carbon) from Kyoto Protocol or related or supporting activities, generally called Emission Reduction Units (ERUs) or Certified Emission Reductions (CERs);

- open market credits, usually referred to as Discrete Emission Reductions (DERs; NOx, VOCs);

- RECs, green tags, green certificates, green tickets, and green credits.

A number of additional terms have not been referenced, as well as uses of the above terms that do not conform to this framework. For instance, a Canadian wind developer markets Verified Emission Reduction Units (VERUs), while a

\footnotetext{
${ }^{11}$ REC can be used as a generic term encompassing many different types of credits, but it can also be used to refer to specific programs or activities (i.e., a Texas RPS-REC).
}

Wisconsin-based nonprofit organization markets ERCs. PG\&E's National Energy Group markets PureWind ${ }^{\mathrm{TM}}$ certificates. These are examples of private voluntary market credits that are seeking acceptance in the consumer marketplace. Other terms are difficult to fit into either the mandated or voluntary categories because they are in transition or may be expected to function in more than one type of market. Some types of GHG credits are examples of credits that could move from the voluntary to the mandated end of the spectrum as purely voluntary agreements give way to different levels and types of national commitments (i.e., national actions as a result of, or in lieu of, an international agreement limiting GHG emissions).

RECs, green tags, green certificates (when used as credits) ${ }_{,}^{12}$ and tickets are distinct concepts that are being used by their purveyors in generally comparable ways to represent a complete bundle of green attributes (all attributes, unless otherwise stated). They are not interchangeable in any legal sense, nor are they tradable across categories (i.e., RECs for green tags), although that could certainly happen in the future if definitions and markets are sufficiently harmonized. Again, the European attempt to harmonize green credits across borders will be instructive as to the pitfalls and benefits. In this report, we will use three terms with the following hierarchy:

- credit-the most generic term encompassing all types of credits, emissions- and non-emissionsrelated;

- green credit-refers specifically to credits containing green attributes, but we will generally avoid using this term in this report because of the potential for confusion with credits deriving from nonemitting but nonrenewable energy technologies;

- $\quad$ REC - a generic subset of credit and green credit referring to credits created by renewable energy (not the same as an RPS-REC, which is a specific kind of REC), which may contain nongreen attributes.

Another way of looking at credits is to look into what markets the credits serve. Although there is

\footnotetext{
${ }^{12}$ Note the contrast with the earlier definition of certificates as referring to the documentation of the underlying generation and its characteristics. There is confusion over the use of the term certificate because of the many different ways in which it is used.
} 
some potential for overlap given today's very loose standards and definitions, the credits with which we are concerned here can also be seen as falling into three main groups, noted below with their main driver:

1. RPS markets-mandated market(s) driven by compliance, represented by RPS-RECs;

2. green power markets-voluntary markets typically motivated by consumer or corporate demand for cleaner energy, improved public relations, lower fuel price risk, good public citizenship, lower costs, the opportunity to earn economic rents by speculating on credit prices, or just the good feeling of buying green;

3. emissions reduction markets-primarily mandated markets typically driven by compliance. These could also include public relations, good public citizenship, and speculation.

RPS credits arise from mandates, emissions credits most often are mandated (with the exception of $\mathrm{CO}_{2}$ as of now), and green power credits are typically voluntary (although mandates can be placed on the individual consumers rather than on suppliers or generators as is being considered in Denmark and the Netherlands).

\section{OTHER VENUES IN WHICH CREDITS COULD BE APPLIED}

- Generation performance standards (GPS) or other benchmark-based activities that can utilize credit trading but to date have been infrequently used in this manner. GPS would allow for trading through comparison of actual emissions on a weight per kilowatt-hour basis to a benchmark for a portfolio of generation sources.

- Utility green pricing programs could utilize credits where local wind projects are uneconomic or otherwise infeasible.

- Penalty green pricing programs could require violating firms subject to fines to buy credits from wind projects, particularly in areas that do not have local wind capacity to purchase. In August 2000, the state of Colorado allowed penalties to be offset by wind purchases from a firm that was in violation of chlorofluorocarbon (CFC) emission regulations in the state.

\section{MONETIZING WIND'S BENEFITS THROUGH CREDIT TRADING}

Credit trading represents an opportunity for wind energy to monetize at least some of its environmental benefits and to generate additional revenue beyond the energy value of its electricity. Now that the basic concepts have been established, this section focuses on some of the more detailed issues involved in the design and implementation of credit trades. This material will help to serve as a framework for the opportunities and guidelines in this report (Chapters 6 and 7). Until recently, wind was purchased by a regulated utility (now an electricity supplier) and the environmental benefits were bundled along with the energy (see Figure 2.2) in a bilateral energy (and sometimes capacity) contract.

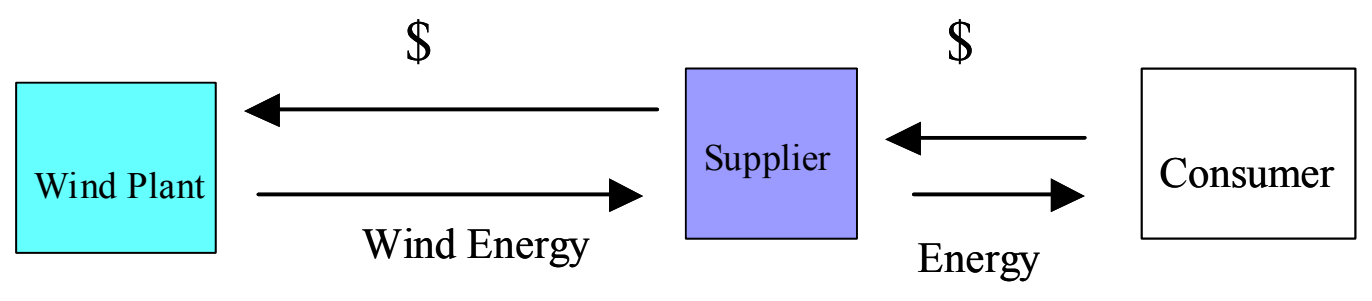

Figure 2.2 Bundled transaction with no differentiated environmental attributes. 


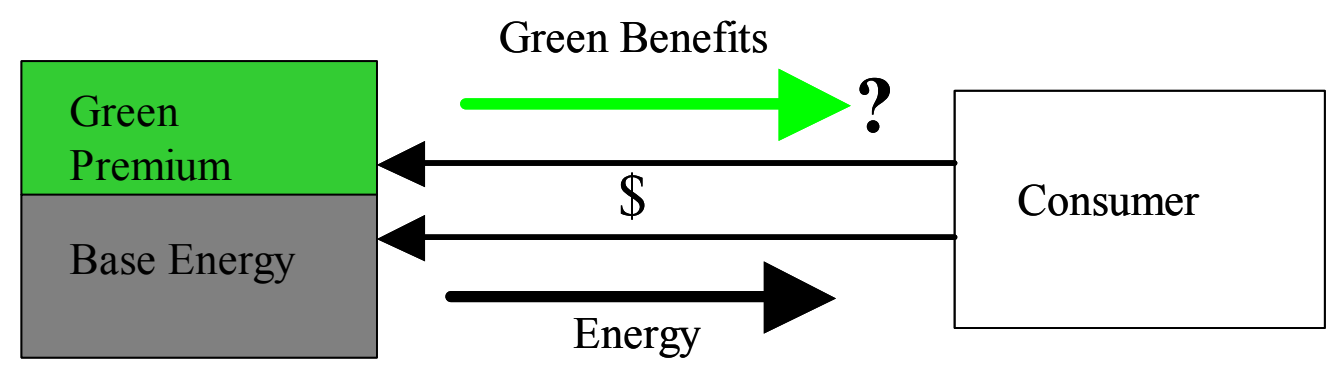

Figure 2.3 Schematic of a green premium transaction.

When green pricing emerged, electricity suppliers began charging a premium (see Figure 2.3 ) to consumers for a loosely defined environmental benefit. Usually, a separate payment was charged for the environmental benefit. Although money flowed from the consumer to the supplier, no "private" environmental benefit was conveyed to the consumer because the benefits were presumed to be bundled with the electricity and public goods. More recently, some private benefits from green energy production became evident (typically emissions reductions that could potentially be used for regulatory compliance purposes), ${ }^{13}$ although they have had limited value and have received little if any attention. Generally, the generator or electricity supplier has kept any identified private benefit, most often by default, and in most cases has not tried to sell green benefits as a separate product. New contracts for green power now usually deal explicitly with any potential avoided emissions or other benefits, and thus avoided emissions are increasingly (in the United States) treated as private benefits that accrue to the purchasing power supplier by contract. It is not clear how often these benefits are passed on to consumers but it appears that this is the exception rather than the rule. In fact, the only case we discovered where benefits are explicitly required to be passed on to consumers is the EcoLogo program in Canada. Still, the legal basis for the existence of these private benefits has been established, although precisely what these benefits are, who owns them, and what can be done with them is still very much unsettled.

\footnotetext{
${ }^{13}$ Under a set-aside program within the $\mathrm{SO}_{2}$ trading program (the Conservation and Renewable Energy Reserve or CRER), wind could earn allowances. However, because of the rules, few such transactions took place. See the catalog for more information.
}

\section{BUNDLING VERSUS UNBUNDLING OF ATTRIBUTES ${ }^{14}$}

Following in the footsteps of "derivatives" in the financial world, ${ }^{15}$ it did not take a tremendous leap for green benefits to be conceived as a separable entity that could be traded independently of energy (see Figure 2.4). Although the trading of a "virtual" commodity separate from the energy may seem to be a large leap, energy markets have long been trading capacity and energy separately, and capacity is a virtual concept not unlike environmental attributes. One central body tracks how much official capacity there is and how that capacity is "assigned" to loads to avoid double selling of the capacity. ${ }^{16}$ This model will prove useful when we look at the issues of tracking ownership of attributes.

Trading these attributes separately from the energy (separate transactions that may result in the benefits and the energy going to different buyers) helps to divorce the financial value of wind's benefits from the problems that wind has in the energy market. It also insulates the transaction involving environmental attributes from the underlying complexity of energy trading. Particularly where trading is settled on an hourly or daily basis, it allows the environmental attributes transaction to

\footnotetext{
${ }^{14}$ For a detailed treatment of the pros and cons of bundling versus unbundling, see Grace, Wiser, and Abbanat (2000).

${ }^{15}$ Financial derivatives are products that are derived from underlying products. For instance, an interest- bearing bond could have its interest payments stripped away and sold to someone other than the bondholder, separate from the underlying principal value of the bond. Although the bond holder could still hold the underlying bond, which hasn't changed in its features or nature, that bond holder would have lost its rights to keep the resulting interest payments.

${ }^{16}$ Analogy provided by Adels (October 19, 2000).
} 
proceed on its own schedule. If the attributes and the energy remain bundled, the trade requires dealing with delivery time and other, often complex issues involved in the energy trade. Adding the environmental attributes reduces the uniform commodity nature of the energy-trading unit. It is no longer just "6:00 A.M. firm power"; it becomes a commodity with baggage that makes it harder to evaluate in the short time spans in which trading decisions are made. ${ }^{17}$

In addition, in states (such as New York) where there are barriers to the development of retail competition and where no green marketers have emerged, there are limited (if any) opportunities for bundled sales of energy and attributes. Separation and sale of attributes is essential to earning a green premium in this context. Similarly, in systems that make it difficult to engage in bilateral transactions, and where all generators are essentially forced to sell into spot markets, the separation of attribute from commodity is essential to gaining a green premium.

However, trading the attributes separate from energy also introduces other issues. Some observers believe that energy and the related environmental attributes should never be separated; they see it as misleading in some fundamental way to do so. There is also concern that consumers may not accept the concept of buying credits representing all the environmental benefits when the underlying power that flows into their home may be primarily coal-based, although there is at least one case ${ }^{18}$ where this scenario has come to pass and consumers have accepted it. This issue becomes more significant if the green resource from which the credits came is located outside of the consumer's airshed (for those concerned about local air pollution problems), where it is more difficult to make the case that there is a local environmental benefit.

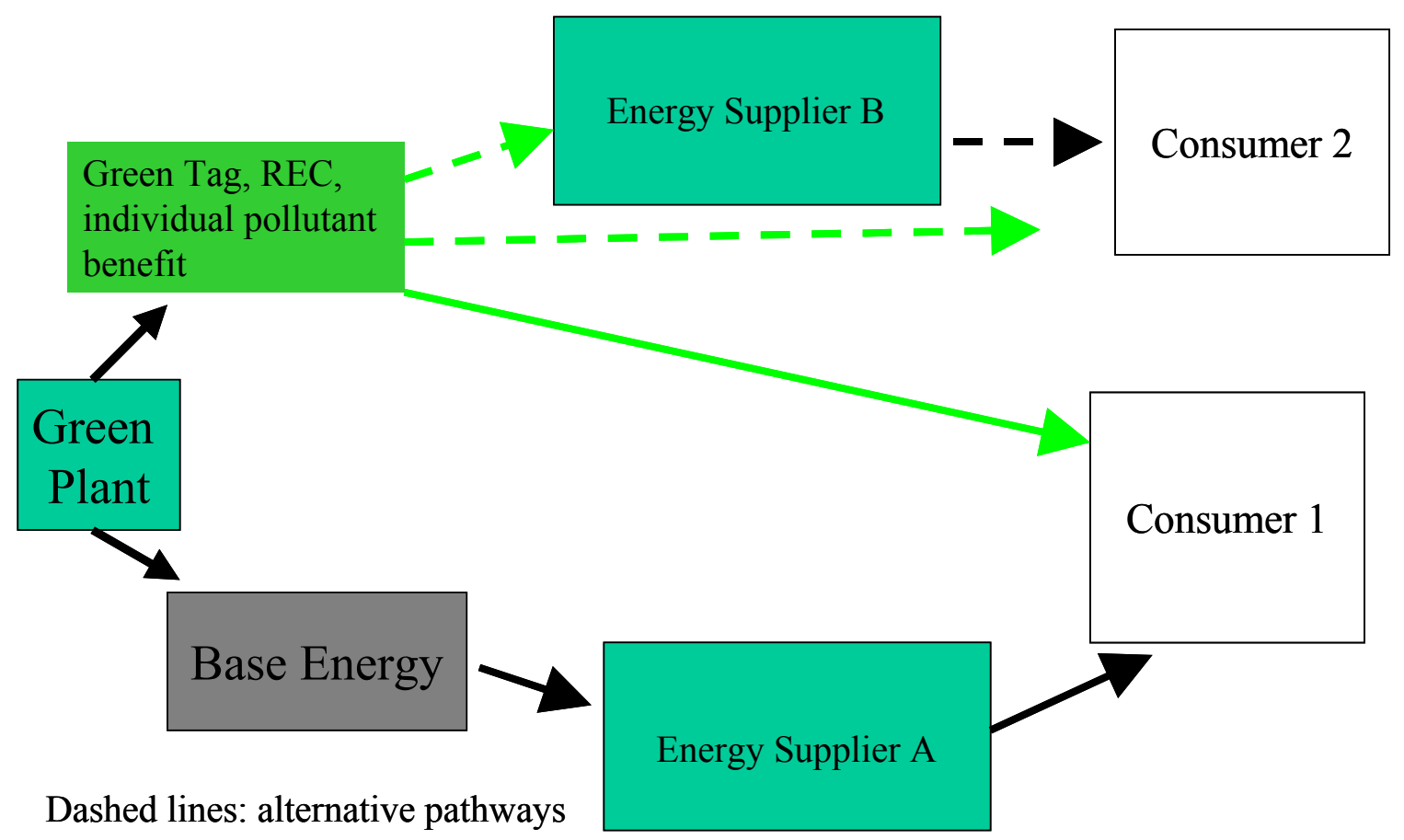

Only one entity can own a given credit at any one time (unless shared as a joint venture)

Figure 2.4 Schematic of a REC or green credit trade.

\footnotetext{
${ }^{17}$ Based on conversations with M. Davis, PG\&E National Energy Group (October 19, 2000), a former energy trader who is trying to sell green certificates based on energy generation from a wind farm owned by PG\&E National Energy Group.
}

\footnotetext{
${ }^{18}$ The Xcel Energy (formerly Public Service Company of Colorado) voluntary wind energy purchase program for consumers includes wind projects located in Wyoming. The energy that actually flows into consumers' homes is likely to be from coal-fired or other conventional generation.
} 


\section{DISAGGREGATION OF ATTRIBUTES}

The concept of renewables set-asides for specific pollutants such as $\mathrm{SO}_{2}$ or $\mathrm{NO}_{x}$, along with the development of new markets for $\mathrm{CO}_{2}$ avoidance, raises the possibility of dealing with the individual attributes separately (see Figure 2.5). This is a significant step beyond simply unbundling attributes from energy. To describe the splitting up of individual attributes (and to distinguish it from the concept of unbundling attributes as a whole), we will use the term disaggregation of attributes.

Disaggregation can be partial (such as splitting off one or more attributes related to specific pollutants) to complete (disaggregation of all attributes into separate elements), but some attributes are far harder to define than others. For instance, it is quite clear what a $\mathrm{CO}_{2}$ avoidance attribute would be (although the amount of $\mathrm{CO}_{2}$ avoided might vary from one context to another), but it is much harder to define those attributes related to the general green qualities that appeal to consumers (such as the greater sustainability, as defined by the buyers of green energy, of an energy system based on renewables). In addition, some of these attributes may be tradable separately and some may not.

There is also some question about whether the highest value is obtained by breaking up the attributes, as well as whether the mass consumer market can understand the purchase of single or small bundles of attributes. However, the development of derivatives markets in the financial sector demonstrates the power of breaking down transactions into constituent elements and then distributing them to the parties that can best utilize them. Small, well-defined tradable commodities help to increase efficiency in markets because buyers do not have to purchase the attributes they don't want.

\section{REGISTRATION AND TRACKING}

Disaggregation also appears to create some significant tracking issues, although these could be dealt with by an appropriate registration and tracking system. If an $\mathrm{SO}_{2}$ avoidance attribute (and presumably the right to claim any $\mathrm{SO}_{2}$ allowances that might be allocated or earned) is sold to a different buyer than the $\mathrm{CO}_{2}$ avoidance attribute, how are marketing claims evaluated and how is appropriate credit for pollution avoidance accorded to the right party? Tracking how energy and its attributes (if bundled) flow from buyer to seller through the "contract path" is difficult and time consuming (e.g., following the daisy chain of sales, which can be quite labor intensive if there are many buyers). Following the contract path for sale of individual attributes would add another level of complexity.

Certificates of origin that precede the creation of credits can identify and document attributes at birth (at time of generation). In this case, ownership of the resulting credit establishes ownership of the specific attributes contained in it. In a credit system backed up by certificates (or a similar form of registry), the intervening energy transactions do not need to be known. Ownership of the credits does need to be demonstrated, but only when claims are made or credits are traded (if needed as part of the buyer's due diligence) or retired. The individual attributes would have to be associated with a unique identifier, as they would have been with certificates in any case. All claims about attributes would have to be reported to a central registry or clearinghouse. The clearinghouse function would serve to establish that only one claim is being made about any one attribute (or group of attributes). In the case of RPS-RECs, such clearinghouses track all trades by establishing accounts for each trading party and either debiting or crediting that account so that no RPS-REC is counted twice. To be valid, the registry must back up marketing claims. The same principle could work for trading of individual attributes, although it would be more complicated.

Attribute trading also creates a need to be able to track (or at least establish the authenticity of) the ownership and location (jurisdiction) of the attributes because attribute accounting systems are in their infancy and often cannot (or choose not to) track them across jurisdictional borders. This difficulty in tracking and accounting for attributes is the subject of intense scrutiny, and the detailed issues involved can be highly complex. At the moment, the problem is primarily a lack of coordination and compatibility of information systems that exist or are being developed as a result of deregulation and the formation of new jurisdictions such as independent system operators (ISOs), transmission organizations, and energy markets. In addition, the principle of the moment is to allow states to take the lead on many of these issues, so the result is a hodgepodge of activities and systems. Slowly but surely the states (or 
regions) will no doubt develop compatible systems, but it appears that it will take some time. Because these systems are being designed to track energy and relevant attributes that are produced primarily from conventional emitting sources, they are ill prepared to track and account for the environmental attributes of non-emitting technologies. On the other hand, the development of a national registry (or series of coordinated regional registries) of the relevant attributes for renewables would greatly simplify this task.

The next logical step is to look more closely at the particular attributes that are being traded. We are talking principally about the non-energy tradable attributes (primarily environmental attributes) associated with the premium typically paid for wind. There are many other primary attributes as well (i.e., location of the plant, year of installation or "vintage") but these are generally not considered tradable. Enumeration of these attributes can be difficult because there is a long list of benefits from renewable energy that advocates often cite. Still, many of these probably have little value (what consumers would pay for it) and would never be separately tradable in any case.

Figure 2.5 visually represents some of the individual attributes that can be identified, but the category labeled as Other contains a large number of hard-to-define qualities of renewables generation. This category could include many of the "soft" benefits offered by wind, perhaps including the good citizen feeling that consumers experience when they buy green or the knowledge that the wind project may provide general economic benefits if located in a rural area. We explore the Other category in more detail in the section "What Is Green?" in Chapter 3.

Next, we need to think about the issues involved in splitting up the attributes and using them separately. This introduces a whole host of potential problems centered on the question of whether double selling is occurring, as different green products package these attributes differently. Tracking bundles of all green attributes sold separately from energy has plenty of its own challenges. Knowing what you have left after selling off some particular piece is an even greater challenge. Figure 2.6 illustrates how different packages might bundle attributes differently. Double selling would occur if, for instance, a green tag or REC representing all the green attributes was sold and $\mathrm{CO}_{2}$ was then sold separately to someone else. No clear rules about disclosure of such transactions currently exist, and given the "fuzziness" of many of the definitions, there is room for unintentional mistakes as well. This is a significant concern at this early stage of green market development in terms of consumer confidence and because consumer protection laws provide substantial penalties for misrepresentation to the public.

\section{How Common Energy Purchases are Similar to Credit Purchases}

Now that we have presented credit trading in detail for analytical purposes, we should note that it can also be presented much more simply for consumers by comparing it to other purchases that they have made successfully and comfortably. Except in the examples of small grids that have a single generation source, there is no certainty about where the purchased electrons come from. This uncertainty arises from the highly uncertain way that electrons move through a large grid. For instance, an electricity buyer may note that there is a wind farm nearby, and that buyer may agree to buy (in effect) all of his or her electricity supply from that wind plant (plus appropriate backup power). The energy flowing into the buyer's home could be primarily from a local coal plant, but most buyers probably don't give this arrangement another thought because (1) most buyers are unaware of this technical issue, and (2) most of those that are aware simply accept it as part of the technical realities of our electric system. The buyer is paying a green premium, either as a separate charge or bundled with the electricity, but the physical reality is that the green premium is not connected to the energy flowing into the home. Functionally, this is a similar arrangement to one in which a buyer is purchasing credits in a separate transaction from a credit supplier that may be different from the electricity supplier. In fact, purchase of "brown" energy is really no different from either of these cases, because there is never any certainty about which electrons flow into a house. Credit trading can be presented as a very familiar type of transaction, an approach that should make credit buyers much more comfortable. 


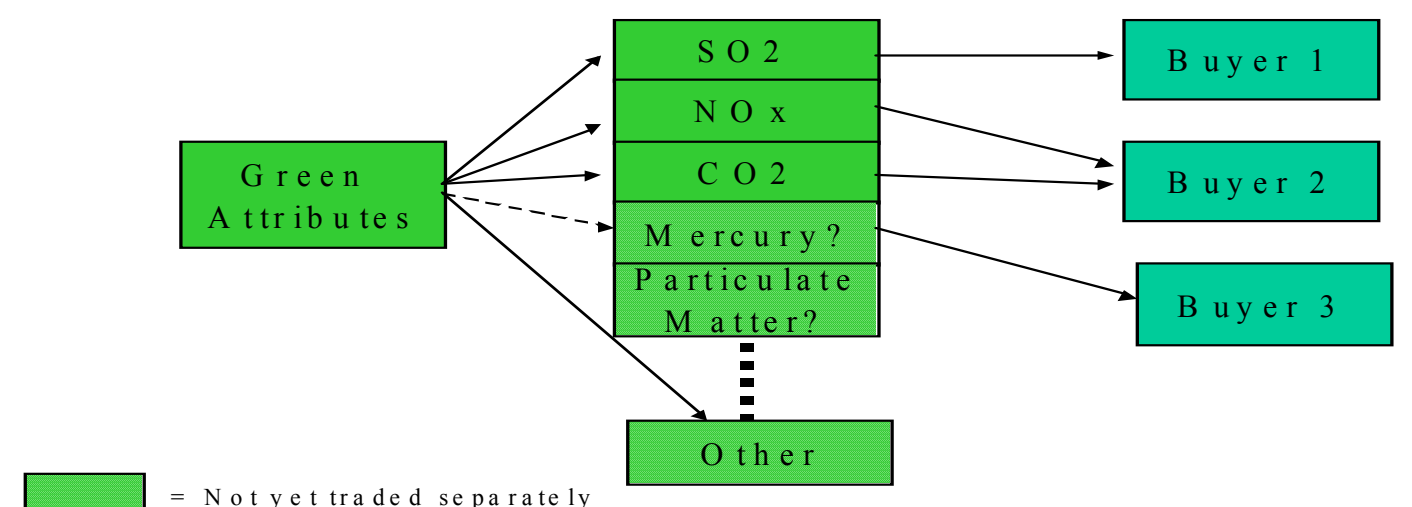

* M ake-up and levels of specific attributes depends on location (i.e.,

jurisdictions have different requirem ents; grids have different em issions

Figure 2.5 Schematic of a renewable energy credit with multiple green attributes.

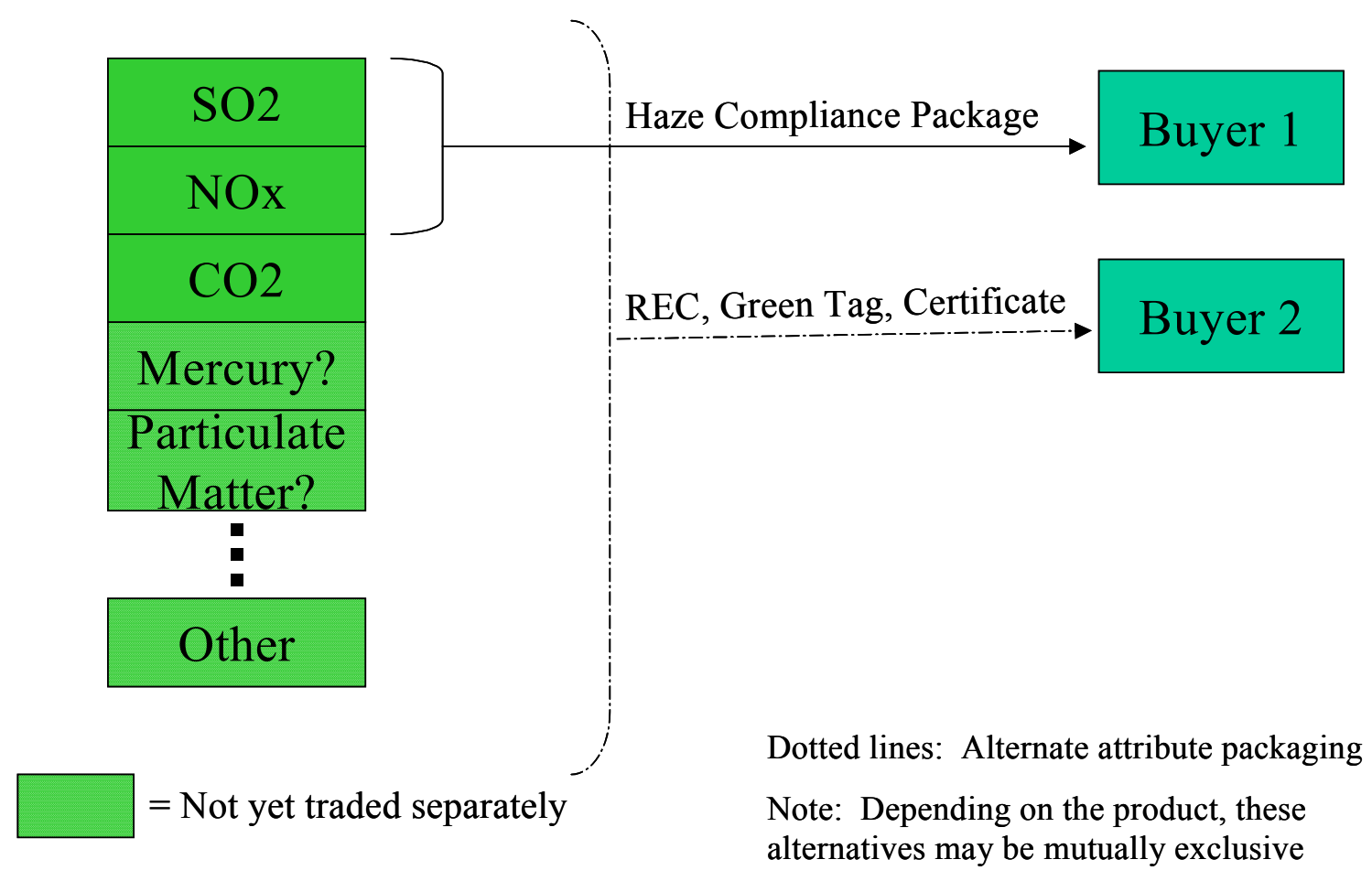

Figure 2.6 Packaging credit trades. 


\section{CREDIT TRADING SYSTEM REQUIREMENTS}

Many of the existing credit trading markets that we have covered involve small numbers of trades and relatively few players. Still, they have provided value and have helped firms achieve environmental goals in a relatively cost-effective manner. In this section, we will touch on the basic elements needed to make a liquid and viable credit market function.

A sound credit trading market in any form requires transparency, accountability, and liquidity.

Transparency is necessary so that market participants can understand how and when they can benefit from credit trading activity.

Accountability is necessary to ensure that attributes are not being sold twice and that buyers and sellers are not gaining solely from distortions in the market (such as lack of information), and to ensure that a real and permanent benefit to the environment occurs as a result of trading. Liquidity makes the market stronger and more valuable as a whole because it means that risks relating to ownership, valuation, transfer mechanisms, and regulatory shifts have been mitigated to some degree. Liquidity, however, is hard to define, because it depends on an ever-shifting mix of market size, trading unit size, commodity nature of trading units, time horizon of markets and trades, number of players, clarity of trading rules, and other factors. Simplicity of rules and operations will be key to making credit trading markets work, along with appropriate information gathering and tracking by a credible body that is capable of auditing trades periodically. Many states now have or are developing rules about disclosure of emissions and other data in association with the opening of customer choice in electricity markets. Generators may lose monetary or regulatory benefits if they don't inform customers of sold benefits for which those customers otherwise believe they are paying. Coordination of programmatic and operational characteristics of disclosure and tracking systems with other states and regions and with other policies (RPS, GPS, etc.) will help market participants develop more viable markets. Given the complexity of the issue, the special needs of renewables, and the moderate pace of the development of information systems in the states and regions, it is hard to imagine how the market will function in the near to moderate term without some kind of national or regional independent registry for, at a minimum, all green electricity generation projects. The registry can serve to fill in the gaps or supply a double check on data collected by other organizations.

\section{Update on the New England Disclosure Project}

Although the Disclosure Project itself has been moribund for more than 3 years, New England has recently taken a big step toward the development of a full certificates system that would track energy and attributes through the New England ISO control area. The system will be utilized to determine compliance with RPS, GPS, and disclosure requirements in the region's states. This effort, approved by NEPOOL (the New England Power Pool) on November 3, 2000, would be the culmination of years of work that started with the NECPUC (New England Coalition of Public Utility Commissioners) Disclosure Project and the NECPUC Model Disclosure Rule. The design of the current generation information system (GIS) is intended to coordinate the region's disclosure policies with RPS and GPS policies. Certificates in this case serve as a registration vehicle for all attributes associated with generation, including emissions characteristics. However, because wind has no actual emissions to report (and then reduce), no emissions-related attribute will be recorded for wind.

Certificates will be generated for each generation unit, and retail load-serving entities will have to buy certificates equal to their retail sales in the region. For states that have an RPS or GPS, they will have to buy certificates to meet those obligations. Marketers will need to buy certificates to back up their claims. The books will be closed every quarter, and unclaimed certificates will revert to the ISO, and then auctioned. In this way, participants can't hold back certificates and wait for better pricing at the end of a reporting cycle (or any other time). This arrangement creates problems for wind because wind's production can be very uneven in the various quarters. Typically in the east, there are winter peaking periods followed by low wind summers. Any underproduction during one quarter cannot be made up during another quarter under the New England ISO rules. 


\section{Chapter 3 \\ Discussion of Issues}

Most of the major issues relevant to this examination of credit trading have been broached in previous sections, but in this chapter, we discuss several issues that either need more exploration ("What Is Green?" and "The Local Benefits Problem") or need to be raised for the first time ("Behind the Meter?").

\section{WHAT IS GREEN AND WHY DOES IT MATTER?}

Credit trading markets thrive on clear definitions and rules. Currently, there is a disturbing lack of definition in the credits developing around green power markets. Green tags and green credits may be roughly comparable, but how they relate to each other is not yet clear. RPS-RECs emanating from RPS also represent all environmental attributes but can differ from state to state depending on the language in the statute or regulation. It may be clear from statutes or regulations what an $\mathrm{SO}_{2}$ or $\mathrm{NO}_{x}$ emissions credit is, but the relationship between an $\mathrm{NO}_{x}$ emissions credit and a green tag or a REC is not. Is a green tag still a green tag if some individual attribute is sold off? At what point does it stop being green?

These issues matter for a variety of reasons, not the least of which is that a viable green power market must have sufficient clarity in the rules and products presented to allow consumers to make reasonable, informed choices. In addition, marketers must be able to make reasonable claims without fear of being penalized arbitrarily or unfairly. In the green power markets themselves, there is a reasonable case to be made that each competing product has a right to make its case to consumers, and the better products will win out. Whether letting "a thousand flowers bloom" is a healthy way for green power markets to evolve is a matter for stakeholders to decide and act on. However, it is at the intersection of the green power markets and other existing or potential markets, such as emissions trading or RPS markets, that some interesting and potentially troublesome issues emerge. Can a given wind project participate in these various markets at the same time with the same energy, or are these markets mutually exclusive? The answers to these questions will determine to a large extent the nature and design of credit trading that can emerge. In the next sections, we explore these issues in more detail.

\section{RELEVANT LAWS AND GUIDELINES}

A recent document prepared by the National Association of Attorneys General (NAAG, 1999) discusses what constitutes acceptable marketing in the green power arena. The NAAG document notes that:

- Consumer protection law prohibits (or at least strongly discourages) selling the same thing twice (Federal Trade Commission. [August 2, 1984]. "Policy Statement Regarding Advertising Substantiation Program.").

- Green power, at this time, cannot be defined with any precision and so any claims made about it should be well substantiated (Federal Trade Commission. [1998]. "Guides for the Use of Environmental Marketing Claims.").

- Many competing claims about green power in the market may not be receiving sufficient scrutiny.

- Marketers should avoid implying a significant benefit if the benefit is in fact negligible.

Early on, the document cites an example of deceptive advertising that is indicative of the complexities involved in marketing environmental derivatives in the mainstream consumer market. A hydro generator legally sells green tags representing the nonpolluting attributes of the power being generated. The same hydro generator then markets the energy with the company's name, which includes the word "hydropower." According to the NAAG document, this implies that the electricity still includes the green attributes that were sold with the tag. Because it is impossible to determine the origin of electrons that actually flow to a given buyer, the task of ensuring that market claims are real can be a difficult one. The task can be simplified, however, through a system whereby clear title to attributes can be shown and tracked. Marketing claims must then match up with attribute ownership.

Other examples are given where the "greenness" of electricity is somehow clouded or diminished (these are called "leakages" in emissions trading parlance). One such case might be where water is 
pumped into a hydro station using coal-fired power, which represents a significant source of emissions relative to the hydro project's size. Under an attribute credit trading system, this would be equivalent to having sold (or otherwise lost control of some of the positive environmental attributes of the hydro station. In both cases, the greenness of the resulting energy would have been diminished.

\section{WHEN GREEN IS NO LONGER REALLY GREEN}

The logic of the NAAG guidance would lead us to believe that green power that has had some of its environmental attributes (benefits) stripped off would require a disclaimer indicating that it is no longer as green as before. The question then becomes "when does it cease to be green?" or at least "when can it no longer be marketed as green"? A corollary problem is how many shades of green are acceptable in terms of the law or the market. Some groups are struggling to figure out how the differentiation might be achieved in a manner that would not confuse or put off consumers..$^{19}$ It may well prove infeasible to use a system with a high number of green gradations, unless the consumer easily understands them. To date, no formal system of evaluating levels of greenness has received sufficient scrutiny to be accepted.$^{20}$ Green-e, the leading renewable energy electricity product certification body in the United States, and similar green labeling and certification programs are looking primarily at levels and types of renewables in various energy products. These programs are just beginning to address the issue of selling off attributes and their effect on the remaining products.

The most difficult and most legally uncertain question has to do with what is left once a variety of environmental attributes are sold off. One conceptual framework assumes that all attributes can be spun off from a given kilowatt-hour of electricity from any source, with the remainder being "null" energy, or energy without any

\footnotetext{
${ }^{19}$ Green-e, supported through the Center for Resource Solutions, and the Pembina Institute (Canada) are two such groups.

${ }^{20}$ Certain subsets of buyers may be able to able to handle more complex transactions and units, but the general public is unlikely to respond well to a complex system.
}

environmentally beneficial characteristics. Some renewables advocates argue that an irreducible green component will remain even if all the defined attributes are sold off. Theoretically, one could spin off a virtually unlimited number of environmental (or other) attributes from a given green kilowatt-hour (the "how many angels can fit on the head of a pin" philosophical inquiry), but at some point the value of the incremental attributes diminishes rapidly. As a case in point, the fact that wind energy may avoid some mercury emissions in certain areas, and that avoiding mercury emissions is valuable, doesn't mean that there is a valuable "mercury avoidance" attribute that could be sold. On the other hand, there is nothing preventing two or more private parties from creating a mercury emission credit trade to establish the concept and pave the way for a potential new revenue stream for wind projects.

The concept that there is some irreducible green core is given some weight by the idea that some green qualities have value beyond the specific pollution prevention attributes that can be spun off (e.g., sustainability that enhances energy security, the value placed on the perceived likelihood that future generations will have a better environment, etc.). These are generalized benefits that are difficult, if not impossible, for the market to split out into individual commodity units. Some observers maintain that even renewable energy with its environmental attributes sold off will always be preferred over polluting options by a substantial number of consumers, but this gets into very questionable territory in terms of how such a product would be marketed. The NAAG guidance clearly states that marketers should avoid implying a significant benefit where one does not exist. We prefer not to make assumptions about where the market might go with this issue over time, but many observers believe that having many highly nuanced claims on the market would seriously harm the credibility of the green power market.

Green tags, green certificates, and green pricing are all generally thought to represent the full range of environmental benefits, ${ }^{21}$ but what they actually convey varies from program to program and from state to state. Green tags typically convey

\footnotetext{
${ }^{21}$ Recognizing that most consumers probably have not given this much thought nor have a conceptual framework from which to evaluate such a product.
} 
ownership of attributes from the subject energy generation; green-pricing programs may or may not convey ownership depending on the relevant programs and contractual or regulatory language. These products could be in danger of challenge under consumer protection laws if specific attributes were sold off while the green tag or green product continued to be marketed as before without reference to the diminution. Of course, the market may simply accept such practices, but the possibility of a court challenge renders the market less certain and stable than traders and other market participants would like. Any credit, or marketing programs such as green pricing, that purports to represent the full environmental benefits of renewable energy projects would appear to have to reference any significant diminution of green benefits from selling off attributes. What "significant" means will have to be tested in the markets and perhaps in the courts.

RPS-RECs, as defined by RPS legislation, presumably represent all of the associated attributes (at least environmental attributes). However, only one state RPS (Texas) of the 10 states that now have RPS in place (see list of states in Case Study \#1, Chapter 8 ) says explicitly that all the attributes are represented by the RPS-REC. Some experts have assumed that RPS-RECs would become a vehicle for conveying various constituent environmental attributes (such as $\mathrm{SO}_{2}, \mathrm{NO}_{x}$, or $\mathrm{CO}_{2}$ avoidance), and that constituent attributes could then be sold off to maximize value. In the case of Texas, Public Utility Commission (PUC) staff feels strongly that to achieve compliance, RPS-RECs must remain essentially "whole" to meet the stated obligation of each retail supplier (E.S. Schubert, PUC of Texas, personal conversation, September 2000). This treatment would result in RPS-RECs being very much like green tags in the sense of representing all environmental benefits but not subject to disaggregation of constituent attributes. ${ }^{22}$ In this scenario, RPS-RECs and green tags would be mutually exclusive concepts. The same kilowatthour could not create both a REC and a green tag. The Texas RPS-REC market is just now getting off the ground, and the markets will determine over the coming months just what a REC conveys and

\footnotetext{
${ }^{22}$ Actually, whether green tags are subject to disaggregation is unclear at this time. Some practitioners are attempting to sell green tags with the $\mathrm{CO}_{2}$ attribute removed and still call them green tags (although they might be called light green tags).
}

what value it will carry. In time, when RECs and green tags emerge in the same jurisdiction, the distinctions will become clarified.

In summary, whether individual or groups of green attributes can be split off from an underlying green credit depends on the type of credit and the market it serves. Assuming that Texas serves as a model for the future direction of state and federal RPS policies, it appears that RPS markets are likely to allow only whole RPS-RECs-that is, RPS-RECs that are undiminished by the sale or other disposal of green attributes, including emissions attributes. It is far less certain whether green power markets for individual consumers will allow anything other than fully intact RECs to be sold. If "light green" credits are allowed on the individual consumer market, clear statements of what these credits contain (or don't contain) will be required. For institutional buyers on the green power market, or for buyers in the emissions credit markets, greater flexibility and a wider variety of credit products are warranted.

Regardless of the market being served, careful statements of what the credits contain or convey will be required. Any entity splitting off an individual or group of green attribute(s) from a green credit that is purported to represent all environmental attributes cannot then market that credit as a green credit without a disclosure as to what has been sold. What the green power industry, electricity suppliers, consumers, regulators, and other interested stakeholders have to decide is how many, if any, "shades of green" the green power market (i.e., consumers) can handle, and whether giving institutional buyers more products to choose from than individual consumers in any way compromises the development of green power markets.

\section{THE LOCAL BENEFITS PROBLEM}

One of the exciting benefits of credits is that they can remove geographic location as an important determinant of value, thereby sidestepping wind's problem that the best resources are often not located near load (and therefore pollution) centers. ${ }^{23}$ RECs could theoretically be sold to a buyer thousands of miles away whose grid never

\footnotetext{
${ }^{23}$ Of course, this scenario has limited potential if the energy cannot be absorbed where it would be produced. Without an energy sale (or use, in a demand reduction mode), there are no green tags or offsets created.
} 
receives any energy from the wind site from which the green tags were sold. The problem here is that, with the exception of greenhouse gases where impacts may be mainly global, the buyer does not realize any local benefits from the clean energy generation. ${ }^{24}$ The primary objection of some environmental groups to credit trading is based precisely on this issue. They claim that trading has the potential to create pollution "hotspots" or simply move pollution from one area to another. Whether consumers will find these credits credible to begin with is an open question. It may be difficult for consumers to accept national markets for such credits if local benefits are hard to understand. At this time, $\mathrm{NO}_{x}$ allowances can only be traded within certain regions, trading of $\mathrm{SO}_{2}$ allowances is beginning to experience some efforts to limit trades geographically, and in some states there are increasing limits on the geographic direction of those trades. Some types of pollution reduction benefits will likely continue to be limited to local trading. Others will have characteristics that allow them to be traded nationally or internationally.

The market hasn't yet determined what premium would be paid for local benefits, but it seems clear that most new regulations and programs will have a substantial local component. Where effects are local, benefits will probably be expected to follow along the same lines. GHG markets may be the exception. But even where there are local cobenefits from GHG reduction-primarily particulate matter-that will be the subject of stringent new regulations (particulate matter [PM] 2.5 , etc.). The PM credit markets will likely be local or regional even if the broader global warming reduction benefits are national or international.

\section{RISKS FROM CREDIT TRADING}

The major risks from credit trading arise from the uncertain nature of the credits and the attributes contained within them. A substantial part of the risk stems from the lack of definition and rules surrounding credit trading. A well-crafted contract for a trade will specify what is being traded and the consequences if terms of the contract are not met,

\footnotetext{
${ }^{24} \mathrm{CO}_{2}$ or other GHGs have global effects and limited direct local impacts, although particulate matter regulations (primarily from carbon-based fuels), as they get more stringent, may create recognition of more local effects.
}

but there are no standard contracts to date and many of the terms in use are vague or are evolving over time. What is allowed in marketing claims is also very unsettled, so a contract could validly transfer attributes from one party to another, but if one party intentionally or unintentionally misrepresents to a consumer what is contained in the transfer, one or more parties may be liable under consumer protection statutes. Wind companies need to be very careful about selling off attributes and still making claims about the green nature of the power. In addition, wind companies should insulate themselves from liability for claims made by those who purchase the attributes, but this assumes an ability to be explicit about what is being sold. In an emerging and evolving market, this is easier said than done. It is conceivable that the sale of all green attributes would mean that a wind company could not even market its power as "wind" because that would imply to buyers that there was some greenness that came along with the purchased power (see the hydro example in the Relevant Laws and Guidelines section discussing the NAAG guidelines on green power marketing). Because few claims have been tested, marketing claims should be very conservative to avoid being challenged.

The risks are even higher if credit sales cover future years of generation (forward markets). Rules could change, wind projects could fail to generate electricity as claimed, and what is being displaced could change as well (so that avoided emissions that were expected may not materialize). There is also the risk that wind projects could sell credits into a particular market on a long-term basis without understanding what other options are available and how credit markets might change over time. Such a project might then forgo substantial future revenues, albeit in exchange for smaller, more certain revenues today. For projects that attempt to use revenues from credit sales for financing purposes (i.e., as a partial basis for debt repayment or, more likely, as part of equity returns), it becomes particularly important to ensure the integrity of the credits.

\section{BEHIND THE METER?}

The design of credit trading programs makes it difficult for small sources to receive credit because they are virtually all based on meter readings and other information reported to an ISO or other group. Systems that are "behind the meter," such as 
small wind or solar home systems or those that have net meters, do not generate the requisite information to allow disclosure, verification, and tracking. Because metering these sources could be expensive, some type of indicative reporting might need to be put in place. The Sacramento Municipal Utility District (SMUD) has a solar program that reportedly provides a second meter and allows excess production to be supplied to the premium green market, but it is unclear how expensive this was to implement. Such programs would be resisted by some parties and criticized as costly or complex to set up, although the experience in Nevada and New England has shown that it does not need to be. It would also be difficult to ensure accurate reporting without a consistent, objective data source like a meter. Individually trading and tracking all these systems could also be expensive, so some type of aggregating entity might be needed to bring small sources into the credit trading system. ${ }^{25}$

\footnotetext{
${ }^{25}$ Texas, for instance, will allow REC "aggregators," such as electric cooperatives, to perform this function for RPS-REC compliance and trading purposes.
} 


\section{Chapter 4 \\ Barriers and Opportunities}

\section{BARRIERS TO CREDIT TRADING}

Barriers to credit trading vary depending on what particular market we are considering. The most important barrier to credit trading as a whole is the lack of recognition by regulators of attributes that are traded separately from energy. This is particularly problematic when cross-jurisdictional trades are involved, since importing jurisdictions may not recognize the imported attributes, but it is still a significant issue within many jurisdictions. If marketing claims are to be made based on credit trades, the attributes must be recognized by regulatory authorities and accounted for in disclosure rules. ${ }^{26}$

Including credit trading in RPS policies would require it being included explicitly in legislation and then being approved through the regulatory process, but there is a lack of awareness among legislators, regulators, and lobbyists of the value that credit trading can have in easing and lowering the cost of RPS implementation. Emissions trading markets are driven primarily by compliance with laws and regulations, so the initial barrier here again is being recognized in authorizing legislation and in regulation. Legislators and regulators also lack awareness about the many ways in which renewable energy can contribute to pollution control through credit trading. Consumer-driven green power markets are especially problematic because, although consumer choice is about giving consumers the widest possible range of products to choose from, regulators can often frustrate these markets from developing by refusing to recognize (or simply ignoring) new products.

As constraints increase on the ability to unbundle or disaggregate attributes (from energy or from other attributes), the economic efficiency of credit trading diminishes. This occurs because transaction

\footnotetext{
${ }^{26} \mathrm{~A}$ recent example is a marketer of green certificates from wind projects in New York who is trying to sell them into New England. However, potential customers cannot "claim" the green certificate attributes because of the way imports into New England are treated under disclosure rules. Because marketing claims must be backed up by what is reported on disclosure forms, these attributes in effect do not exist for marketing purposes in New England.
}

costs of credit trading rise with increased reporting and registration requirements, monitoring and verification, and other quality assurances, whether in response to the need for consumer protection or self-imposed by marketers to create brand recognition and standards. Economic efficiency must be weighed against the need to develop understandable and viable consumer markets for green power, which may require some limitations on unbundling. Different markets have different abilities to absorb highly nuanced credits. Institutional buyers are more likely to be able to understand, and to need, credits based on individual or highly specialized bundles of attributes. As a result, they may be more willing to absorb the transaction costs of generating and trading unbundled attributes. A significant barrier to the efficient use of credit trading would arise if institutional buyers were limited, as consumers may well be, to buying only complete packages of green attributes. Developing credit markets should be able to recognize the different needs of different buyers and the transaction costs associated with them. Any limitations placed on any buyers need to have compelling justifications and should be carefully designed to avoid unnecessarily reducing efficiency. Remember, efficiency is perhaps credit trading's most compelling feature. The argument that credit trading can help to lower the cost of achieving environmental and energy goals could bring some opponents of renewable energy on board.

\section{BARRIERS TO WIND IN CREDIT TRADING}

Most of the barriers to wind in the credit trading arena extend from wind's barriers in other arenas, especially where those issues translate into higher costs that reduce wind's competitiveness versus other options. They include intermittency of resource and generation, particularly the inability to schedule delivery (dispatchability); costs charged to wind for balancing or other ancillary services; and higher implementation costs, including transmission construction costs for what is often remote siting. Wind's technical constraints pertain primarily to delivery, which may or may not be important in certain types of credit trading. Where time-of-day delivery is a primary determinant of 
value, wind will be at a disadvantage if the wind resource does not coincide well with market needs. In some emerging pollution control markets, high value is placed on displacing emissions at times of peak emissions (from electricity generation, transportation, and other sources on a smoggy summer afternoon, for instance). Natural gas and other cleaner dispatchable technologies may have a significant advantage if they can deliver emissions reductions or offset at a time when prices are highest.

The most straightforward way in which wind can be disadvantaged in credit trading is by not being defined as an eligible technology in a relevant trading program. Despite evidence to the contrary, many states still believe that they do not have a significant wind resource. For this reason, other technologies are defined in law or regulation (for instance, RPS or SIPs), leaving wind out. Given the competitiveness of wind and the tremendous exposure the technology has received in the past several years, particularly in debates about emissions reductions and the role of renewables, it is increasingly unlikely that wind would be completely closed out of significant trading programs. However, limitations on the amount of wind that can be included (such as in Nevada's RPS, which requires a 50\% solar market share) are an example of how wind's cost competitiveness can be constrained by eligibility rules.

Wind can also be harmed by rules that attempt to clear or otherwise control the amount and timing of credits available in the market. For example, the New England ISO disclosure rules will clear the market of unused credits, by reclaiming and then auctioning them, to avoid a market participant hoarding certificates and forcing the prices up. In the New England case, the ISO chose a quarterly clearing period (to match similar features in a complementary policy in Massachusetts). Although unintentional, the effect would be that a wind plant that produced more energy (and therefore attributes) than there was demand for in one period would have its excess attributes taken away. That plant would effectively lose the financial benefit from that higher production of attributes. In the lowest producing season, wind would thus be unable to make up for the lack of attribute production. Some kind of annual clearing would work much better for wind, although it might also raise the cost of compliance for a given jurisdiction if all sources were on the same annual schedule.
For programs that rely on capacity or energy requirements from renewables or set-asides of tradable allowances, these could be too small and short term, and perhaps allocated based on politics rather than relative economics. More likely is the playing field being closed (or limited) to new entrants (as opposed to existing emitters in the case of allowances), so that wind generators will be unable to receive substantial numbers of allowances or create credits. More significantly, wind could be hurt by unfavorable rules for earning credits or allowances.

Some emerging certification systems entertain the possibility of treating technologies differently based on environmental impact (also referred to as "shades of green," but referring in this case to the relative environmental impact of the technologies themselves rather than the result of selling off attributes from credits). An extremely stringent standard that penalized wind for its avian issues or visual impact could reduce the advantage wind would have over conventional technologies by making wind a less desirable choice to consumers in green power markets.

Wind could also be penalized for intermittency or perceived technical issues (by discounting emission reduction calculations, for instance). More fundamentally, wind could be disadvantaged by the choice of low conversion rates or benchmarks against which to calculate emissions reductions (this happened in the $\mathrm{SO}_{2}$ trading program when renewables were allowed to earn only one allowance per $500 \mathrm{MWh}$ of generation). Conversion rates could, for example, make a default assumption that wind would displace a system-wide average that was supplied heavily by nonemitting hydropower but that relied on diesel gensets for its marginal generation. The choice of conversion rates or procedures can be both technically complex and highly political. Although some methods are undoubtedly more reflective of actual emissions savings or other green benefits than others, credit markets are most interested that a given amount of benefit not be subject to change once it has been determined. In addition, credit markets will best be able to project into the future (and thus provide a revenue stream based on multiple years of generation) when the green benefits, particularly emissions savings, can be determined in advance. 


\section{Consequences of Prohibiting Disaggregation of Attributes in Consumer Markets}

One scenario that should concern the wind industry is if consumer green power markets develop in such a way as to allow only full packages of attributes (all attributes together, whether tied with the energy or not) to be sold. (The mechanism for prohibiting disaggregation could either be regulatory or within the green certification process.) A vibrant market for $\mathrm{CO}_{2}$ credits is developing, and if wind projects that sell off the $\mathrm{CO}_{2}$ avoidance attribute are not allowed to then sell their power as green in the consumer markets (and assuming that $\mathrm{CO}_{2}$ prices are not likely to be sufficient to cover the "over-market" cost of wind), wind projects may be prevented from participating in the $\mathrm{CO}_{2}$ markets. A wind project would have to choose to participate in either the consumer market or the emissions market. This becomes much less of an issue if wind is allowed to participate in other emissions markets as well, such as $\mathrm{SO}_{2}$ or $\mathrm{NO}_{x}$; this creates multiple revenue streams for a wind project. One alternative might be to allow $\mathrm{CO}_{2}$ to be sold off and still be sold into green power markets in recognition of its global impacts. In this way, wind could participate in the consumer green power markets even if the $\mathrm{CO}_{2}$ attribute is missing, and consumers would have the option of buying green power (perhaps at a slight discount) without the $\mathrm{CO}_{2}$ component. Consumers could then decide whether capturing the $\mathrm{CO}_{2}$ component is important to them, and wind companies could decide where the best deal for the $\mathrm{CO}_{2}$ component can be realized.

Finally, it will complicate wind's ability to respond to various credit trading opportunities if wind projects have to shop their $\mathrm{SO}_{2}$ avoidance in one place, $\mathrm{NO}_{x}$ in another, $\mathrm{CO}_{2}$ in another, and so on. It would be far more efficient if these markets were able to develop one-stop shopping for allowances, quotas, or various types of credits. Although the private sector should be able to develop such a system if there is demand for it, regulatory rules and procedures (including disclosure rules) can either complicate or facilitate such a system.

\section{OPPORTUNITIES FOR WIND POWER}

Wind power generation, which has no associated harmful air emissions, stands to gain significantly from credit trading in a variety of venues. Credit trading is not burdened by some of wind power's own challenges, including transmission access (energy does not have to be delivered with the credit to a particular buyer) and intermittency (credit trading divorces wind from the timesensitive demands of energy markets). At times, these technical issues have been obstacles to the full realization of wind power benefits, but credit trading can increase wind's appeal to investors. Although wind has not benefited from regulatory schemes that attempted to include wind and other renewables as much as advocates and analysts originally anticipated, that can change.

Stakeholders interested in promoting wind energy can influence the plethora of existing and proposed regulatory programs to advance wind power development. Meanwhile, in the nonregulated arena, sellers and buyers of wind-based RECs are now entering into independent transactions, whether for altruistic reasons (improving the environment) or individual gain (capturing economic rents from the trading of credits or public relations benefits vis-à-vis competing firms). Entrepreneurial activity in the nonregulated market for emission trading can also grow to the benefit of wind power and should be strongly encouraged, particularly because the nonregulated markets are generally less susceptible to political vagaries and barriers.

The emerging credit trading arena should be able to, where appropriate, break down the various attribute bundles into individual components and reassemble them into packages based on market demand. Some buyers will want baskets of benefits (i.e., tailored compliance packages for industry or green buyers of attribute bundles in the retail electricity market). Others will want single benefits (e.g., $\mathrm{CO}_{2}$ credits or $\mathrm{SO}_{2}$ emissions offsets) that will continue to be valuable because of the underlying regulatory structure and their particular circumstances or set of interests. The primary question for policy makers is how to organize such markets so that the maximum amount of choice and flexibility is achieved consistent with consumer protection and broader market or social goals. From the wind industry's point of view, the vital question would be: where would credit trading be most effectively used to encourage the growth of markets for wind power?

\section{WHERE'S THE VALUE?}

Trying to quantify the value for renewables of the various venues within which credit trading can be 
used is beyond the scope of this report, but other analyses have made reasonable attempts to do so. Most analyses by expert observers show the greatest potential value for clean sources of energy coming from RPS policies and carbon trading (the latter assuming binding national commitments for carbon reduction), but the range of potential values and the time frame for action is extremely wide and uncertain. Still, it is instructive to look briefly at some of these studies.

Green tickets traded on the Automated Power Exchange (APX) market get about $\$ 0.005 / \mathrm{kWh}$ (J. Hamrin, Center for Resource Solutions, personal conversation, 2000). However, two new studies suggest that the combined value of $\mathrm{SO}_{2}$ and $\mathrm{NO}_{x}$ credits-based on historical values-would be $\$ 0.0018$ to about $\$ 0.0036$ per kWh (Wooley 2000; Alderfer, Eldridge, and Rivera 2000). For more expensive renewables, this amount is still insignificant. For a relatively low-cost renewable like wind, it begins to have some meaningful value, particularly when the value of other credits might be added on top of it (stemming from controls on mercury, particulate matter, or perhaps some variant of light green tags). Adding in potential values from $\mathrm{CO}_{2}$ trading, one paper adds another $\$ 0.003 / \mathrm{kWh}$. Still, prices of the $\mathrm{SO}_{2}, \mathrm{NO}_{x}$, and $\mathrm{CO}_{2}$ credits are highly uncertain and depend on how the programs are implemented in the future. Opinions on these future values vary widely.

Analyses of RPS policies by several groups suggest that prices for RPS credits could be an order of magnitude higher than the prices for emissions credits. Prices in these studies vary depending on the level of the RPS target for renewables but range from $\$ 0.01 / \mathrm{kWh}$ to $\$ 0.031 / \mathrm{kWh}$ levelized. ${ }^{27}$ Clearly, these levels are sufficient to drive substantial amounts of new renewables into the market. An analysis by the Union of Concerned Scientists (UCS) projects up to 5,500 MW of new renewables as a result of state RPS policies and tens or hundreds of thousands of megawatts of new wind generation from national RPS (UCS 2000). The range of potential carbon credit prices varies even more widely, from a few mills (tenths of a cent) per kilowatt-hour to several cents per kilowatt-hour and above. However, these prices may not have the same effect as RPS because many

\footnotetext{
${ }^{27}$ Prices are 30-year levelized as cited in UCS 1999.
}

more options for reducing carbon would be available. We are not suggesting that these estimates can be compared directly to each other but are presenting them to give a general sense of the potential value of each policy or type of credit.

\section{WHERE TO FOCUS?}

Value, however, is not measured only by the potential size of markets or the level of support offered by various types of policies or credits. The probability of certain outcomes should also influence how and where value is perceived. One of the issues that we have struggled with in this project is its relatively short time horizon. The scope of work for this project calls for a 3-year time horizon with some attention to significant opportunities beyond that time frame. We have found that there are only a few opportunities that, on their own, are likely to have a significant effect on wind markets within this period of time, and most of those opportunities depend on a significant boost for renewables in the context of restructuring legislation in Congress. Although a well-

constructed national RPS policy with significant commitments to new renewables is possible in this context and would likely give wind the largest and longest term benefit, the politics of working within the restructuring debate are complex and highly uncertain. A more plausible scenario, or at least a reasonable contingency plan, might include a combination of new or modified policies, programs, and consumer choice markets that are mutually reinforcing. Although these scenarios are not mutually exclusive, the NWCC's available resources may limit the exploration of multiple opportunities.

\section{RPS Markets}

As mentioned earlier, national RPS would probably be the most effective policy for expanding markets for wind, and credit trading would help to lower the cost of implementing significant RPS. As restructuring legislation is considered, the opportunity to establish national RPS will be front and center in the new Congress. Improving existing RPS policies in one or more of the states is a possibility, and adding credit trading to those policies or improving planned trading programs seems plausible. Although the likelihood of major new capacity being generated in these states (beyond current commitments) in the near term has appeared to be fairly small, the dynamics may have changed with the recent power crisis in California, 
which has laid bare the exposure of that economy to fuel price risk. In this scenario, RPS might become more politically palatable because of the fuel price risk hedge that renewables provide. New state RPS have a somewhat longer pathway and lower probability, but high potential value for wind power. Only two states, lowa and Minnesota, seem reasonably well placed to move on new RPS anytime soon, and these states already have a relatively high commitment to wind.

\section{Emissions Credit Markets (Excluding Carbon)}

New National Ambient Air Quality Standards (NAAQS) would create substantial new demand for offsets and avoidance and would likely raise prices for credits substantially, particularly in nonattainment areas. On the other hand, these standards may be delayed or diluted as a result of court decisions, congressional action, or administration policies. In terms of new individual pollutant programs, mercury could have substantial value, but the setting of mercury emission standards will depend heavily on politics and the results of ongoing talks with emitters. The $\mathrm{NO}_{x}$ and $\mathrm{SO}_{2}$ programs have separate, longer term schedules (with the possible exception of a particular $\mathrm{NO}_{x}$ program discussed below) and are relatively set at this point in terms of their potential effect on renewables. A major rewrite of the Clean Air Act may be several years away at best, but there are some exciting possibilities that may reopen this venue for wind and other renewables. ${ }^{28}$ Despite having faded in the previous Congress, several proposed bills now in Congress seek to integrate several pollutant control programs into one vehicle (the so-called "multi-pollutant" or "Four Pollutant" bills that could address $\mathrm{NO}_{x}, \mathrm{SO}_{2}, \mathrm{CO}_{2}$, and mercury). These bills encourage credit trading and, to varying degrees, incorporate renewables. As with national RPS, the electricity restructuring legislation that will be taken up in the 107th Congress provides a real opportunity for the inclusion of a multi-pollutant bill.

\section{Carbon Markets}

Despite the huge potential value, the uncertainty over when (or whether) a binding agreement will

\footnotetext{
${ }^{28}$ For detailed treatments of the opportunities for renewables in the context of Clean Air Act re-authorization, see Wooley, Morss, and Young 2000; Wooley 2000; and Alderfer 2000.
}

be put in place makes it difficult for us to recommend a focus on this arena over the next few years. In terms of arenas in which the NWCC can have a significant impact in the next 3 years, international carbon trading would have to rank fairly low. Given the diverse interests of the NWCC, it is also hard to imagine getting both consensus and resources to participate in the formation of significant carbon trading markets that would involve wind in a major way. ${ }^{29}$ Where recognition of carbon reductions today can be provisionally recognized ("early credit"), value that can benefit wind may still be created. It is also a useful exercise to determine where limited but targeted action on the carbon front in the next 3 years might help to create substantial long-term value for wind.

In addition to early credit for carbon reductions, the one reasonably near-term exception is the Clean Development Mechanism (CDM) under the Kyoto Protocol. Although this mechanism could theoretically have begun in 2001, it is still a long way from being operational. Wind is likely to be defined as one of the favored technologies on the "positive" list, or the list of project types that will automatically be approved for emission reduction. Although the CDM is not applicable for U.S. projects, it certainly offers a significant potential opportunity for the industry to find financial and policy support for wind projects in developing countries.

\section{Green Power Markets}

Large-scale development of RECs will also be a significant boon to wind markets. At issue is when this demand will result in significant new renewable capacity. Because private green markets do not necessarily need the government's OK to conduct trades (except in terms of how such credits are recognized and treated, such as in emissions disclosure rules), RECs designed for consumer choice markets have the apparent benefit of being relatively insulated from the vagaries of national or state government politics. Credit trading can help to overcome some of the barriers to green power markets, particularly barriers to switching suppliers (which is not necessary with credits unbundled

\footnotetext{
${ }^{29}$ Carbon sequestration in the form of planting and maintaining trees was pushed by the U.S. negotiators at the climate change talks in The Hague in November 2000 and seems likely to garner the support of many business groups.
} 
from energy purchase). Credit trading offers consumers more choice, greater flexibility, and the potential for lower cost green power options, but a substantial amount of consumer education needs to occur before RECs lead to substantial new demand. Whether sufficient consumer education could take place within the project's 3-year time frame is unclear, but the medium- to long-term potential for growth in the green power market makes investing some near-term resources worthwhile. Because of the ease of green credit transactions, and the fact that underlying energy purchases and logistics remain unchanged, these instruments are ideal for sophisticated institutional buyers that can aggregate significant purchases (such as federal and state governments, business alliances, and associations of municipal or cooperative utilities). The NWCC should seek to support and expand the current work by DOE and the National Renewable Energy Laboratory (NREL) to aggregate federal agencies into large purchases of wind power utilizing RECs (NREL's work has used the term "green tags"). State agencies could follow a similar model.

\section{System Benefits Charges}

SBCs may represent a relatively small but very near-term opportunity for affecting credit trading and the wind industry. Although many of the other venues for applying credit trading are subject to various political and legal uncertainties, a number of SBCs are already established. Funding for these is set up by legislation and automatically collected from fees charged on electricity use. Some SBC funds have great built-in flexibility, although significant political constraints usually still apply. In a number of cases, states have not determined how to fully utilize the funds, although there are many competing demands. SBC funds could be utilized by consumers to buy down the purchase price of green electricity, but could have a longer term influence by facilitating credit markets. Because such buy-downs might be resisted as direct subsidies, SBCs are also particularly well suited in their "public interest" mode to help jump-start credit markets and even partially stand behind them until they are on their feet. SBC public education funds may be especially useful in helping to develop a comfort level among consumers about credit trading.

Table 4.1 summarizes a qualitative ranking of each of the areas in which credit trading could be applied. Although wind could receive some benefit from all of these opportunities, only a few have enough potential and probability to deserve substantial attention. These, which are ranked medium or higher, are highlighted in bold type in the table. 
Table 4-1. Ranking of potential credit trading venues.

\begin{tabular}{|c|c|c|c|c|c|}
\hline & & Probability $^{30}$ & $\begin{array}{c}\text { Wind market } \\
\text { benefit }\end{array}$ & Timeframe $^{31}$ & Overall \\
\hline \multirow[t]{11}{*}{$\begin{array}{c}\text { Pollution } \\
\text { Regulation }\end{array}$} & $\begin{array}{c}\text { Clean Air Act } \\
\text { Amendments of } 1990 \\
\text { (CAAA 1990) } \\
\text { Reauthorization }\end{array}$ & Medium & Medium & Near-Medium & Medium \\
\hline & Tighter NAAQS & Medium & Low-Medium & Medium & Low-Medium \\
\hline & $\mathrm{SO}_{2}$ Program Revision & Low-Medium & Low-Medium & Medium & Low-Medium \\
\hline & $\mathrm{NO}_{x}$ Program Revision & Low-Medium & Low-Medium & Medium & Low-Medium \\
\hline & NOx SIP Call & Medium-High & Low & Near & Medium \\
\hline & Mercury & Low-Medium & Low-Medium & Medium & Low-Medium \\
\hline & Four Pollutant Bill & Medium High & Medium-High & Near & Medium-High \\
\hline & PM & Medium & Low-Medium & Near-Medium & Low-Medium \\
\hline & New Source Offsets & Low & Low & Medium & Low-Medium \\
\hline & Western Haze Rule & Medium & Medium & Medium-Long & Medium \\
\hline & Penalties/Mitigation & Medium & Low-Medium & Near & Medium \\
\hline RPS-state & Modifying Existing RPS & Medium & Low-Medium $^{32}$ & Medium & Low-Medium \\
\hline RPS-state & "New" states & Low & Medium-High & Medium & Low-Medium \\
\hline RPS-national & & Low-Medium & \begin{tabular}{|l|} 
High \\
\end{tabular} & Near & Medium-High \\
\hline $\begin{array}{c}\text { Green Power } \\
\text { Markets }\end{array}$ & RECs, tags, tickets, etc. & High & Medium-High & Near-Medium & Medium-High \\
\hline $\begin{array}{c}\text { International } \\
\text { RECs }\end{array}$ & (not RPS-RECs) & Low-Medium & Medium & Medium & Low-Medium \\
\hline Carbon/GHG & & Medium & Medium-High & Medium-Long & Medium \\
\hline SBC & & High & Low-Medium & Near & Medium \\
\hline
\end{tabular}

${ }^{30}$ Probability of being enacted within this project's 3-year time horizon. Opportunities that could be enacted within a 3-year time frame but that would have effects substantially further out in time were discounted (ranked lower).

${ }^{31}$ Near: 3 years or less; medium: $4-7$ years; long: longer than 7 years.

${ }^{32}$ Some states have very effective RPS in place; others will generate little new capacity. 


\section{Chapter 5 \\ Summary}

Credit trading has broad appeal because it helps to lower the cost (and hassle) of meeting environmental goals, whether the goals are mandated or voluntary. Credit trading also represents one of the most effective and efficient tools for allowing the market to identify and monetize the benefits that wind supplies. Credit trading can also increase flexibility and choice for consumers, particularly in areas that do not have reasonable transmission access to good wind, other renewable resources, or green power electricity products. Finally, credit trading can be applied to a wide variety of policies to control pollution or support renewables.

Achieving acceptance of credit trading by consumers, regulators, and other stakeholders in retail electric markets is a challenge that needs careful attention, but credit trading need not be more confusing or threatening than switching electric suppliers or buying green energy through an existing supplier. In fact, an advantage of credit trading is that consumers do not necessarily need to change their existing electric service provider at all. Public education campaigns can help to increase the consumer's comfort level with credit trading.

Ideally, a given megawatt-hour of wind generation would have clearly defined and mutually exclusive attributes, uniquely identified and tracked, so that there would be no uncertainty about whether a particular attribute had been sold previously. For sizable and liquid markets for credits to develop and mature, a common set of terms and practices must be agreed upon. It is also important to ensure the integrity of credit trading by setting standards, harmonizing regulatory requirements (especially disclosure rules) across jurisdictions, and seeking full disclosure and transparency of the environmental characteristics of all generation. At the same time, market architects must be careful not to inhibit innovation and efficient development of markets by over-regulating or proscribing activities without clear and compelling justification. Developing some type of national registry (or coordinated regional registries) for clean energy generation attributes would go a long way toward establishing the foundation that credit trading requires to be a significant contributor to markets for renewables.

Developing a national RPS or a multi-pollutant cap and trade program within the context of electricity restructuring legislation represents the most promising near-term opportunities for wind market development based on credit trading, although the likelihood of these happening may be lower than with some other options. Outside of this particular legislative window for a national RPS or a multipollutant program, voluntary green power markets offer the shortest pathway for wind market and credit trading development. Other possibilities include the Western Haze Program ${ }^{33}$ and the $\mathrm{NO}_{x}$ SIP Call. Lastly, some smaller but very near-term opportunities that could benefit wind include using SBC funds to support credit trading, as well as the incorporation of green power purchases (through credit trading where appropriate) as an alternative to monetary penalties or mitigation activities in the enforcement of national and state pollution regulations.

We believe that the NWCC can be most effective in creating near- and long-term benefits for wind by encouraging the development of fair rules for wind in the creation and trading of credits in a variety of regulatory, policy, and market venues. Efforts to ensure that wind technology and credit trading are included in national RPS and a multi-pollutant bill should be counterbalanced by efforts to support private market activity and, particularly, to promote credit trading within green power markets. The opportunities and guidelines in the chapters that follow seek to strike such a balance.

\footnotetext{
${ }^{33}$ Refers to the planned activities by western states to minimize haze that were designed as a backup in case the new federal standards do not make it through the courts after being challenged.
} 


\section{Chapter 6 Opportunities}

Although there is considerable uncertainty about the value and timing of many of the venues in which credit trading could be used, there are some clear steps that could be taken now or in the near future to improve wind's prospects in these arenas. Several of the following opportunities could involve substantial undertakings on their own, especially when in combination with others. But NWCC members, participants, or other interested parties could act on some of these opportunities, either independently or in collaboration with others. The opportunities include the following:

1. Help to educate regulatory and other decision makers and market participants to recognize the separation of attributes from energy and the need to allow attributes to be used for compliance with energy and environmental policy requirements and to meet market demand for attributes.

2. Develop credit ownership and transfer contract language linked to wind activity (i.e., within wind power purchase agreements) that reduces risks associated with determining ownership and the transfer of environmental attributes.

- Gather and disseminate the operational language for contracts, agreements, RFPs, and other documents that engage parties in credit trading transactions.

- Develop best practices guide for contracting related to renewables-based credit trading.

There is burgeoning interest in these transactions, and those who are interested would benefit by having access to various approaches to making these transactions happen.

3. Facilitate stimulation of private voluntary markets to help jump-start "new" tradable attributes or products, and to help achieve recognition of these products in the market.

Purchase "voluntary" renewable energy credits and give them to strategically important stakeholder groups (e.g., air pollution regulators, public utility commissioners, utility or electric supplier organizations). The purpose would be to encourage such groups to evaluate what the attributes represent in their particular jurisdiction and what issues affect their use.

- Create a mercury trade in the Great Lakes region dispersion area where coal is dominant and acidification of the lakes is a major issue. Seek out an institutional buyer (either corporate or environmental), and structure a bilateral trade that establishes recognition of a mercury avoidance credit. Work with the Emissions Marketing Association, EPA, and local air pollution regulators to explore widespread replication of the concept.

- Develop and execute a multi-credit trade, involving pollutants with credit trading history, that is most likely to allow wind participation (i.e., $\mathrm{CO}_{2}, \mathrm{SO}_{2}$, and $\mathrm{NO}_{x}$ together or some combination of two, perhaps including mercury) and that demonstrates the viability of separating and trading attributes locally, regionally, and globally.

- Create a "soup-to-nuts" credit that enumerates and monetizes as many distinct attributes as is feasible.

4. Focus on key policy, legislative, and regulatory areas in which activity is expected over the near term, providing opportunities to influence rules and programs. Encourage the inclusion of credit trading to reduce program costs and of wind energy as a technology option to achieve clean air objectives.

\section{Multi-pollutant bill(s)}

Credit trading provides an opportunity for wind within the context of the multi-pollutant bills that the 107th Congress is expected to consider. If this issue is taken up, it would be beneficial for wind if:

- credit trading is included;

- wind is included as an eligible technology;

- the rules for wind's participation are fair and nondiscriminatory vis-à-vis other emissions avoidance options. 


\section{RPS-REC trading}

Wind will be a prime beneficiary where efficient RPS are in place, and credit trading can help to lower the cost of RPS implementation.

\section{Green power markets}

Encourage the use of credit trading as a means to increase choice and to reduce the cost of purchasing green power in both regulated and unregulated electric power markets.

\section{SBC}

Work with system benefit charge (SBC) administrators in key states to tune their staff into the credit trading opportunity. The $\$ 2.8$ billion that SBCs are expected to spend can be particularly valuable in helping to jump-start and stabilize credit trading markets. SBC public education funds may be especially helpful in creating a comfort level about credit trading among consumers and political or regulatory decision makers.

5. Creation of a renewable energy credit registry (one national registry or multiple regional registries), or another comparable mechanism, would allow recognition of attributes from renewable generation, help to avoid double counting, and help to cope with crossjurisdictional "seams" issues. ${ }^{34}$

\section{- Environmental benefits inventory (EBI):}

Establish a template inventory of environmental benefits enumerating mutually exclusive green attributes (that have measurable environmental benefit) for wind-generated electricity. The inventory would include all potential secondary or derived benefits (attributes), such as avoided emissions. The inventory would not in itself quantify any attributes (such as tons of a particular pollutant avoided), or place any monetary value on an attribute. It would simply enumerate all potential attributes associated with wind generation in the various jurisdictions around the United States. The inventory could then be used by others to quantify

\footnotetext{
${ }^{34}$ With the creation of a unique certificate representing specific generation attributes, the registry itself would not necessarily need to track sales of attributes, but some mechanism for matching up attributes with claims made would be required.
}

the magnitude of, and assign value to, the environmental attributes depending on the specific context of the jurisdiction in which a particular plant would be located (e.g., using the Emissions \& Generation Resource Integrated Database [E-GRID], other summary emissions data, or plantspecific data). The EBI is different from, but complementary to, "certificates"

documenting the basic characteristics of energy generation.

6. Develop a coalition of stakeholders and other potential partners to promote priority activities to target audiences.

- Focus on educating key stakeholders on the value of credit trading. Focus on the similarity between credit trading transactions and conventional energy transactions to increase comfort level with the concept. Partner groups include: renewables advocates, environmental groups, green marketers, nongovernmental organizations (NGOs), foundations, business coalitions (BCSE, Sustainable Business Council), and electricity suppliers. Target audiences for education about credit trading include all of the above groups but also include:

- policy working groups on RPS and disclosure, especially at the state level;

- inter-state cooperation staff working on harmonization of policies (esp. disclosure, RPS, and air pollution regulations);

- ISO staff;

- air pollution regulators at the local, state and federal level, especially EPA staff working on encouraging renewables within various programs and state and local air pollution officials;

- National Association of Regulatory Utility Commissioners (NARUC) staff and key commissioners;

- PUCs in key states;

- emissions traders (Emissions Marketing Association);

- wind industry trade groups;

- renewables industry trade groups; 
- $\quad$ NGOs and foundations working in related environmental and energy market areas;

- Federal Energy Regulatory Commission (FERC) or Federal Trade Commission (FTC) and NAAG;

- consumers and consumer groups

- Target opportunities to testify at meetings or present written materials to air pollution and energy policy makers and regulators. Look for opportunities to achieve objectives related to credit trading by working within the context of other, related issues and venues. For instance, the definition of jurisdictional boundaries and operational rules as discussed in the 2000 Regional Transmission Organization (RTO) hearings may have provided a substantial opportunity to raise RTO design issues that affect credit trading.

7. Work with local, state, and EPA staff to include wind in all relevant regulatory programs, especially CAA cap and trade programs and including penalties and mitigation.

\section{NOx SIP Call}

EPA guidance on renewable energy and energy efficiency (RE/EE) set-asides is being taken seriously in Massachusetts, Maryland, New York, New Jersey, and New Hampshire, among others.

\section{New NAAQS}

If new, tighter air emissions standards are to go into effect, there should be a focus on including a renewables set-aside or other credit program for $\mathrm{PM} 2.5, \mathrm{SO}_{2}, \mathrm{NO}_{x}$, and other regulated pollutants, especially in existing and expected nonattainment areas.

\section{Clean Air Act Reauthorization}

If broad reauthorization of the CAA is undertaken, wind can play an important role in a variety of the programs. It can be included as a technology eligible to receive set-asides of allowances, "earn" credits or otherwise participate in incentive programs approved under the reauthorization.

\section{Penalties and Mitigation}

Companies that are subject to penalties and mitigation actions (related to abrogation of pollution rules) can utilize the purchase of credits (or bundled green energy) as a mechanism to reduce emissions.

\section{Western Regional Air Partnership (WRAP)}

If emissions ceilings are reached under this haze control program, there are provisions for renewables goals and credit trading. The large regional trading areas under WRAP include many very good wind sites. The program is still under definition. 


\section{Chapter 7 \\ Credit Trading Guidelines}

These guidelines are intended to aid in developing credit trading as a mechanism within a broad array of environmental and energy management venues at the local, state, and federal level in the United States. Guidelines are separated into two categories: (1) defining the market and (2) market operation.

\section{DEFINING THE MARKET}

\section{Clear Definitions}

Attributes, credits, and products should be clearly defined and standardized to avoid disputes, double counting, and distrust of newly emerging markets, without discouraging necessary market and product innovation.

\section{Thorough Disclosure}

Full disclosure is important to the development and operation of credit trading markets. Disclosure should be easy to understand, standardized, and compatible across jurisdictions. It should also apply across the board to all electricity providers. Environmental attributes sold must be disclosed. However, some believe that disclosure may not be sufficient to clarify claims about green power products that do not contain all of their environmental attributes (see NAAG 1999).

\section{Eligibility}

Wind generators should be included in all relevant programs and regulatory arenas as entities allowed to receive allowances (on an "as-generated" basis) or to generate credits.

\section{Recognition of Attribute Unbundling from Energy}

Laws, regulations, and markets should recognize that renewable energy attributes (e.g., those representing emissions) can be unbundled and traded separately from energy.

\section{Attribute Disaggregation}

Laws, regulations and markets should recognize that environmental attributes can be disaggregated from each other where appropriate and consistent with consumer protection guidelines and the healthy development of markets. Disaggregated environmental attributes might best be suited for environmental compliance programs. Aggregated environmental attributes might best be suited for consumer retail markets.

\section{Substantial Market Size and Local Benefits}

Trading markets should encompass the largest feasible geographic area while remaining consistent with the functional characteristics of the attributes being traded. Where appropriate, trading markets and credit products in these markets should take local interests into account so that the environmental, economic, and public health benefits of clean generation can make meaningful contributions to local environmental problems.

\section{Output-Based Standards}

Output-based standards should be used to determine the rates at which credits are earned..$^{35}$ Rates should reflect emissions avoidance against system-wide average or marginal emissions unless displacement of specified units can be determined without significant cost or delay.

\section{Nondiscrimination}

Credit-trading market rules and rates should not discriminate against any resource because of intermittency or non-dispatchability.

\section{Early Credit}

Early credit (credits allowed for "new" projects installed before the relevant sponsoring program began) should be allowed for non-emitting technologies whenever feasible to maximize nearterm environmental benefits.

\section{Integrity of Credits}

Credits derived from wind power and traded should be real and verifiable to protect the value of wind development and to ensure the long-term viability of the markets served by such credits.

\footnotetext{
${ }^{35}$ Defined as emission standards based on units of gross energy output, not on units of gross fuel input.
} 


\section{MARKET OPERATION}

\section{Liquidity}

Markets should be liquid, so that single trades cannot dominate the market.

\section{Market Certainty}

Market design should provide a time horizon (preferably 8-10 years or more) that is sufficient to allow forward and options contracts to facilitate market activity (i.e., multi-year contracts for credits). Rules and procedures should give market participants the confidence that rules will not be changed so as to invalidate prior trades. To move forward efficiently, markets must be clearly defined.

\section{Fungibility and Mobility of Credits}

To facilitate creation of larger markets, attributes from renewables should be mobile across jurisdictional borders and, where possible, across policy and program borders as well. This, which can also be described as the merging of markets on a regional, national, or multi-pollutant basis, requires an ability to track cross-border and crossprogram trading to avoid double counting.

\section{Disconnection of Credit Trading from Time of Delivery Requirements}

Credit trading markets should operate independently of energy markets to maximize efficiency and flexibility. Connecting credit trading to time of delivery or other technical requirements of energy markets may discriminate against intermittent energy resources such as wind.

\section{Penalties for Misrepresentation}

Penalties for significant misrepresentation of what is being sold (e.g., knowingly selling attributes twice) should be significant (e.g., loss of license, stiff fines).

\section{Administration of Regulatory Noncompliance Penalties and Mitigation Activities}

Emitters that are in noncompliance should be allowed to buy credits from clean sources in an amount roughly equivalent to appropriate penalties.

\section{Annual Market Clearing}

The market for credits or certificates should be cleared only once per year to allow intermittent resources such as wind to make up for seasonal periods of low production.

\section{Banking and Borrowing Allowed}

Settlement (true-up) mechanisms should allow limited borrowing or banking from adjoining time periods.

\section{Trackability}

Attributes and kilowatt-hours should be uniquely identified and tracked (or at least subject to audit) to avoid double counting. 


\section{Chapter 8 \\ Case Studies}

\section{CASE STUDY 1: RPS CREDIT TRADING WITH AND WITHOUT OUT-OF-STATE RESOURCES}

RPS establish minimum amounts of total electric generation or sales that must be generated by eligible renewable energy sources. Ten states now have RPS in place, and six of those states have determined that trade of RPS-RECs ${ }^{36}$ may be utilized for both efficiency ${ }^{37}$ and compliance purposes, although only two have actually developed rules to do so. ${ }^{38}$

Six of the states that have RPS in place have chosen to allow, at least under certain circumstances, outof-state resources to be used to meet RPS requirements (see Table 8.1 on page $\mathrm{xx}$ ). The decision about allowing out-of-state resources can have some profound effects on the cost, location, tracking and verification, and distribution of benefits of renewable projects built under the RPS. Although we will briefly discuss the major effects of allowing out-of-state resources to illuminate the issues involved, this case study focuses on what role RPS-REC trading would play in each of these scenarios. The conduct of this case study is complicated because no historical records of RPSREC trading programs exist. Texas is the furthest along and is just now putting its REC trading program in place, but there are no other programs against which to compare the Texas case. The case study, then, is based on our projections of the most likely REC trading scenarios as evidenced by the program designs to date.

\section{Description of Texas RPS}

\footnotetext{
${ }^{36}$ A note on terminology: REC is a generic term for a tradable renewable energy credit that may or may not result from RPS. Therefore, we use the term RPS-REC to refer to the specific type of REC created under RPS. In addition, one should be careful to identify the state of origin (e.g., Texas RPS-REC) because each of the state-based RPS-RECs is unique and noninterchangeable, at least at this stage.

${ }^{37}$ The efficiency claim comes from the fact that complying entities can comply through purchase of credits from the most competitive source (which presumably will have lower REC unit costs) rather than have to comply through less-flexible bilateral contracts or through their own generation.

${ }^{38}$ Texas and Wisconsin (the latter is still a proposed rule).
}

To date, Texas is the closest of any RPS state to having a working credit trading program in place. The Texas RPS legislation sets capacity targets for eligible renewables, which in turn are converted into percentage purchase requirements placed on all energy suppliers selling to Texas customers. A Texas RPS-REC represents $1 \mathrm{MWh}$ of renewable energy that is "physically metered and verified in Texas" and meets other eligibility requirements. All competitive retailers must "retire" or submit sufficient RECs to meet their annual requirements to compliance officials. By the Texas definition, a REC is a "tradable instrument that represents all of the renewable attributes associated with one (1) MWh of production from a certified renewable generator." In addition, the implementing rule says specifically that "RECs may trade separately from energy." Although Texas allows out-of-state resources to be tapped, the requirement that a project be physically metered and verified in Texas generally means that there must be a dedicated transmission line into the state. That may work technically and economically in some cases, but it will most likely restrict projects to within state lines.

\section{The In-State Resource Scenario}

When only in-state resources are allowed for RPS compliance, the value of tradable credits is relatively straightforward, although the complexity of implementing RPS credit trading will vary depending on how a state sets up its emissions disclosure and tracking system (i.e., whether such systems can establish that the credits are real, have only been used once, and are accurately accounted for in the system). Credit trading can certainly help to lower the cost of compliance by allowing the most efficient credit generators to create credits while allowing other parties to comply by purchasing such credits. ${ }^{39}$ The creation and use of the credits (RECs or certificates) can be highly valuable for tracking and determining compliance as well, because the credits or certificates

\footnotetext{
${ }^{39}$ This economic efficiency may not be present in all cases but is an underlying assumption that supports the use of REC trading. This case study does not examine this assumption but accepts it at face value on the basis of a generic evaluation of its reasonableness.
} 
themselves (whether physical or electronic in form) are actually used (turned in or retired) for compliance. This evidence of property rights, although it has not yet been tested, should serve as a basis for claims that prevent more than one entity from claiming the attributes from a given project used for RPS compliance. This should also mean that such property rights should be recognized in a neighboring state. This does not necessarily mean that an overlapping or duplicative claim for the same attributes couldn't be made in a neighboring state, but it is presumed that it could be challenged. ${ }^{40}$

\section{The Out-Of-State Resource Scenario}

Allowing out-of-state resources introduces a number of problems arising from working across state boundaries. The RPS policies in place today are based on state-specific legislation and are not generally written with cross-border RPS compliance in mind (even where it was envisioned that out-of-state resources might be utilized). Where information systems for tracking and verifying generation and emissions are not in place, are insufficient, or are incompatible across state boundaries, determining whether RECs are being used more than once ${ }^{41}$ becomes a difficult issue. Other issues involve how the broader geographic area created with the allowance of out-of-state resources affects the market for RPS power, as well as the ability of the RPS state to capture the environmental benefits of the RPS-mandated clean energy. Technical issues may crop up as well, because out-of-state resources may also be outside of a given control area or energy market and thus

\footnotetext{
${ }^{40} \mathrm{As}$ an example of just how unsettled the law is in the green power arena, a claim might be made that energy from a wind farm used to comply with (create credits for) the Texas RPS is still in some sense "green" and could be sold as green power in another jurisdiction.

${ }^{41}$ For example, a supplier could use RPS-RECs to comply with the RPS in one state, and then turn around and do the same in another state. Alternatively, a firm could use RPS-RECs to comply in one state and then sell some of the "constituent" emissions reductions represented by the REC in another state. Without appropriate tracking, neither state would be aware that the same emissions reductions or other environmental benefits had been sold twice. Although consumer protection laws offer some safeguards against this practice, it would need to be recognized and challenged by an appropriate body.
}

be subject to somewhat different treatments. These issues, however, are outside the scope of this case study.

Issues raised by allowing out-of-state resources can be grouped into three categories:

1. Tracking and verification Especially problematic across jurisdictional lines where complementary information disclosure and tracking systems are not in place.

2. Supply and demand

Allowing out of state resources increases supply and likely lowers the price for RPS power. This may be good for consumers and possibly bad for RPS generators unless there are substantially better resources out of state that allow lower prices (in states without much of a resource, this argument is diluted). It may also protect low-cost existing renewables that don't need protection.

3. Local benefits

Allowing out-of-state resources makes it more difficult to capture the environmental benefits locally, although this depends heavily on the particular jurisdiction's geography and resource distribution.

Where cross-border issues arise, the use of credit trading for RPS compliance can be particularly valuable because the REC creation and retirement process can serve as a "registry" that can then be used to determine whether a particular credit (or constituent parts of it) was being used for other purposes. In some cases, such double counting would clearly violate the rules, but it is unclear in some jurisdictions whether such practices would be penalized or even recognized. For instance, would an eligible wind plant owner who sold RECs to a complying entity in the RPS state still be able to sell its power to consumers either in that state or another state as "green"? In most cases, it is unclear or simply has not yet been dealt with by the market or the legal system.

In Texas, it appears that projects that created RPSRECs that were then retired for compliance with the RPS could not create other credits that could then be separated into constituent attributes such as $\mathrm{CO}_{2}$ (Eric Schubert, senior economic analyst, Public Utility Commission of Texas, telephone conversation, September 2000). If such sales were made, Texas PUC staff noted that the RPS-RECs 
would then cease to exist, but it also appears that the Texas PUC would be unable to actively police such actions.

\section{Finding}

The basic function of RECs in the two scenarios (allowing and not allowing out-of-state resources) is essentially similar, resulting in both efficiency and administrative value. RECs can be utilized to establish ownership of given attributes (i.e., emissions reductions or other characteristics, both green and non-green). Possession (physical or electronic) of RECs establishes a right to make green claims related to eligible RPS sources. However, RECs can play an even more important role when out-of-state resources are allowed because tracking and verifying RPS generation across state borders can be eased by registration and compliance procedures built into the REC process. Double counting can be minimized through procedures that require suppliers to attest that the given resources are dedicated to RPS compliance and are not being claimed more than once (i.e., in another jurisdiction that may have different rules).

Even so, accurately accounting for all the attributes and claims being made can still be a daunting task, given the early stage of development of most states' disclosure and tracking systems. Definitional problems also complicate this field because it is not yet clear what all the green (and non-green) attributes are of various sources of generation, much less who owns them, how they are conveyed, or how the various green marketing concepts that claim to contain one or more of these attributes relate to each other. Although deliberate misrepresentation is certainly an area of concern, unintentional errors are also possible. A wellconceived RPS-REC trading program can help to alleviate these issues by defining what the REC contains (attributes) and how the REC conveys property rights, as well as establishing clear and certain procedures for the creation, use, and retirement of the RECs (clearing mechanism). Texas has made a good start at this by including sufficient information in its RPS-REC certification process to ensure that each project has a unique identifier. The value of such a process can extend well beyond the RPS itself. In fact, RPS-RECs can serve as a model for establishing definitions, procedures, and property rights that will help to make green markets function more credibly and efficiently.

\section{CASE STUDY 2: MADISON WINDPOWER PROJECT}

In August 2000, Kinko's agreed to purchase wind power certificates from Pacific Gas and Electric (PG\&E) Corporation's 11.5-MW Madison Windpower Project in Madison, New York. The certificates were associated with up to $50 \%$ of Kinko's statewide electric demand (approximately 4.5 million kWh).

The certificates were sold through a proprietary program, called PureWind "' (See Figure 8.1), which was established by PG\&E's National Energy Group. The program is a strictly voluntary initiative to support new renewable energy development in regions that lack renewable energy pricing programs or green power retail choice. PureWind sells the green characteristics of renewable energy without actually dispatching energy to the purchaser. In this way, the group is able to monetize green attributes of its wind energy that previously lacked any monetary value.

The Madison Windpower Facility is a merchant wind project that generates wholesale electricity and delivers it to the New York ISO grid, which pays Madison Windpower the wholesale electricity price at the time the electricity is delivered. One PureWind certificate is created for every megawatthour of electricity delivered to the ISO. Program participants, like Kinko's, can purchase whatever quantity of wind power they wish to support.

Buyers assume ownership of all the environmental attributes of the certificates they purchase, including any future emissions credits that may be created under regulatory bodies. If Kinko's wants its purchase to show up on its energy label, it must get its retail provider to purchase an equivalent amount of electricity (energy) from the New York ISO and file a conversion transaction with the Public Service Commission.

To assist the Madison Windpower Project with the extra costs associated with wind power technology, the New York State Energy Research and Development Authority (NYSERDA) awarded it a research and development grant. NYSERDA's goal is to stimulate renewable energy power development in New York. It accomplishes this goal by awarding grants to selected developers to buy down the extra costs of renewable energy projects compared to conventional projects. 


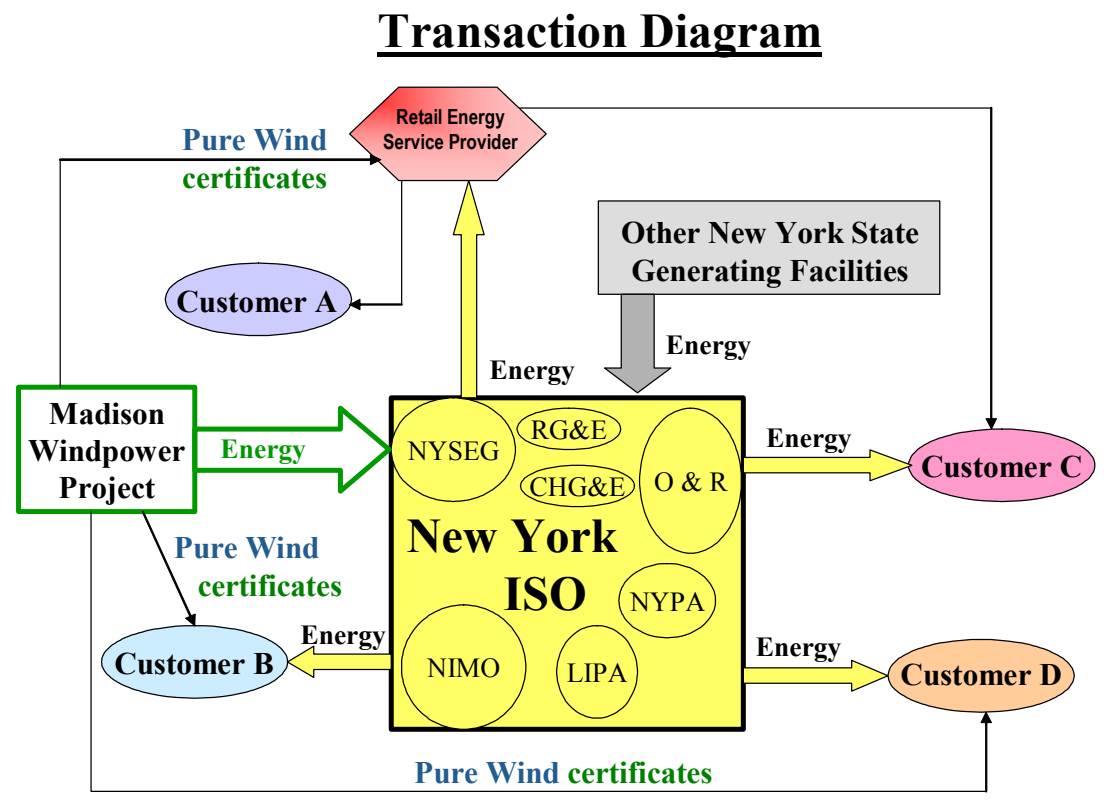

Figure 8.1 Schematic of the Madison Windpower and PureWind"' project (provided by PureWind"', PG\&E National Energy Group)

According to PG\&E, in an average year, total output for the Madison Windpower facility will avoid 12,078 tons of $\mathrm{CO}_{2}, 65$ tons of $\mathrm{SO}_{2}$, and 19 tons of $\mathrm{NO}_{\mathrm{x}}$-amounts based on average emissions from New York State power plants. Kinko's PureWind ${ }^{\text {tw }}$ certificates represent a yearly savings of approximately 750 tons of emissions, principally $\mathrm{CO}_{2}$. Kinko's benefits from the transaction by improving its corporate environmental image, while still supplying the same products and services to its customers. It remains unclear if Kinko's will be able to sell the certificates as future emissions credits.

Because there is no legal entity to support trading in green attributes of power in New York, this transaction is voluntary. Furthermore, there is no legal monitoring and verification body that could certify PG\&E National Energy Group's claim that each certificate generated at the Madison Windpower Facility represents a certain amount of emissions.

Besides the absence of any legally recognized exchange for green energy attributes in New York, there appear to be two principal barriers to the growth of this market. First, market rules governing attribute transactions between potential suppliers and buyers of green energy are lacking, which results in high transaction costs. Second, the traditional energy provision structure fails to recognize consumer preferences and choices, including potential preferences for green energy. The existing state and federal regulatory structures, along with utilities' adherence to traditional methodologies (which continue to support a supply-side structure for energy provision) have created this environment.

\section{CASE STUDY 3: BONNEVILLE ENVIRONMENTAL FOUNDATION}

The Bonneville Environmental Foundation (BEF) is a nonprofit public benefit corporation dedicated to encouraging and funding projects that develop clean, environmentally preferred, renewable power systems in the Pacific Northwest. BEF has developed a green renewable energy program that delivers the environmental benefits created by the facility to the customer, with the goal of directly offsetting the environmental impact of the customer's conventional energy use. BEF currently sells two products: Environmentally Preferred Power (EPP) and green tags. EPP is generated from existing resources that several environmental organizations have examined and endorsed as 
having a minimal environmental impact. These resources are sold to wholesale utility customers.

BEF green tags are sold from new renewable energy projects to the power pool as simple generic power. The primary benefits from these green tags are reductions in $\mathrm{CO}_{2}, \mathrm{SO}_{x}, \mathrm{NO}_{x}, \mathrm{CO}$, mercury, and particulates. BEF is currently the national leader in sales of green tags from wind power.

The revenues generated from green tag sales can mitigate, in part or in total, the comparatively higher cost of the renewable facilities. BEF is now focusing on one or more wind projects with a combined project capacity of up to $200 \mathrm{MW}$. The foundation is working with several regional energy and environment nonprofit organizations and other stakeholders to determine if the specific facilities meet the criteria of site selection, development, and operation, among others.

After contractually binding the transfer of the green tags, the electricity sold by the project does not claim any additional environmentally beneficial characteristics. The contracts should mitigate the risk that any environmental benefits associated with the electricity generated are double counted. BEF is also exploring ways to register the credits and record the energy sales with EPA or another relevant entity to ensure the credibility of the certificate program after credit exchanges occur.

As a side project, BEF is pursuing the sale of discrete $\mathrm{CO}_{2}$ emission reduction credits (which are disaggregated from the REC) to the Oregon Climate Trust (OCT). OCT was created in July 1997, after Oregon House Bill (HB) 3283 established the first binding measure in the United States to control $\mathrm{CO}_{2}$, the most prevalent of GHGs. HB 3283 requires new energy facilities built in the state to avoid, sequester, or displace a portion of their previously unregulated $\mathrm{CO}_{2}$ emissions. For example, a new gas-fired power plant in Oregonthe first type of facility for which a specific reduction target was established-must meet a net emissions rate of $0.675 \mathrm{lb}$ of $\mathrm{CO}_{2}$ per kilowatthour. This rate of $\mathrm{CO}_{2}$ emissions is $17 \%$ less polluting than the least-polluting comparable plant operating in the United States. With this baseline and target reduction, a power plant developer may choose to meet part or all of its reduction target by paying mitigation funds to a qualified nonprofit, which, in turn must use the funds to carry out projects that avoid, sequester, or displace the $\mathrm{CO}_{2}$ the plant will emit in excess of the required standard. OCT is a qualified nonprofit established for this purpose.

Five electric utility operators in Oregon donated start-up money to fund OCT's initial activities. In April 1999, the trust received the first payment of $\$ 1.2$ million in mitigation funds from the Klamath Cogeneration Project, a partnership between the city of Klamath Falls and PacifiCorp. This led to the primary focus for activities in 2000, which directly supported projects that avoid, sequester, or displace $\mathrm{CO}_{2}$ emissions to the atmosphere. As part of its next-stage activities, OCT is likely to purchase $\mathrm{CO}_{2}$ reduction credits from the $\mathrm{BEF}$ green tag program.

To capture the $\mathrm{CO}_{2}$ reduction specific benefits of $\mathrm{BEF}$ green tags, $\mathrm{BEF}$ is proposing to buy back the $\mathrm{CO}_{2}$ attributes from the purchasers of the green tags with OCT funds (see Figure 8.2). The $\mathrm{CO}_{2}$ benefits would then be retired by OCT, per its mandate. BEF would own the remaining green attributes, which would retire as many of the attributes as possible. The generation of kilowatt hours and associated environmental benefits will be metered at the project site and reported to the Bonneville Power Administration (BPA). BPA will in turn verify the output for BEF, which will then convey the data to green tag customers and OCT.

BEF does not intend to sell these "light green tags" (tags containing all attributes except $\mathrm{CO}_{2}$ ) to commercial or residential customers. Instead, the transaction is intended to co-finance the purchase of the green tags because OCT is not in a position to cover the full cost of the tag. BEF may consider a sale of distinct $\mathrm{CO}_{2}$ credits when: (1) a customer is interested only in becoming $\mathrm{CO}_{2}$ neutral, or (2) when a customer is not interested in taking environmental credit for the purchase. In either case, the credit would not be resold.

BPA has committed to bringing new wind or other renewable energy sources onto the grid with the funds generated by BEF green tag and carbon credit sales. This is important to the project's argument that the program will create additional environmental benefits, including $\mathrm{CO}_{2}$ emission reductions that would not have been possible without the program. This notion of an incremental 
environmental benefit-that the activities would not have taken place without the BEF and OCT transactions-helps to ensure that the program is actually contributing to environmental gains in the absence of a regulatory limit on $\mathrm{CO}_{2}$ emissions. At the same time, the BPA commitment to "replace inventory" allows a bulk or volume purchasing strategy to be compatible with commitments to individual customers (such as OCT) that their purchase led directly to the promised offsets.

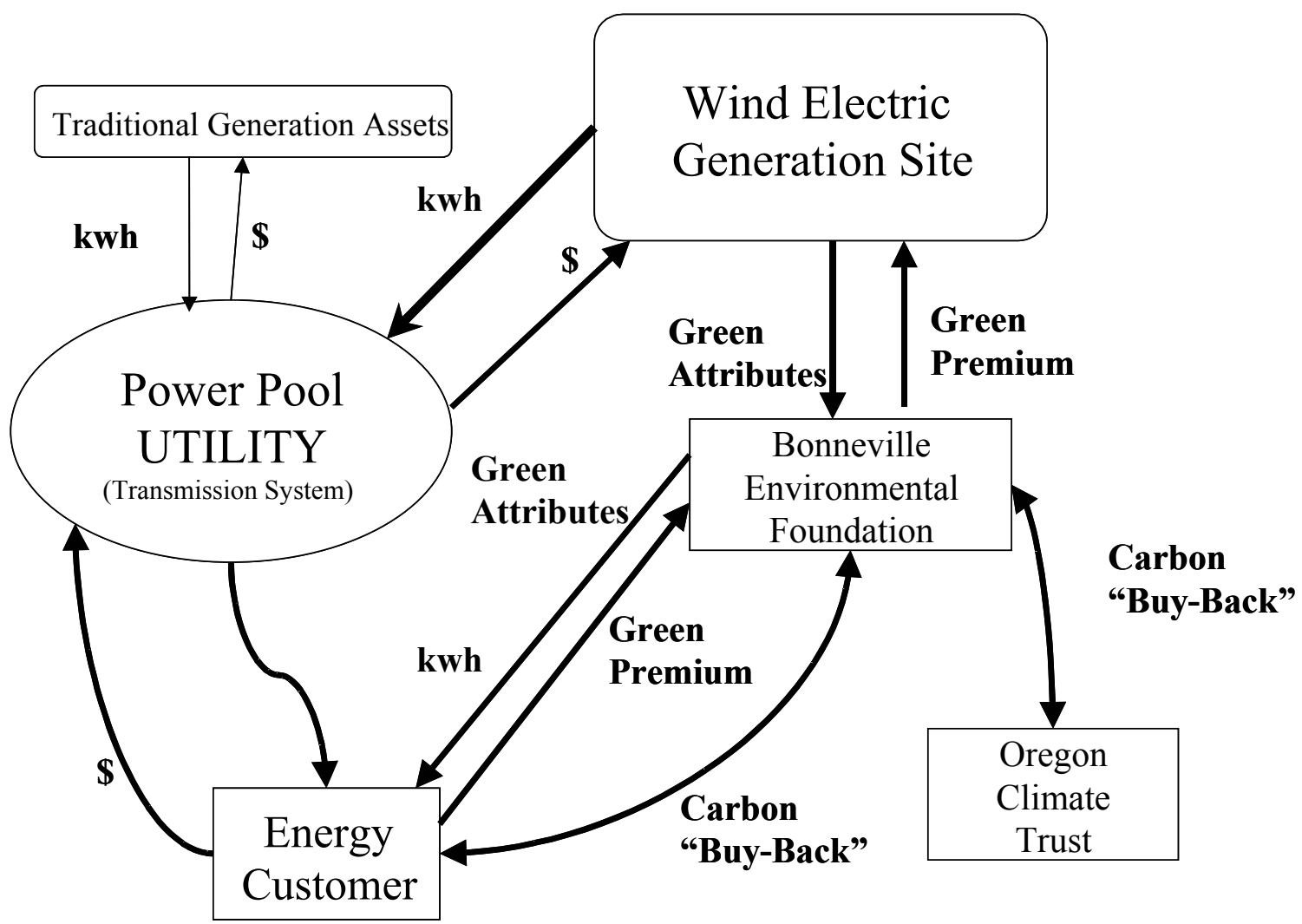

Figure 8.2 BEF purchase of green tags and OCT carbon buy-back 
Table 8-1. Credit trading in RPS in U.S. states.

\begin{tabular}{|l|l|l|l|}
\hline \multicolumn{1}{|c|}{ State } & Credit trading allowed & $\begin{array}{c}\text { Program designed and } \\
\text { in place }\end{array}$ & $\begin{array}{c}\text { Out-of-state resources } \\
\text { allowed }\end{array}$ \\
\hline Arizona & To be determined & No & No (for wind) \\
\hline Connecticut & Yes & No ${ }^{38}$ & Yes \\
\hline Maine & No ${ }^{39}$ & No & Yes \\
\hline Massachusetts & Yes & No & Yes \\
\hline Nevada & Yes & No ${ }^{40}$ & No \\
\hline New Jersey & Yes & No & Yes (with restrictions) \\
\hline New Mexico & Not addressed & No & No \\
\hline Pennsylvania & Not addressed & No & Unspecified \\
\hline Texas & Yes & Yes (rule approved) & Yes (with restrictions) \\
\hline Wisconsin & Yes & No & Yes \\
\hline
\end{tabular}

Source: Bolinger, Porter, and Wiser (August 2000).

${ }^{38}$ Left for private markets.

${ }^{39}$ May be allowed, but PUC decided not to implement.

${ }^{40}$ Under development.

${ }^{41}$ Only for renewables above RPS standard. 


\section{Finding}

The BEF-OCT project represents a very valuable current case of how environmental benefits of wind power can be detached from kilowatt-hours of electricity generated. It is also an experiment in how the individual types of benefits may be disaggregated further from each other to capture additional revenue flows to the benefit of wind power. The risk of this approach can be twofold: (1) loss of the original environmental benefit through trading that enables higher emissions of some form, and (2) confusion on the part of consumers about the underlying environmental nature and value of the credit.

On the first point, this particular transaction is not liquid enough to threaten the underlying environmental benefits through trading. No other emitters are buying these kinds of credits to increase their emissions, so the risk is low or nonexistent. In addition, OCT is retiring the $\mathrm{CO}_{2}$ credits, so there is no risk of loss through further trading. The project sponsors also point out that without a cap on $\mathrm{CO}_{2}$ emissions, the risk of increased emissions resulting from trading will always exist. Meanwhile, the case serves as a test for the origin of secondary and tertiary markets for credits. The case could serve as a basis for simulations of further trades of the same credit to see how regulatory regimes in different states would or would not be able to work with them. Potential confusion on the part of REC consumers, identified as risk (2) above, is more difficult to address. BEF points out that what is passed through the transaction is defined explicitly in the enabling contracts. In addition, BEF is participating in the establishment of industry standards that will make tracking and disclosure easier. BEF is executing two transactions, similar to the one illustrated in Figure 8.2. The transaction is designed to meet the demands of two different buyers. The end user of the original REC could be fully informed of the underlying environmental benefit of the REC simply by being fully informed of the second transaction, the buy-back of the $\mathrm{CO}_{2}$. The end users in this case would see the funds flow back to them in return for surrendering ownership of the $\mathrm{CO}_{2}$ component of the REC. If the price of the REC is discounted before it is sold to the end user by the amount equal to OCT's purchase of the $\mathrm{CO}_{2}$, the end user needs to know that. In the case of the BEF transaction, the end user is retiring the credit. But in other instances, the buyer may wish to sell the credit again to another buyer, in which case the value of the light green REC is difficult to determine. 


\section{Chapter 9 \\ The Credit Trading Catalog}

Table 9.1 summarizes many local, regional, state, and federal programs, along with private market activities that include a component for credit trading or otherwise have the potential to use credits from wind plants. These programs have been cataloged in a large database that includes detailed characteristics and ranking criteria for each listed program. A brief summary of many of the main entries is included following the table. The focus of the catalog is on the United States, but a number of the main international credit trading programs or activities are covered in Chapter 2 of this report under Credit Trading Precedents and summarized at the end of this chapter.

A detailed electronic database is also available on the NWCC Web site. Appendix A is an example of a data sheet from the database.

Table 9-1: List of U.S. Credit Trading Programs and Activities

\begin{tabular}{|c|c|c|c|c|c|c|c|c|c|}
\hline & Title & Sponsor & $\begin{array}{l}\text { Type of } \\
\text { Program }\end{array}$ & Driver & $\begin{array}{c}\text { Wind } \\
\text { Can } \\
\text { Participate }\end{array}$ & $\begin{array}{l}\text { Can Be } \\
\text { Modified } \\
\text { for Wind }\end{array}$ & $\begin{array}{l}\text { Market } \\
\text { Potential } \\
\text { for Wind }\end{array}$ & $\begin{array}{c}\text { Present } \\
\text { Value to } \\
\text { Wind }\end{array}$ & $\begin{array}{c}\text { Time } \\
\text { Horizon }\end{array}$ \\
\hline 1 & $\begin{array}{l}\mathrm{SO}_{2} \text { Allowance } \\
\text { Trading }\end{array}$ & EPA & $\begin{array}{l}\text { Cap and } \\
\text { Trade }\end{array}$ & $\begin{array}{l}\text { Clean Air } \\
\text { Act }\end{array}$ & No & Yes & High & Low & Medium \\
\hline 2 & $\begin{array}{l}\mathrm{NO}_{x} \text { Budget } \\
\text { Trading Program } \\
\text { and the NOx SIP } \\
\text { Call }\end{array}$ & $\begin{array}{c}\text { Ozone } \\
\text { Transport } \\
\text { Commission/E } \\
\text { PA }\end{array}$ & $\begin{array}{l}\text { Cap and } \\
\text { Trade }\end{array}$ & $\begin{array}{l}\text { Clean Air } \\
\text { Act }\end{array}$ & No & Yes & High & Low & Medium \\
\hline 3 & $\begin{array}{l}\text { New Jersey Open } \\
\text { Market Emissions } \\
\text { Trading Program } \\
(\text { OMET) }\end{array}$ & $\begin{array}{l}\text { New Jersey } \\
\text { Department of } \\
\text { Environmental } \\
\text { Protection } \\
\text { (NJDEP) }\end{array}$ & $\begin{array}{l}\text { Cap and } \\
\text { Trade }\end{array}$ & $\begin{array}{c}\text { Clean Air } \\
\text { Act, } \\
\text { ozone } \\
\text { attainment }\end{array}$ & No & Yes & High & Low & Medium \\
\hline 4 & $\begin{array}{l}\text { RECLAIM (Regional } \\
\text { Clean Air Incentives } \\
\text { Market) }\end{array}$ & $\begin{array}{l}\text { South Coast } \\
\text { Air Quality } \\
\text { Management } \\
\text { District } \\
\text { (SCAQMD) }\end{array}$ & $\begin{array}{l}\text { Cap and } \\
\text { Trade }\end{array}$ & $\begin{array}{c}\text { Clean Air } \\
\text { Act }\end{array}$ & No & Yes & High & Low & Medium \\
\hline 5 & $\begin{array}{l}\text { NOx Allowance } \\
\text { Trading Program } \\
\text { (Massachusetts) }\end{array}$ & $\begin{array}{c}\text { State of } \\
\text { Massachusetts }\end{array}$ & $\begin{array}{l}\text { Cap and } \\
\text { Trade }\end{array}$ & $\begin{array}{l}\text { Clean Air } \\
\text { Act }\end{array}$ & No & Yes & High & Low & Medium \\
\hline 6 & $\begin{array}{l}\text { Texas Natural } \\
\text { Resource } \\
\text { Conservation } \\
\text { Commission } \\
\text { (TNRCC) Emissions } \\
\text { Banking and } \\
\text { Trading Program }\end{array}$ & TNRCC & $\begin{array}{l}\text { Cap and } \\
\text { Trade }\end{array}$ & $\begin{array}{c}\text { Clean Air } \\
\text { Act }\end{array}$ & No & Yes & High & Low & Medium \\
\hline 7 & $\begin{array}{l}\text { Connecticut } \mathrm{NO}_{x} \\
\text { Credit Trading and } \\
\mathrm{NO}_{x} \text { Allowance } \\
\text { Trading }\end{array}$ & $\begin{array}{c}\text { Connecticut } \\
\text { Department of } \\
\text { Environmental } \\
\text { Protection }\end{array}$ & $\begin{array}{l}\text { Cap and } \\
\text { Trade }\end{array}$ & $\begin{array}{c}\text { Clean Air } \\
\text { Act }\end{array}$ & No & Yes & High & Low & Medium \\
\hline 8 & $\begin{array}{l}\text { Emissions } \\
\text { Reduction Market } \\
\text { System }\end{array}$ & State of Illinois & $\begin{array}{l}\text { Cap and } \\
\text { Trade }\end{array}$ & $\begin{array}{l}\text { Clean Air } \\
\text { Act }\end{array}$ & No & Yes & High & Low & Medium \\
\hline
\end{tabular}


Table 9-1: List of U.S. Credit Trading Programs and Activities (continued)

\begin{tabular}{|c|c|c|c|c|c|c|c|c|c|}
\hline & Title & Sponsor & $\begin{array}{l}\text { Type of } \\
\text { Program }\end{array}$ & Driver & $\begin{array}{c}\text { Wind } \\
\text { Can } \\
\text { Participate }\end{array}$ & $\begin{array}{l}\text { Can Be } \\
\text { Modified } \\
\text { for Wind }\end{array}$ & $\begin{array}{c}\text { Market } \\
\text { Potential } \\
\text { for Wind }\end{array}$ & $\begin{array}{c}\text { Present } \\
\text { Value to } \\
\text { Wind }\end{array}$ & $\begin{array}{c}\text { Time } \\
\text { Horizon }\end{array}$ \\
\hline 9 & $\begin{array}{l}\text { The Western } \\
\text { Regional Air } \\
\text { Partnership's } \\
\text { (WRAP) Market } \\
\text { Trading Forum }\end{array}$ & WRAP & $\begin{array}{l}\text { Cap and } \\
\text { Trade }\end{array}$ & $\begin{array}{l}\text { Regional } \\
\text { Haze Rule }\end{array}$ & Yes & N/A & High & Low & Medium \\
\hline 10 & KEFI Exchange & KEFI & $\begin{array}{c}\text { Emissions } \\
\text { Banking and } \\
\text { Trading }\end{array}$ & $\begin{array}{c}\text { Kyoto } \\
\text { Protocol }\end{array}$ & Yes & N/A & High & Medium & Medium \\
\hline 11 & Kyoto Protocol & $\begin{array}{c}\text { International } \\
\text { Treaty }\end{array}$ & \begin{tabular}{|} 
Emissions \\
Banking and \\
Trading
\end{tabular} & $\begin{array}{l}\text { Climate } \\
\text { Change }\end{array}$ & Yes & N/A & High & Medium & Medium \\
\hline 12 & $\begin{array}{l}\text { International } \\
\text { Carbon } \\
\text { Sequestration } \\
\text { Incentive Act }\end{array}$ & $\begin{array}{l}\text { U.S. Senator } \\
\text { Sam } \\
\text { Brownback }\end{array}$ & $\begin{array}{c}\text { Federal Bill - } \\
\text { investment } \\
\text { tax credits }\end{array}$ & $\begin{array}{c}\text { Kyoto } \\
\text { Protocol }\end{array}$ & No & No & Low & Low & Long \\
\hline 13 & $\begin{array}{l}\text { New England } \\
\text { Disclosure Project } \\
\text { and Model Rule on } \\
\text { Information } \\
\text { Disclosure }\end{array}$ & $\begin{array}{l}\text { New England } \\
\text { Conference of } \\
\text { Public Utility } \\
\text { Commissioners }\end{array}$ & $\begin{array}{l}\text { Generation } \\
\text { Disclosure }\end{array}$ & $\begin{array}{l}\text { Consumer } \\
\text { Demand }\end{array}$ & Yes & $\mathrm{N} / \mathrm{A}$ & Medium & Medium & Short \\
\hline 14 & $\begin{array}{l}\text { Retail Electricity } \\
\text { Disclosure Program } \\
\text { and Green Labeling }\end{array}$ & $\begin{array}{l}\text { California } \\
\text { Energy } \\
\text { Commissions }\end{array}$ & $\begin{array}{c}\text { Generation } \\
\text { Disclosure, } \\
\text { Green } \\
\text { Labeling } \\
\end{array}$ & $\begin{array}{c}\text { Consumer } \\
\text { Demand }\end{array}$ & Yes & N/A & Medium & Medium & Short \\
\hline 15 & $\begin{array}{l}\text { Northeast States for } \\
\text { Coordinated Air } \\
\text { Use Management } \\
\text { (NESCAUM) Draft } \\
\text { Model Rule for } \\
\text { Generation } \\
\text { Performance } \\
\text { Standards }\end{array}$ & $\begin{array}{l}\text { Connecticut } \\
\text { Department of } \\
\text { Environmental } \\
\text { Protection }\end{array}$ & GPS & $\begin{array}{c}\text { Clean Air } \\
\text { Act }\end{array}$ & Yes & N/A & Medium & Medium & Short \\
\hline 16 & Climate Wise & EPA and DOE & $\begin{array}{l}\text { Government } \\
\text {-Industry } \\
\text { Partnership } \\
\text { Program } \\
\end{array}$ & $\begin{array}{c}\text { Kyoto } \\
\text { Protocol }\end{array}$ & Yes & N/A & Low & Low & $\mathrm{n} / \mathrm{a}$ \\
\hline 17 & $\begin{array}{l}\text { Green-e Renewable } \\
\text { Electricity } \\
\text { Certification } \\
\text { Program }\end{array}$ & $\begin{array}{c}\text { Center for } \\
\text { Resource } \\
\text { Solutions and } \\
\text { other } \\
\text { stakeholders }\end{array}$ & $\begin{array}{c}\text { Green } \\
\text { Labeling }\end{array}$ & $\begin{array}{l}\text { Consumer } \\
\text { Demand }\end{array}$ & Yes & $\mathrm{N} / \mathrm{A}$ & Medium & Medium & Short \\
\hline 18 & PureWind & $\begin{array}{c}\text { PG\&E Corp. } \\
\text { National } \\
\text { Energy Group }\end{array}$ & $\begin{array}{c}\text { Green } \\
\text { Labeling }\end{array}$ & $\begin{array}{l}\text { Consumer } \\
\text { Demand }\end{array}$ & Yes & N/A & High & Medium & Short \\
\hline 19 & $\begin{array}{l}\text { Environmental } \\
\text { Choice Program } \\
\text { (EcoLogo) }\end{array}$ & $\begin{array}{l}\text { TerraChoice } \\
\text { Environmental } \\
\text { Services Inc }\end{array}$ & $\begin{array}{c}\text { Green } \\
\text { Labeling }\end{array}$ & $\begin{array}{l}\text { Consumer } \\
\text { Demand }\end{array}$ & Yes & $\mathrm{N} / \mathrm{A}$ & High & High & Short \\
\hline
\end{tabular}


Table 9-1: List of U.S. Credit Trading Programs and Activities (continued)

\begin{tabular}{|c|c|c|c|c|c|c|c|c|c|}
\hline & Title & Sponsor & $\begin{array}{l}\text { Type of } \\
\text { Program }\end{array}$ & Driver & $\begin{array}{c}\text { Wind } \\
\text { Can } \\
\text { Participate }\end{array}$ & $\begin{array}{l}\text { Can Be } \\
\text { Modified } \\
\text { for Wind }\end{array}$ & $\begin{array}{c}\text { Market } \\
\text { Potential } \\
\text { for Wind }\end{array}$ & $\begin{array}{c}\text { Present } \\
\text { Value to } \\
\text { Wind }\end{array}$ & $\begin{array}{c}\text { Time } \\
\text { Horizon }\end{array}$ \\
\hline 20 & $\begin{array}{l}\text { Automated Power } \\
\text { Exchange }\end{array}$ & $\begin{array}{l}\text { Automated } \\
\text { Power } \\
\text { Exchange }\end{array}$ & $\begin{array}{c}\text { Green } \\
\text { Power } \\
\text { Exchange }\end{array}$ & $\begin{array}{l}\text { Market } \\
\text { Driven }\end{array}$ & Yes & N/A & Medium & Medium & Short \\
\hline 21 & $\begin{array}{l}\text { BPA's Conservation } \\
\text { and Renewable } \\
\text { Discount }\end{array}$ & BPA & Green Tags & $\begin{array}{l}\text { Consumer } \\
\text { Demand }\end{array}$ & Yes & N/A & Medium & Medium & Short \\
\hline 22 & $\begin{array}{l}\text { Green Tags } \\
\text { Program }\end{array}$ & BEF & Green Tags & $\begin{array}{l}\text { Consumer } \\
\text { Demand }\end{array}$ & Yes & $\mathrm{N} / \mathrm{A}$ & Medium & Medium & Short \\
\hline 23 & $\begin{array}{l}\text { Renewable Energy } \\
\text { Certificate System }\end{array}$ & \begin{tabular}{|c|} 
RECS \\
Secretariat/Con \\
sultants on \\
Energy \& \\
Environment \\
\end{tabular} & RECs & $\begin{array}{l}\text { Consumer } \\
\text { Demand }\end{array}$ & Yes & N/A & Medium & Medium & Short \\
\hline 24 & $\begin{array}{l}\text { Green Power for a } \\
\text { Green L.A. Program }\end{array}$ & $\begin{array}{l}\text { Los Angeles } \\
\text { Department of } \\
\text { Water and } \\
\text { Power }\end{array}$ & RECs & $\begin{array}{l}\text { Consumer } \\
\text { Demand }\end{array}$ & Yes & N/A & Medium & Medium & Short \\
\hline 25 & $\begin{array}{l}\text { Oregon Climate } \\
\text { Trust }\end{array}$ & OCT Board & $\begin{array}{c}\text { GHG } \\
\text { mitigation } \\
\text { investments }\end{array}$ & $\begin{array}{c}\text { House Bill } \\
3283\end{array}$ & Yes & N/A & High & $\begin{array}{c}\text { High } \\
\text { Medium }\end{array}$ & Medium \\
\hline 26 & $\begin{array}{l}\text { Bay Area Air } \\
\text { Quality } \\
\text { Management } \\
\text { District (BAAQMD) } \\
\text { Emissions Banking }\end{array}$ & BAAQMD & $\begin{array}{c}\text { New Source } \\
\text { Permits/ } \\
\text { Review }\end{array}$ & $\begin{array}{l}\text { Clean Air } \\
\text { Act }\end{array}$ & No & Yes & High & Low & Medium \\
\hline 27 & $\begin{array}{l}\text { Maryland Air } \\
\text { Emission Offset } \\
\text { Banking and } \\
\text { Trading Program }\end{array}$ & $\begin{array}{c}\text { Maryland } \\
\text { Department of } \\
\text { the } \\
\text { Environment }\end{array}$ & $\begin{array}{c}\text { New Source } \\
\text { Permits/ } \\
\text { Review }\end{array}$ & $\begin{array}{l}\text { Clean Air } \\
\text { Act }\end{array}$ & No & Yes & Medium & Low & Medium \\
\hline 28 & $\begin{array}{l}\text { California's New } \\
\text { Source Review }\end{array}$ & $\begin{array}{l}\text { California's } \\
\text { Local Districts }\end{array}$ & $\begin{array}{c}\text { New Source } \\
\text { Permits/ } \\
\text { Review }\end{array}$ & $\begin{array}{l}\text { Clean Air } \\
\text { Act }\end{array}$ & No & Yes & Medium & Low & Medium \\
\hline 29 & Offset Trading & EPA & $\begin{array}{c}\text { New Source } \\
\text { Permits/ } \\
\text { Review }\end{array}$ & $\begin{array}{l}\text { Clean Air } \\
\text { Act }\end{array}$ & No & Yes & Medium & Low & Medium \\
\hline 30 & $\begin{array}{l}\text { Michigan Air } \\
\text { Emission Trading } \\
\text { Program }\end{array}$ & $\begin{array}{c}\text { Michigan } \\
\text { Department of } \\
\text { Environmental } \\
\text { Quality, Air } \\
\text { Quality } \\
\text { Division }\end{array}$ & $\begin{array}{l}\text { Open } \\
\text { Market, } \\
\text { Voluntary } \\
\text { Trading }\end{array}$ & $\begin{array}{l}\text { Clean Air } \\
\text { Act }\end{array}$ & No & Yes & High & Low & Medium \\
\hline 31 & $\begin{array}{l}\text { El Paso Cross- } \\
\text { Border Emissions } \\
\text { Trading }\end{array}$ & $\begin{array}{c}\text { City of El Paso, } \\
\text { Texas }\end{array}$ & $\begin{array}{l}\text { Open } \\
\text { Market, } \\
\text { Voluntary } \\
\text { Trading }\end{array}$ & $\begin{array}{l}\text { Clean Air } \\
\text { Act }\end{array}$ & No & Yes & Medium & Low & Medium \\
\hline
\end{tabular}


Table 9-1: List of U.S. Credit Trading Programs and Activities (continued)

\begin{tabular}{|c|c|c|c|c|c|c|c|c|c|}
\hline & Title & Sponsor & $\begin{array}{l}\text { Type of } \\
\text { Program }\end{array}$ & Driver & $\begin{array}{c}\text { Wind } \\
\text { Can } \\
\text { Participate }\end{array}$ & $\begin{array}{l}\text { Can Be } \\
\text { Modified } \\
\text { for Wind }\end{array}$ & $\begin{array}{c}\text { Market } \\
\text { Potential } \\
\text { for Wind }\end{array}$ & $\begin{array}{c}\text { Present } \\
\text { Value to } \\
\text { Wind }\end{array}$ & $\begin{array}{c}\text { Time } \\
\text { Horizon }\end{array}$ \\
\hline 32 & $\begin{array}{l}\text { Emission Reduction } \\
\text { Credit Registry } \\
\text { System }\end{array}$ & $\begin{array}{c}\text { Pennsylvania } \\
\text { Department of } \\
\text { Environmental } \\
\text { Protection }\end{array}$ & $\begin{array}{l}\text { Open } \\
\text { Market, } \\
\text { Voluntary } \\
\text { Trading }\end{array}$ & $\begin{array}{l}\text { Consumer } \\
\text { Demand }\end{array}$ & No & Yes & High & Low & Medium \\
\hline 33 & $\begin{array}{l}\text { Renewable Energy } \\
\text { Credits Program }\end{array}$ & $\begin{array}{c}\text { Electric } \\
\text { Reliability } \\
\text { Council of } \\
\text { Texas (ERCOT) }\end{array}$ & $\begin{array}{l}\text { Open } \\
\text { Market, } \\
\text { Voluntary } \\
\text { Trading }\end{array}$ & $\begin{array}{c}\text { Public } \\
\text { Utilities } \\
\text { Regulatory } \\
\text { Act }\end{array}$ & Yes & N/A & High & Medium & Short \\
\hline 34 & $\begin{array}{l}\text { Innovative Market } \\
\text { Program for Air } \\
\text { Credit Trading } \\
\text { (IMPACT)/ } \\
\text { Economic Incentive } \\
\text { Program (EIP) }\end{array}$ & $\begin{array}{c}\text { EPA/State of } \\
\text { Massachusetts }\end{array}$ & $\begin{array}{l}\text { Open } \\
\text { Market, } \\
\text { Voluntary } \\
\text { Trading }\end{array}$ & $\begin{array}{l}\text { Clean Air } \\
\text { Act }\end{array}$ & No & Yes & $\begin{array}{l}\text { Medium } \\
\text { High }\end{array}$ & Low & Long \\
\hline 35 & $\begin{array}{l}\text { Cleaner and } \\
\text { Greener - } \\
\text { Multipollutant } \\
\text { Reporting System }\end{array}$ & $\begin{array}{c}\text { The Leonardo } \\
\text { Academy }\end{array}$ & $\begin{array}{l}\text { Open } \\
\text { Market, } \\
\text { Voluntary } \\
\text { Trading }\end{array}$ & $\begin{array}{l}\text { Consumer } \\
\text { Demand }\end{array}$ & Yes & N/A & Medium & Low & Medium \\
\hline 36 & Senate Bill 547 & $\begin{array}{c}\text { Senators } \\
\text { Chafee, Mack, } \\
\text { and Lieberman }\end{array}$ & Proposal & $\begin{array}{c}\text { Kyoto } \\
\text { Protocol }\end{array}$ & Yes & N/A & High & $\begin{array}{c}\text { Low } \\
\text { Medium }\end{array}$ & Medium \\
\hline 37 & $\begin{array}{l}\text { Credit for Voluntary } \\
\text { Early Actions Act } \\
(\text { H.R 2520) }\end{array}$ & $\begin{array}{l}\text { Represent- } \\
\text { atives Lazio } \\
\text { and Dooley }\end{array}$ & Proposal & $\begin{array}{l}\text { Kyoto } \\
\text { Protocol }\end{array}$ & Yes & N/A & High & $\begin{array}{c}\text { Low } \\
\text { Medium }\end{array}$ & Medium \\
\hline 38 & $\begin{array}{l}\text { A Proposal for } \\
\text { Credible Early } \\
\text { Action in U.S. } \\
\text { Climate Policy }\end{array}$ & $\begin{array}{c}\text { Raymond } \\
\text { Kopp, Richard } \\
\text { Morgenstern, } \\
\text { William Pizer, } \\
\text { and Michael } \\
\text { Toman }\end{array}$ & Proposal & $\begin{array}{c}\text { Kyoto } \\
\text { Protocol }\end{array}$ & Yes & $\mathrm{N} / \mathrm{A}$ & High & Low & Long \\
\hline 39 & $\begin{array}{l}\text { H.R. } 2569 \text { - Fair } \\
\text { Energy Competition } \\
\text { Act of } 1999\end{array}$ & Pallone (NJ) & Proposal & $\begin{array}{l}\text { Utility } \\
\text { Restruc- } \\
\text { turing }\end{array}$ & Yes & $\mathrm{N} / \mathrm{A}$ & High & Low & Long \\
\hline 40 & $\begin{array}{l}\text { H.R. } 4861 \text { - Clean } \\
\text { Power Act }\end{array}$ & Lazio & Proposal & $\begin{array}{l}\text { Utility } \\
\text { Restruc- } \\
\text { turing }\end{array}$ & Yes & $\mathrm{N} / \mathrm{A}$ & High & Low & Long \\
\hline 41 & $\begin{array}{l}\text { Alternate Energy } \\
\text { Law }\end{array}$ & State of lowa & RPS & $\begin{array}{l}\text { Utility } \\
\text { Restruc- } \\
\text { turing }\end{array}$ & Yes & $\mathrm{N} / \mathrm{A}$ & $\begin{array}{l}\text { Medium } \\
\text { High }\end{array}$ & $\begin{array}{l}\text { Medium } \\
\text { High }\end{array}$ & Medium \\
\hline 42 & $\begin{array}{l}\text { Renewable } \\
\text { Portfolio Standard - } \\
\text { Maine }\end{array}$ & State of Maine & RPS & $\begin{array}{l}\text { Utility } \\
\text { Restruc- } \\
\text { turing }\end{array}$ & Yes & $\mathrm{N} / \mathrm{A}$ & $\begin{array}{l}\text { Medium } \\
\text { High }\end{array}$ & $\begin{array}{l}\text { Medium } \\
\text { High }\end{array}$ & Medium \\
\hline 43 & $\begin{array}{l}\text { Renewable } \\
\text { Portfolio Standard: } \\
\text { Massachusetts }\end{array}$ & $\begin{array}{c}\text { State of } \\
\text { Massachusetts }\end{array}$ & RPS & $\begin{array}{l}\text { Utility } \\
\text { Restruc- } \\
\text { turing }\end{array}$ & Yes & $\mathrm{N} / \mathrm{A}$ & $\begin{array}{c}\text { High } \\
\text { Medium }\end{array}$ & $\begin{array}{c}\text { Medium } \\
\text { High }\end{array}$ & Medium \\
\hline 44 & $\begin{array}{l}\text { Portfolio Standard: } \\
\text { Nevada }\end{array}$ & $\begin{array}{l}\text { State of } \\
\text { Nevada }\end{array}$ & RPS & $\begin{array}{l}\text { Utility } \\
\text { Restruc- } \\
\text { turing }\end{array}$ & Yes & N/A & $\begin{array}{l}\text { Medium } \\
\text { High }\end{array}$ & $\begin{array}{c}\text { Medium } \\
\text { High }\end{array}$ & Short \\
\hline
\end{tabular}


Table 9-1: List of U.S. Credit Trading Programs and Activities (continued)

\begin{tabular}{|c|c|c|c|c|c|c|c|c|c|}
\hline & Title & Sponsor & $\begin{array}{l}\text { Type of } \\
\text { Program }\end{array}$ & Driver & $\begin{array}{c}\text { Wind } \\
\text { Can } \\
\text { Participate }\end{array}$ & $\begin{array}{l}\text { Can Be } \\
\text { Modified } \\
\text { for Wind }\end{array}$ & $\begin{array}{c}\text { Market } \\
\text { Potential } \\
\text { for Wind }\end{array}$ & $\begin{array}{c}\text { Present } \\
\text { Value to } \\
\text { Wind }\end{array}$ & $\begin{array}{c}\text { Time } \\
\text { Horizon }\end{array}$ \\
\hline 45 & $\begin{array}{l}\text { Environmentally } \\
\text { Friendly Portfolio } \\
\text { Standard }\end{array}$ & $\begin{array}{c}\text { Arizona } \\
\text { Corporation } \\
\text { Commission }\end{array}$ & RPS & $\begin{array}{l}\text { Utility } \\
\text { Restruc- } \\
\text { turing }\end{array}$ & Yes & $\mathrm{N} / \mathrm{A}$ & High & Medium & Medium \\
\hline 46 & $\begin{array}{l}\text { Renewable } \\
\text { Portfolio Standard: } \\
\text { New Jersey }\end{array}$ & $\begin{array}{c}\text { New Jersey } \\
\text { Board of } \\
\text { Public Utilities }\end{array}$ & RPS & $\begin{array}{l}\text { Utility } \\
\text { Restruc- } \\
\text { turing }\end{array}$ & Yes & N/A & High & Medium & Medium \\
\hline 47 & $\begin{array}{l}\text { Energy Efficiency } \\
\text { and Renewable } \\
\text { Energy Set Aside } \\
\text { (under NOx SIP Call) }\end{array}$ & EPA & $\begin{array}{l}\text { Renewables } \\
\text { Set- Aside }\end{array}$ & $\begin{array}{l}\text { Clean Air } \\
\text { Act }\end{array}$ & Yes & N/A & High & Low & Medium \\
\hline 48 & $\begin{array}{l}\text { Northern States } \\
\text { Power Wind } \\
\text { Generation } \\
\text { Mandate }\end{array}$ & $\begin{array}{c}\text { State of } \\
\text { Minnesota }\end{array}$ & $\begin{array}{l}\text { Renewables } \\
\text { Set- Aside }\end{array}$ & Legislation & Yes & N/A & High & High & Medium \\
\hline 49 & $\begin{array}{l}\text { Renewable Energy } \\
\text { Set- Aside: New } \\
\text { York }\end{array}$ & $\begin{array}{c}\text { State of New } \\
\text { York }\end{array}$ & $\begin{array}{l}\text { Renewables } \\
\text { Set- Aside }\end{array}$ & $\begin{array}{l}\text { Utility } \\
\text { Restruc- } \\
\text { turing }\end{array}$ & Yes & N/A & High & Low & Medium \\
\hline 50 & $\begin{array}{l}\text { Renewables Set- } \\
\text { Aside:- Washington }\end{array}$ & $\begin{array}{c}\text { State of } \\
\text { Washington }\end{array}$ & $\begin{array}{l}\text { Renewables } \\
\text { Set- Aside }\end{array}$ & $\begin{array}{l}\text { Utility } \\
\text { Restruc- } \\
\text { turing }\end{array}$ & Yes & N/A & High & High & Short \\
\hline 51 & $\begin{array}{l}\text { Conservation and } \\
\text { Renewable Energy } \\
\text { Reserve (CRER) }\end{array}$ & EPA & $\begin{array}{l}\text { Renewables } \\
\text { Set-Aside }\end{array}$ & $\begin{array}{l}\text { Clean Air } \\
\text { Act }\end{array}$ & Yes & N/A & Low & Low & $\mathrm{N} / \mathrm{A}$ \\
\hline 52 & $\begin{array}{l}\text { Non-Bypassable } \\
\text { Distribution Charge }\end{array}$ & $\begin{array}{l}\text { California } \\
\text { Energy } \\
\text { Commission, } \\
\text { Renewables } \\
\text { Program } \\
\text { Committee }\end{array}$ & SBC & $\begin{array}{l}\text { Utility } \\
\text { Restruc- } \\
\text { turing }\end{array}$ & Yes & $\mathrm{N} / \mathrm{A}$ & Medium & Medium & Short \\
\hline 53 & $\begin{array}{l}\text { Renewable Energy } \\
\text { Resources Trust } \\
\text { Fund }\end{array}$ & $\begin{array}{c}\text { Citizens Utility } \\
\text { Board }\end{array}$ & SBC & $\begin{array}{l}\text { Utility } \\
\text { restruc- } \\
\text { turing }\end{array}$ & Yes & N/A & Medium & Medium & Short \\
\hline 54 & $\begin{array}{l}\text { Massachusetts } \\
\text { Renewable Energy } \\
\text { Trust Fund }\end{array}$ & $\begin{array}{c}\text { State of } \\
\text { Massachusetts }\end{array}$ & SBC & $\begin{array}{l}\text { Utility } \\
\text { Restruc- } \\
\text { turing }\end{array}$ & Yes & $\mathrm{N} / \mathrm{A}$ & Medium & Medium & Short \\
\hline 55 & $\begin{array}{l}\text { Montana's } \\
\text { Universal System } \\
\text { Benefits Program }\end{array}$ & $\begin{array}{l}\text { State of } \\
\text { Montana }\end{array}$ & SBC & $\begin{array}{l}\text { Utility } \\
\text { Restruc- } \\
\text { turing }\end{array}$ & Yes & $\mathrm{N} / \mathrm{A}$ & Medium & Medium & Short \\
\hline 56 & $\begin{array}{l}\text { System Benefits } \\
\text { Charge: Rhode } \\
\text { Island }\end{array}$ & $\begin{array}{l}\text { State of Rhode } \\
\text { Island }\end{array}$ & SBC & $\begin{array}{l}\text { Utility } \\
\text { Restruc- } \\
\text { turing }\end{array}$ & Yes & $\mathrm{N} / \mathrm{A}$ & Medium & Medium & Short \\
\hline 57 & $\begin{array}{l}\text { Renewable Energy } \\
\text { Investment Fund }\end{array}$ & $\begin{array}{l}\text { Connecticut } \\
\text { Clean Energy } \\
\text { Fund }\end{array}$ & $\begin{array}{l}\text { SBC to } \\
\text { Investment } \\
\text { Fund }\end{array}$ & $\begin{array}{l}\text { Utility } \\
\text { Restruc- } \\
\text { turing }\end{array}$ & Yes & $\mathrm{N} / \mathrm{A}$ & High & & Medium \\
\hline 58 & Climate Challenge & DOE & $\begin{array}{c}\text { Voluntary } \\
\text { Reduction } \\
\text { Commitment }\end{array}$ & $\begin{array}{l}1992 \text { Rio } \\
\text { Treaty }\end{array}$ & Yes & $\mathrm{N} / \mathrm{A}$ & Medium & Medium & Short \\
\hline
\end{tabular}


Table 9-1: List of U.S. Credit Trading Programs and Activities (continued)

\begin{tabular}{|c|c|c|c|c|c|c|c|c|c|}
\hline & Title & Sponsor & $\begin{array}{l}\text { Type of } \\
\text { Program }\end{array}$ & Driver & $\begin{array}{c}\text { Wind } \\
\text { Can } \\
\text { Participate }\end{array}$ & $\begin{array}{l}\text { Can Be } \\
\text { Modified } \\
\text { for Wind }\end{array}$ & $\begin{array}{c}\text { Market } \\
\text { Potential } \\
\text { for Wind }\end{array}$ & $\begin{array}{c}\text { Present } \\
\text { Value to } \\
\text { Wind }\end{array}$ & $\begin{array}{c}\text { Time } \\
\text { Horizon }\end{array}$ \\
\hline & & & Program & & & & & & \\
\hline 59 & $\begin{array}{l}\text { Voluntary } \\
\text { Reporting of } \\
\text { Greenhouse Gases } \\
\text { Program }\end{array}$ & DOE & $\begin{array}{l}\text { Voluntary } \\
\text { Reporting } \\
\text { Program }\end{array}$ & EPAct & No & N/A & Low & Low & $\mathrm{n} / \mathrm{a}$ \\
\hline 60 & $\begin{array}{l}\text { New Jersey } \\
\text { Sustainability } \\
\text { Greenhouse Gas } \\
\text { Action Plan }\end{array}$ & $\begin{array}{c}\text { State of New } \\
\text { Jersey }\end{array}$ & \begin{tabular}{|c|} 
Voluntary \\
Statewide \\
GHG \\
Emissions \\
Reduction \\
commitment
\end{tabular} & $\begin{array}{c}\text { Kyoto } \\
\text { Protocol }\end{array}$ & & & High & Low & Medium \\
\hline
\end{tabular}

\section{PART I: CREDITS ARISING FROM MANDATED MARKETS}

Under the CAAA of 1990, the EPA developed market-based trading systems and strongly encourages states or regions to implement them in their pursuit of emissions reductions targets. Most trading in the United States falls into two categories: (1) offset trading, which is designed to accommodate new growth, and (2) allowance trading, which is aimed at improving air quality.

\section{Offset Trading}

Offset trading, also called New Source Review (NSR), was designed to allow major new sources of emissions to be built in nonattainment areas, or those that do not meet NAAQS under the Clean Air Act, without further adversely affecting the region's air quality. Created under the NSR provisions of the CAAA of 1990, the offset trading market is one of the oldest emissions trading systems in the United States. Although the program is still in place in many nonattainment areas today, it represents a transition between traditional command-andcontrol and what is today considered an active, functional emissions trading market.

The theory behind the offset trading concept is that the operator of any new source (or major modification to an existing source) that causes an increase in overall emissions levels in a given airshed must purchase the rights to emit pollutants from an existing source. Offset credits, often referred to as ERCs, are equal to 1 ton/yr reduction in emissions for the life of the facility. Offsets are pollutant-specific so that, for example, a reduction in $\mathrm{NO}_{x}$ creates an $\mathrm{NO}_{x}$ offset.

Under this program, companies that wish to develop major new sources of emissions and their precursors (e.g., $\mathrm{NO}_{x}, \mathrm{VOCs}, \mathrm{SO}_{2}, \mathrm{CO}$, and $\mathrm{PM}$ ) must not only install stringent pollution control technologies, but must also provide supplemental emission reductions, or offsets, by mitigating the emissions of neighboring sources beyond the level of the expected new emissions. An emission offset is a permanent reduction in a source's emission rate for a given pollutant. The offset is created by taking action over and above what would otherwise be required of the source, such as by installing advanced technology controls or by permanently shutting down an air pollution source (the latter is the most common).

Although the offset trading program is well established and has enjoyed some success, the market for offset credits is much less active than some of the other active emissions trading programs. The administrative process is cumbersome and transaction costs are generally quite high. In addition, the process of creating an offset is complex and time-consuming and requires a substantial initial investment to complete an emissions reduction project before the credits are created. For a source that wishes to rely on offset credits as a revenue stream to fund such a project, the process can be frustratingly backwards.

There are some examples of regional new source emission programs have been fairly successful on a smaller scale. In California, for example, a state- 
level NSR program, which was derived from the Clean Air Act Program, issues several different categories of new source permits under the discretion of 35 different air pollution control districts throughout the state. Each district must adopt its own rules and regulations that comply with state and federal laws. Generally, the districts must include requirements for Best Available Control Technology (BACT) or Lowest Achievable Emissions Rate (LAER). Many also include elements of banking and trading of emissions offsets. Entities that implement new emission control measures beyond those required by the district regulations can bank the resulting emission reductions to offset future capacity increases or other emission increases from new projects. The banked emission offsets can also be traded or sold. Similar programs are in place in Maryland and Texas. At present, these programs do not allow renewables to participate.

\section{Allowance Trading}

Allowance trading (also known as cap and trade) was developed under the Acid Rain Program (Title IV) of the CAAA of 1990. Title IV sets as its primary goal the reduction of annual $\mathrm{SO}_{2}$ emissions by 10 million tons below 1980 levels. To achieve these reductions, the law requires a two-phase tightening of the restrictions placed on fossil-fuel-fired power plants to about one-half of the amount emitted in 1990. The program introduced a trading system for $\mathrm{SO}_{2}$ that facilitates lowest cost emission reductions and an overall emissions cap to ensure that the environmental goal is obtained. The $\mathrm{SO}_{2}$ program has been widely heralded as an environmental and economic success, often being used as a model for the design of other environmental programs. We discuss the specifics of the $\mathrm{SO}_{2}$ program and other allowance trading programs in greater detail below.

The critical element of allowance trading is the allocation of allowances. The specific rules of trading depend on the individual program, but the basic premise is that a total quantity of a pollutant that can be emitted is capped for a given region during a given time period. The region is assigned an "emissions budget," which is then divided among the emitters in that area in the form of allocations based on historical emissions, capacity, or units produced. As an alternative, the allowances can be auctioned. This has been done with a small percentage of the allowances available under the Acid Rain Program. Either way, the total emissions cap and the corresponding allocations represent a net air quality improvement. To operate within the budget set by the cap, source polluters can install pollution control technologies, modify their processes or fuel use, or curtail their use of emission sources. Additional allowances can be created by voluntarily reducing the source's total emissions below the level of its allocation. These allowances may be used, sold to another entity, or banked for future use or sale. In this way, allowances are given value both as an asset and as a rationed commodity, empowering sources to use financial markets to sustain their operations within the cap. If it is less costly than implementing on-site mitigation measures, sources can legitimately purchase additional allowances to come into compliance.

Among the most controversial elements of the cap and trade program are the systems for allocating allowances. In general, allowances are either auctioned off to the regulated facilities, or they are allocated directly by state or air quality authorities. In the latter case, there are essentially two methods for allocating credits to individual sources-inputbased and output-based. Input-based allocation methods apply a standard emissions rate to the sources' historical emissions per unit of fuel consumed ("input"). The more fuel a source consumes, the more allowances they are allocated. Output-based allocations are assigned based on actual electricity (number of kilowatt-hours) produced ("output"). Either input- or output-based allocations can be permanent or updated on a periodic basis. In either case, allowances are allocated only to the limited number of sources of the specific pollutant being regulated; for this reason, no allocations for renewable energy generators have been included. Without a mechanism that provides due value to the emissions reduction benefits derived from clean energy production, this segment of the power production pool has nothing to trade and thus no basis for participating in trading.

Assigning allocations to renewable energy generators using an input-based system is inappropriate because renewable energy generation requires little or no fuel inputs (except in the case of biomass). However, the EPA has used input standards in the $\mathrm{SO}_{2}$ and $\mathrm{NO}_{x}$ trading programs, in part because of the lack of experience with the technical aspects of allocating emissions 
credits based on output methods, and in part because of heavy political lobbying for input allocations from the fuel sources that benefit from them. This has been seen as one of the key stumbling blocks for renewable energy generators wishing to participate in the program, but recent developments at EPA are promising. In actions related to the NOx SIP Call (the SIP and Section 126 rulemakings), where the EPA would dictate the allocations, the agency decided to issue allocations based on output beginning in 2005 for compliance years starting in 2008. Until 2005, input-based allocations will be used because output data were not available for earlier years

Addressing the issue of allowance allocations is one of several ways in which the Clean Air Act could, but does not, recognize or promote the air quality benefits of renewable energy. However, because the Clean Air Act is frequently subjected to reviews and amendments, there is a great potential for the act to become more accommodating to renewable energy. For example, by allocating allowances to renewable energy generators based on avoided emission value or by creating a renewables set-aside of allowances specifically registered to renewable energy generators, cap and trade systems could allow the renewable energy industry to participate in the emissions trading market.

Despite the lack of adequate recommendations in the Clean Air Act, various programs that hold promise for the renewable energy industry have emerged at the state and regional level. In some cases minor provisions for including renewable energy options such as set-asides have been introduced at the state level in some trading and some nontrading programs. In addition, various forms of renewable energy policy initiatives, such as RPS and SBC have been introduced, either as part of statewide electric utility restructuring policy or in response to consumer demands for green energy. In the following section, we summarize the array of programs, both in place and proposed, that could have a positive impact on renewable energy markets.

\section{$\mathrm{SO}_{2}$ Allowance Trading}

Developed under the CAAA's Acid Rain Program, the $\mathrm{SO}_{2}$ cap and trade emissions program has been the most successful in terms of reducing air pollution. It has also been the most active allowance trading market that we have seen yet.
The cap and trade system depends on market-based trading of emissions allowances, the currency with which the participants meet compliance with the CAAA's acid rain requirements. Prices have ranged from $\$ 69$ to $\$ 212$. Under the system, utilities are allocated a number of allowances each year, based on their historical emissions rates. One allowance gives the utility the right to emit 1 ton of pollutant; at the end of the year the utility must hold a number of allowances at least equal to its total emissions that year. Polluters that reduce their emissions below the number of allowances they hold may trade with other units in their system, sell the allowances to other polluters, or bank the allowances for future use. The total utility emissions cap was ratcheted down in two phases, the first beginning in 1995 and the second beginning in 2000. By 2010, total utility emissions will be limited to one-half of the total utility emissions in 1980.

Because allowances are fully marketable commodities, this system gives utilities the flexibility to adopt the most cost-effective method to meet compliance, whether by implementing emissions reduction measures or by purchasing excess allowances from another source.

As part of the program, utilities are required to install and maintain continuous monitoring systems for $\mathrm{SO}_{2}$. This year, phase II of the program will bring small and mid-sized utility units into the program.

\section{NOx Budget Program}

The Ozone Transport Commission's (OTC) NOx Budget Program was introduced after the success of the $\mathrm{SO}_{2}$ trading program as a way to address summertime $\mathrm{NO}_{x}$ emissions (which cause ozone to form) in the northeastern United States. Because of the unique challenges presented by ozone formation (ozone is not emitted directly, but is formed when $\mathrm{NO}_{x}$ and VOCs react in sunlight) and the difficulty of controlling it using a state-by-state approach, Congress created the OTC in 1990 as part of the CAAA. The OTC includes eleven northeastern states plus parts of northern Virginia and the District of Columbia. We should note that the NOx Budget Program is separate and distinct from the Acid Rain "Phase I and II" NOx reduction program, which is not a trading program. Sources affected by both programs must demonstrate compliance with each. 
In 1994, the OTC members signed a memorandum of understanding that commits each state to adopting regulations that will result in a regionwide total $\mathrm{NO}_{x}$ allocation target for the ozone season, from May 1 to September 30 each year. The program caps ozone-season $\mathrm{NO}_{x}$ emissions at 219,000 tons in 1999 and 143,000 tons in 2003, which is less than half of the 1990 baseline emissions. The $\mathrm{NO}_{x}$ Budget Program is implemented through a model rule, developed by the OTC, the EPA, and other key stakeholders. The model rule identifies specific policy elements that each member state must adopt to create an integrated interstate emissions trading program. Each state is also responsible for tracking its sources' compliance with the program and calculating its baseline and allocations. EPA's role is to run the emissions and allowance tracking systems in support of the program. States are responsible for enforcing program requirements.

The $\mathrm{NO}_{x}$ Budget Program is a cap and trade system whereby each state is given a portion of the total $\mathrm{NO}_{x}$ budget and is then responsible for dividing its allowance allocations among the sources of $\mathrm{NO}_{x}$ in that state; each permit represents the limited authorization to emit 1 ton of $\mathrm{NO}$. For each ton of $N \mathrm{~N}_{x}$ a source emits, it must surrender one allowance at the end of the budget period. Sources must be able to demonstrate that their emissions have not exceeded the total allocation permits that they hold for that period. Excess allowances may be bought, sold, traded, or banked. Several states in the OTC have adopted set-asides to reward renewable energy, energy efficiency, or both.

\section{NOx SIP Call}

Under the federal authority of the Clean Air Act, the EPA is authorized to impose tighter emissions controls than those outlined in the act itself by calling for revisions, or "calls" to SIPs to prevent air emissions from one state from interfering with another state's ability to comply with air quality standards. In 1998, the EPA finalized the NO× SIP Call, a rule requiring 22 states and the District of Columbia to submit SIPs that address the regional transport of ground-level ozone through reductions of summertime $\mathrm{NO}_{x}$. The rule is intended to further address the problems of ground-level ozone in the eastern United States by including a greater number of states in the Midwest and the South than are affected by the OTC NOx Budget Program. The $\mathrm{NO}_{x}$ SIP Call is the first U.S. environmental policy to use a "regional" approach to air quality control and the first to impose an interstate pollution control authority to oversee the program.

The NOx SIP Call model rule includes a cap and trade program that is based on the principles underlying the $\mathrm{SO}_{2}$ program and the OTC NOx Budget Program. Under the NOx SIP Call, each of the 22 states is assigned a cap on seasonal $\mathrm{NO}_{\mathrm{x}}$ emissions. States may choose to meet their obligations through emissions trading. Sources trading under both programs may trade freely with each other; however, only sources in those states that choose to participate can trade.

The program also includes an incentive set-aside for energy efficiency and renewable energy. Under the current rule, from 1999 to 2002, "incentive" allowances are allocated to all entities that save electricity through the implementation of energy efficiency or renewable energy projects. Starting in 2003, this incentive set-aside will be reduced to $5 \%$ of the total allowances (see explanation of setasides below).

The states of New Jersey, Massachusetts, Pennsylvania, and Connecticut have enacted statebased initiatives to meet the requirements of the NOx SIP Call. Because of litigation from several parties, the original deadlines for SIP submissions were postponed. Currently, the court has reinstated the SIP submission deadline of October 2000 was reinstated and the 2003 deadline has been extended to May 31, 2004.

\section{Renewable Energy Set-Asides}

EPA has developed renewable energy set-asides to allow the renewable energy and energy efficiency industries to participate in and benefit from the existing allowance trading programs. A set-aside is a pool of emissions allowances that come from within a national, regional, or state emissions budget and are not distributed to emissions sources. Instead, the allowances are held out specifically for renewable energy and energy efficiency project developers and vendors that implement an eligible project within that state. There has been considerable debate about how setaside programs can be set up and the most effective methods for allocating set-asides. Establishing an effective clean energy set-aside program that is equitable and results in real air quality gains over the long term requires that several issues be 
addressed, including:

- What types of technologies are considered renewable?

- Who is eligible to earn allowances?

- How are allowances earned?

- What quantity of allowances can be earned?

The EPA's CRER program, implemented under the $\mathrm{SO}_{2}$ allowance-trading program, serves as an example of an unsuccessful renewable energy setaside program. Under the CRER, the EPA set aside $300,000 \mathrm{SO}_{2}$ allowances specifically for energy generators that implemented either demand-side energy efficiency measures or renewable energy projects that displaced power plant emissions between 1991 and 1999. One allowance could be earned for every $500 \mathrm{MWh}$ of energy saved or produced through biomass, solar, geothermal, and wind resources. If fully allocated, the CRER would have displaced 885 million tons of $\mathrm{SO}_{2}$ over its life. However, mainly because of poor planning, little real cost incentive, and restrictive rules that excluded independent power generators from participating, the CRER program expired several years ago with less than $12 \%$ of its allowances having been allocated.

However, the concept of set-asides is valid if managed properly, and the trial and error period of set-aside planning is finally beginning to bear fruit. The CRER offered a substantive energy efficiency/renewable energy set-aside option. This program allowed states that are participating in the model emissions trading program to voluntarily set aside a portion of their total $\mathrm{NO}_{\mathrm{x}}$ emissions budget for renewable energy and energy efficiency projects that are implemented in the state to offset or displace electricity generation. Although the state determines eligibility, the EPA furnishes guidelines on the design of set-aside programs, including elements for quantifying and allocating allowances; what types of projects should be eligible for awards; and the creation of a framework for measuring and verifying energy savings for set-aside allowances.

Several states have incorporated set-asides into their SIPs, both within and independent of the $\mathrm{NO}_{\mathrm{x}}$ SIP Call, as part of their regional pollution control programs. For example, under its cap and trade program, Massachusetts is considering $\mathrm{NO}_{x}$ setasides that allocate $1 \%$ of the state's total $\mathrm{NO}_{x}$ budget to energy efficiency and renewable energy developers. The set-asides would be allocated at a rate of $1.5 \mathrm{lb}$ of $\mathrm{NO}_{x}$ per MWh. Other states looking seriously at $\mathrm{NO}_{x}$ set-asides include $\mathrm{New}$ York, New Jersey, New Hampshire, Maryland, and Texas. Minnesota passed legislation requiring that Northern States Power build or contract out for 225 $\mathrm{MW}$ of wind power and $50 \mathrm{MW}$ of energy from closed-loop biomass systems by December 1998 and another $200 \mathrm{MW}$ of wind and $75 \mathrm{MW}$ of biomass energy by December 2002. New Jersey has already adopted a $\mathrm{NO}_{x}$ cap and trade program that includes set-asides for renewables and energy efficiency. In Washington, the BPA has developed a set-aside plan for up to $50 \mathrm{MW}$ of wind and 30 MW of geothermal power. And in New York, a recently passed $\mathrm{NO}_{\mathrm{x}}$ cap and trade program includes a 3\% set-aside of allowances for energy efficiency and renewable energy projects over the next 5 years.

In several cases, states that fall outside the 22-state jurisdiction of the NOx SIP Call are implementing their own statewide or regional cap and trade programs for a variety of pollutants to help nonattainment areas meet air quality standards. We summarize some of the more notable programs in the sections that follow.

\section{RECLAIM Program}

In the early 1990s, southern California's South Coast Air Quality Management District implemented one of the most active and successful of the regional cap and trade programs, the Regional Clean Air Incentives Market (RECLAIM). The program was implemented in the Los Angeles metropolitan area, which the EPA had designated as an extreme nonattainment area. The goal of the RECLAIM program is to reduce both $\mathrm{NO}_{x}$ and $\mathrm{SO}_{2}$ emissions enough for the southern California region to meet the air quality standards set forth by the Clean Air Act.

RECLAIM is a traditional cap and trade program in which the state assigns emissions credits based on past peak production and the requirements of existing rules and control measures, and reduces the total number of credits each year. Polluters are free to make emissions reductions using the least cost path. Credits are assigned each year and can only be used within that year. Businesses are required to hold credits equal to their actual emissions and those that are able to reduce emissions below their reduction targets can sell or trade their excess credits on the open market. 
Renewables are not currently eligible to participate in this program.

\section{Emission Credit Banking and Trading Program}

The Texas Natural Resource Conservation Commission has implemented the Emission Credit

Banking and Trading Program to help meet attainment requirements for sources in the Beaumont-Port Arthur, Dallas-Fort Worth, and Houston-Galveston nonattainment areas. The Houston-Galveston nonattainment area is also subject to the requirements of the NOx SIP rules under the Clean Air Act. The program acts as a mass cap and trade, which issues allowances to grandfathered electric-generating facilities for $\mathrm{SO}_{2}$, $\mathrm{NO}_{x}, \mathrm{VOCs}$, and other criteria pollutants.

\section{Emissions Reduction Market System}

To meet its 1999 requirements for VOCs under the Clean Air Act, Illinois recently enacted a marketbased emissions trading system for the Chicago area. The Emissions Reduction Market System (ERMS) went into effect for the 2000 ozone season. ERMS is a traditional cap and trade system in which participating sources must hold "trading units" equal to their actual VOC emissions. Units are distributed based on an input methodology. Excess units produced by measures that reduce emissions below levels required by the program may be traded, sold, or banked.

\section{RECs Under RPS Legislation}

RPS require that a minimum percentage of a state's annual electric usage comes from renewable energy. Originally added as a rider to state restructuring policy, RPS are now found in several states that have not yet enacted utility deregulation. The scope, nature, and design of individual RPS policies vary considerably from state to state depending on policy objectives and the level of renewable infrastructure already in place. As of 2000, RPS allocations ranged from $1 \%$ to $30 \%$. The policy is generally administered by state PUCs and implemented through a renewable energy purchase requirement imposed on retail energy suppliers. The individual purchase requirement can also often be met through trading in renewable energy credits, which gives the system more flexibility to reduce compliance costs.
In 1995, the American Wind Energy Association (AWEA) outlined specific elements of RPS programs that would effectively support renewable energy market development, essentially aimed at giving investors confidence that their investments will be profitable. According to AWEA, to achieve this goal, RPS initiatives should contain the following elements:

- The obligation to support renewable energy must apply equally to all market participants serving a state, a country, or a group of countries.

- The obligation must be tradable, based on a system of tradable credits, to achieve the renewables goal at least cost.

- The RPS must ensure that demand outstrips supply by setting the obligation at the level of existing renewables and increasing it from that point, by excluding existing renewables, or by using separate tiers for new and existing renewables.

- Requirements for new renewables should begin at least 2 years after all regulations are final, to allow time for competition among all potential resources.

- The obligation must rise gradually and predictably to ensure a stable market.

- Stiff automatic penalties must be imposed on market players that do not comply with the obligation; the penalty must significantly exceed the cost of compliance.

- The RPS must be long term, continuing until green kilowatt-hour prices drop to competitive market levels, when the RPS will sunset.

- Qualifying renewables must be limited to those that need market support and meet certain criteria. Large hydropower, for example, must be excluded.

- There must be flexibility for meeting the obligation, with a limited period for making up shortfalls, a system of credit banking, and a force majeure provision for temporary exemption in case of extreme events, such as natural disasters.

Several states have adopted RPS policies or are in the planning stages of doing so (see Tables 9.2 and 9.3). In addition, a number of the RPS programs around the country allow, or may allow, the use of credit trading (see Table 9.4). 
Table 9.2 State RPS Policies: Purchase Requirement.

\begin{tabular}{|c|c|}
\hline State & Purchase Requirement \\
\hline Arizona & $\begin{array}{l}0.2 \% \text { in } 2001 \text {, rising by } 0.2 \% \text { to } 1 \% \text { by } 2005 \text {, and to } 1.05 \% \text { in } 2006 \text {, then to } 1.1 \% \text { from } 2007 \text { to } \\
2012 \text {. Competitive retail suppliers are exempt until } 2004 \text {. Utility distribution companies may } \\
\text { recover costs by reallocating existing SBC accounts for demand-side management and partly by } \\
\text { environmental portfolio surcharge. }\end{array}$ \\
\hline Connecticut & $\begin{array}{l}\text { Class I or II technologies: } 5.5 \% \text { in } 2000,6 \% \text { in } 2005,7 \% \text { in } 2009 \text { and thereafter; Class I } \\
\text { technologies: } 0.5 \% \text { in } 2000,+0.25 \% / y r \text { to } 1 \% \text { by } 2002,6 \% \text { in } 2009 \text { and thereafter; revised law in } \\
1999 \text { clarifies that standard is energy-based, not capacity-based and allows individual suppliers to } \\
\text { petition PUC for delay of RPS targets of up to } 2 \text { years; PUC has denied at least one petition for } \\
\text { delay; PUC has established that RPS shall not apply to standard offer service, but this decision is } \\
\text { under appeal. }\end{array}$ \\
\hline Maine & $\begin{array}{l}30 \% \text { of retail sales in } 2000 \text { (start of competition) and thereafter as condition of licensing; PUC will } \\
\text { revisit RPS within } 5 \text { years after retail competition. }\end{array}$ \\
\hline Massachusetts & $\begin{array}{l}1 \% \text { of sales to end-use customers from new renewables in } 2003 \text { or } 1 \text { year after any renewable is } \\
\text { within } 10 \% \text { of average spot-market price; }+0.5 \% / y \text { to } 4 \% \text { in } 2009 ; 1 \% / y r \text { increase thereafter until } \\
\text { date determined by Division of Energy Resources (DOER). Preliminary RPS design proposal (June } \\
2000 \text { ) does not propose standard for existing renewables (about } 7 \% \text { ). DOER plans to monitor } \\
\text { market and adopt standard if there is significant attrition of renewables. }\end{array}$ \\
\hline Nevada & $\begin{array}{l}0.2 \% \text { of total Nevada consumption as of January } 1,2001 \text {; increases by } 0.2 \% \text { biannually until } 1 \% \text { is } \\
\text { reached; } 50 \% \text { of requirement from solar; Sierra Pacific given special treatment; rural electric co-ops, } \\
\text { general improvement districts, and others are exempted; with retail competition delay, also possible } \\
\text { that RPS will be delayed. }\end{array}$ \\
\hline New Jersey & $\begin{array}{l}\text { Class I or II technologies: } 2.5 \% \text { when Board of Public Utilities (BPU) adopts interim standards with } \\
\text { no sunset; Class I technologies: } 0.5 \% \text { in } 2001 ; 1 \% \text { by } 2006 ;+0.5 \% / y r \text { to } 4 \% \text { by } 2012 \text {. }\end{array}$ \\
\hline New Mexico & $\begin{array}{l}\text { Up to } 5 \% \text { for standard offer service by } 2002 \text { if it can be shown that renewable resources are } \\
\text { available in state and if cost of standard offer service does not increase; purchase requirement could } \\
\text { initially start at lower level. }\end{array}$ \\
\hline Pennsylvania & $\begin{array}{l}\text { For PECO, West Penn, and PP\&L, } 20 \% \text { of residential consumers served by competitive default } \\
\text { provider: } 2 \% \text { in } 2001 \text {, rising } 0.5 \% / y r \text {; for GPU, } 0.2 \% \text { in } 2001 \text { for } 20 \% \text { of customers, } 40 \% \text { of } \\
\text { customers in } 2002,60 \% \text { in } 2003,80 \% \text { in } 2004 \text { and thereafter. }\end{array}$ \\
\hline Texas & $\begin{array}{l}\text { Legislation establishes renewable energy capacity targets: } 1280 \mathrm{MW} \text { by } 2003 \text { increasing to } 2880 \\
\text { MW by } 2009 \text { ( } 880 \mathrm{MW} \text { of which is existing generation); RPS rule translates capacity targets into } \\
\text { energy purchase requirement percentages. }\end{array}$ \\
\hline Wisconsin & $0.5 \%$ by 2001 , increasing to $2.2 \%$ by 2011 (0.6\% can come from facilities installed before 1998$)$. \\
\hline
\end{tabular}

Source: Bolinger, Porter, and Wiser (August 2000). 
Table 9.3. State RPS Policies: Credit Multipliers and Out-of-State Resources.

\begin{tabular}{|c|c|c|}
\hline State & Credit Multipliers & Out-of-State Renewable Eligibility \\
\hline Arizona & $\begin{array}{l}\text { Various multipliers for early installation before } \\
2003 \text {; in-state installation or content; distributed } \\
\text { solar; net metering; and utility green pricing } \\
\text { programs. Credit multipliers are additive, to } \\
\text { maximum of } 2.0 \text { through } 2003 \text {. Retail provider } \\
\text { can offset } 1 / 2 \text { of RPS requirement in } 2001,1 / 4 \text { of } \\
\text { requirement in } 2002 \text { and } 2003 \text { if they invest in } \\
\text { Arizona solar manufacturing facility }\end{array}$ & $\begin{array}{l}\text { Out-of-state solar appears eligible; landfill gas, } \\
\text { wind and biomass must be in state }\end{array}$ \\
\hline Connecticut & None & Eligible \\
\hline Maine & None & $\begin{array}{l}\text { Eligible; energy must be delivered to the New } \\
\text { England (NE) ISO control area and meet load in } \\
\text { New England, or may in any way satisfy load } \\
\text { within the ISO-NE control area (for generation } \\
\text { under } 5 \mathrm{MW} \text { ); same provisions for the } \\
\text { Maritimes control area }\end{array}$ \\
\hline Massachusetts & None & Eligible \\
\hline Nevada & None & Not eligible \\
\hline New Jersey & None & $\begin{array}{l}\text { Generally eligible; Class II technologies must } \\
\text { come from states open to retail competition }\end{array}$ \\
\hline New Mexico & None & Ineligible \\
\hline Pennsylvania & Unspecified & Unspecified \\
\hline Texas & None & $\begin{array}{l}\text { Ineligible unless dedicated transmission line } \\
\text { into the state }\end{array}$ \\
\hline Wisconsin & None & Eligible \\
\hline
\end{tabular}

Source: Bolinger, Porter, and Wiser (August 2000). 
Table 9.4 State RPS policies: Resource eligibility and credit trading.

\begin{tabular}{|c|c|c|}
\hline State & Resource Eligibility & Credit Trading \\
\hline Arizona & $\begin{array}{l}\text { 2001-At least } 50 \% \text { solar electric-remainder from R\&D, } \\
\text { solar hot water, or other in-state landfill gas, wind, and } \\
\text { biomass. R\&D investments can reduce RPS target by up to } \\
10 \% \text {. } \\
\mathbf{2 0 0 2 - 2 0 0 3 - s a m e ~ a s ~} 2001 \text { except R\&D investments can } \\
\text { reduce RPS target by up to } 5 \% \text {. } \\
\mathbf{2 0 0 4 - 2 0 1 2 - A t ~ l e a s t ~} 60 \% \text { solar electric-remainder from } \\
40 \% \text { solar hot water and in-state landfill gas, wind, and } \\
\text { biomass }\end{array}$ & To be determined \\
\hline Connecticut & $\begin{array}{l}\text { Class I: solar, wind, new sustainable biomass, landfill gas, } \\
\text { and fuel cells; Class II: licensed hydro, municipal solid } \\
\text { waste (MSW), other biomass }\end{array}$ & $\begin{array}{l}\text { Law allows suppliers to satisfy } \\
\text { RPS by participating in credit } \\
\text { trading program approved by the } \\
\text { state, but state PUC indicates it } \\
\text { has no plan to establish credit } \\
\text { trading program. May allow } \\
\text { private entities to develop credit } \\
\text { trading system }\end{array}$ \\
\hline Maine & $\begin{array}{l}\text { Fuel cells, tidal, solar, wind, geothermal, hydro, biomass, } \\
\text { and MSW (under } 100 \mathrm{MW} \text { ); high-efficiency cogeneration of } \\
\text { any size; resource supply under this definition far exceeds } \\
\text { RPS-driven demand }\end{array}$ & $\begin{array}{l}\text { PUC decided against credit } \\
\text { trading to maintain consistency } \\
\text { with regional disclosure tracking } \\
\text { systems }\end{array}$ \\
\hline Massachusetts & $\begin{array}{l}\text { Solar, wind, ocean thermal, wave, tidal, fuel cells using } \\
\text { renewable fuels, landfill gas, waste-to-energy, hydro, low- } \\
\text { emission, and advanced biomass; waste-to-energy and } \\
\text { hydro cannot count toward new standard; new renewables } \\
\text { defined as those which begin commercial operation or } \\
\text { represent an increase in capacity at an existing facility after } \\
\text { December 31,1997; DOER can add technologies after } \\
\text { hearings }\end{array}$ & $\begin{array}{l}\text { The standard allows the use of a } \\
\text { tradable certificate mechanism, } \\
\text { annual settlement, and a limited } \\
\text { degree of banking (but only by } \\
\text { retail suppliers, not generators or } \\
\text { intermediaries) }\end{array}$ \\
\hline Nevada & $\begin{array}{l}50 \% \text { from new solar electric or solar thermal that offsets } \\
\text { electric use; new defined as installed and beginning } \\
\text { operations after July 1, 1997; } 50 \% \text { from wind, solar, } \\
\text { geothermal, and biomass energy resources that are } \\
\text { naturally regenerated in state }\end{array}$ & $\begin{array}{l}\text { Will be based on renewable } \\
\text { energy credits, if applicable; if } \\
\text { PUC establishes such a system, } \\
\text { credits will be issued to } \\
\text { renewable energy resources for } \\
\text { each kilowatt-hour produced }\end{array}$ \\
\hline New Jersey & $\begin{array}{l}\text { Class I: solar, PV, wind, fuel cells, geothermal, wave or } \\
\text { tidal, and methane }\left(\mathrm{CH}_{4}\right) \text { gas from landfills or a biomass } \\
\text { facility, provided that the biomass is cultivated and } \\
\text { harvested in a sustainable manner; Class II: hydro and } \\
\text { resource recovery facilities in states with retail competition; } \\
\text { draft RPS rule would limit hydro to under } 30 \mathrm{MW}\end{array}$ & $\begin{array}{l}\text { Electric suppliers may satisfy the } \\
\text { RPS by participating in a } \\
\text { renewable energy credit trading } \\
\text { program approved by the BPU; } \\
\text { draft RPS rule does not establish } \\
\text { such a system }\end{array}$ \\
\hline New Mexico & Wind, solar, geothermal, biomass, hydro, and fuel cells & Not addressed \\
\hline Pennsylvania & Unspecified & Unspecified \\
\hline Texas & $\begin{array}{l}\text { Solar, wind, geothermal, hydro, wave, tidal, biomass, } \\
\text { biomass-based waste products, landfill gas }\end{array}$ & $\begin{array}{l}\text { Texas is first state to establish } \\
\text { credit trading program; ERCOT } \\
\text { ISO selected as the program } \\
\text { administrator }\end{array}$ \\
\hline Wisconsin & $\begin{array}{l}\text { Wind, solar, biomass, geothermal, tidal, fuel cells that use } \\
\text { renewable fuel, hydro under } 60 \mathrm{MW} \text {; eligibility may be } \\
\text { expanded by PUC }\end{array}$ & $\begin{array}{l}\text { Legislation allows renewable } \\
\text { purchases to be satisfied through } \\
\text { the purchase of renewable } \\
\text { energy credits. Proposed rule } \\
\text { would reward credits only for } \\
\text { renewable energy generation } \\
\text { over RPS requirement. }\end{array}$ \\
\hline
\end{tabular}

Source: Bolinger, Porter, and Wiser (August 2000) and personal communication with Robert Grace of Sustainable Energy Advantage, LLC. 


\section{Texas REC Program}

The Texas PUC has appointed the ERCOT to administer an innovative program to promote the growth of renewable energy capacity in a way that will be both economically and environmentally beneficial. The REC program became effective on July 1,2001 . Under the program, renewable energy generators must register with ERCOT, which in turn prompts the creation of a REC account. RECs are created by the generators and reported to ERCOT in terms of megawatt-hour production. ERCOT then credits a number of RECs to the appropriate REC account, equal to the total megawatt-hours generated by the REC generators during the year. RECs may be transferred from one account to another by ERCOT and have a lifetime of three compliance periods.

Each year (beginning in 2003), ERCOT will allocate the statewide REC requirement for the previous year's compliance period among all competitive retailers in the state. Each retailer must then retire a number of RECs in its account to satisfy the compliance requirements for the year. RECs that are not used remain in the REC account and can be traded, sold, or used at any time until they expire. ERCOT will increase the new renewable energy capacity target to account for shortfalls resulting from RECs produced out of state and for capacity that has been retired from the program.

\section{Carbon Credit Trading}

In part because of the success of the EPA's emissions trading mechanisms, world leaders are now conceptualizing an international GHG emissions trading program. The objective of this program is to reduce GHG emissions such as $\mathrm{CO}_{2}$ and $\mathrm{CH}_{4}$ and, consequently, arrest the growth of emissions that might cause global warming. Under the 1997 Kyoto Protocol to the UNFCCC, developed countries agreed to GHG emissions limits. GHG credit and allowance trading concepts were constructed to complement more traditional command-and-control, negotiated limit, and voluntary programs that countries might use to achieve their commitments. These trading programs are targeted to work across countries and will complement domestic GHG trading programs.

The Kyoto Protocol provides for three trading mechanisms, called "flexibility mechanisms" or "Kyoto mechanisms." Each mechanism allows the exchange of a different type of credit or allowance among different sets of countries and uses a different type of currency to denote the emissions or emission reductions exchanged:

1. Emissions Trading (of Assigned Amounts) Under Article 17 of the Kyoto Protocol, emissions trading is an allowance-like (quotatrading) instrument. It is similar to allowance trading under the U.S. acid deposition control program. Emissions trading allows for the trade of "assigned amounts" among parties to the Kyoto Protocol. ("Parties" are countries of the so-called Annex I or industrialized countries. $)^{42}$ Virtually everyone agrees that legal entities, such as companies, could also trade assigned amounts.

2. Joint Implementation (JI)

This provision (Article 6), which is projectbased, allows GHG credits to be traded among the developed countries. Thus, investors in clean energy projects that exceed emission control obligations can obtain emission reduction units (ERUs). These ERUs (credits) can be used to offset domestic GHG control obligations or can be traded or banked for later use.

3. The Clean Development Mechanism (CDM) This credit-based trading mechanism, which is used in developing countries, is described in Article 12 of the Kyoto Protocol. CDM-based trading takes place between an investor from an Annex I country and a project host in a nonAnnex I country. Although CDM-based reductions (CERs) are like JI-based ERUs, CDMbased trading contains unique uncertainties that, as of this writing, were not yet resolved. The CDM holds out the potential for highquality and low-cost carbon credits. In addition, many people would like to see CDMcredit giving focus on wind and other renewable forms of energy.

An important feature of the CDM is the ability to bank ERCs from projects carried out between 2000 and 2008. These reductions can then be credited toward emission obligations for the 2008-2012 commitment period.

\footnotetext{
42 Annex I = 38 industrialized countries that signed the Kyoto Protocol of 1997, which adopted caps on emissions to be achieved by the first budget period of 2008-2012.
} 
Although the Kyoto Protocol has yet to be ratified by enough countries to make it legally binding, a nascent carbon trading market has developed which has attracted interest and anticipation from many would-be carbon traders. To date, several reduction transactions have taken place. Some form of market-based system for controlling global GHG levels is expected to eventually emerge.

The United States signed the Kyoto Protocol last year, but it has not yet been presented to the U.S. Senate for ratification. Despite the apparent reluctance of the U.S. Congress to ratify the treaty, the market for carbon offsets is becoming active at the state and international level. Already, several international transactions of carbon offsets have taken place (see Table 9.7).

\section{PART II: CREDITS ARISING FROM VOLUNTARY MARKETS}

Although forward transactions, option transactions, and trades or reductions do not fit under any of the three Kyoto mechanisms, they have all taken place. As discussed above, the United States has a number of programs or proposals that recognize voluntary actions to curb carbon emissions. Canada and the European Union (EU) also have such programs or proposals, described briefly below. All are intended to focus on recognizing voluntary action to curb carbon emissions and to capitalize on the potential for carbon offset trading in anticipation of the Kyoto Protocol or other future emissions limitations.

Canada, for example, has instituted a voluntary registry of GHG reduction projects and may adopt a mandatory regime very shortly. A Canadian carbon emissions credit exchange, known as the $\mathrm{KEFI}$ exchange, is actively operating as a credit instrument to offset emission reduction obligations, which could arise during the Kyoto compliance period. In fact, several transactions of carbon offset credits have been documented in Canada. For example, TransAlta (a Canadian utility) recently purchased 24,000 tons of wind project offsets from a German electric utility and has issued an openended request for proposals for purchasing projectbased carbon offsets (see http://www.transalta.com). Ontario Hydro has posted a similar request for proposals. Finally, there are also examples of sales of U.S.-based carbon credits to Canadian buyers. For example, Ontario Hydro purchased credits from Southern California Edison, and from a landfill gas $\mathrm{CH}_{4}$ recovery project. A consortium of Canadian companies, called GEMCO, purchased alternative agriculturebased reductions from a farm bureau in lowa.

Most of the domestic initiatives endorsed by the federal government are voluntary so far. Two examples are DOE's Climate Challenge Program under the Voluntary Reporting of Greenhouse Gases Program of Section 1605(b) of the Energy Policy Act (EPAct) of 1992, which tracks emission reduction measures taken by utilities; and the EPA's Climate Wise Program, which provides technical assistance on carbon emissions audits and analysis. However, we are also seeing some individual states beginning to adopt state-level policies. Many believe that the domestic market will accelerate in the near- to medium-term as the implications of state-level regulations take hold and as other states follow suit. For example, in Oregon the state PUC has mandated the creation of the OCT, which is funded by electricity generators in Oregon. The OCT procures project-based carbon credits to offset the GHG emissions generated by utilities in the state. Very recently, the governor of New Jersey announced a mandatory plan to reduce the state's GHG emissions to the levels outlined in the Kyoto Protocol by 2005, 3 years earlier than the protocol stipulates. We discuss these initiatives in greater detail below.

In the United States, regulation at the federal level may only be a matter of time. Several members of Congress have recently taken steps to introduce legislation aimed at curbing GHG emissions. The most advanced initiatives are Senate Bill S.2617, introduced by Republican Senators Chafee, Mack, and Lieberman, and Senate Bill 547, introduced by Representatives Lazio and Dooley. Senate Bill 547 would amend the Clean Air Act to encourage early action to reduce GHGs and guarantee credit that can be applied against mandatory limits imposed later. These proposals also include language that would allow credits earned through additional reduction efforts to be sold through a trading mechanism.

Currently, three basic levels of policy are related to climate change and carbon offsets:

- Evolving state requirements in Oregon, New Jersey, and Massachusetts;

- The national policy context, which includes voluntary programs and senate proposals; 
- The international framework under the Kyoto Protocol, and the option to trade carbon credits.

\section{Climate Challenge}

DOE established the Climate Challenge Program in collaboration with the electric utility industry as a mechanism under the voluntary reporting of GHG emissions guidelines, Section 1605(b) of EPAct, for identifying and implementing activities that can reduce, avoid, or sequester GHGs. Utilities participating in the program must sign a contractual agreement with DOE, committing them to one or more of six types of emission reduction commitments, depending on their size, resource mix, load growth, and other issues. In addition, they must report annually to DOE on their progress. Activities that utilities can undertake include energy efficiency improvements, fuel switching (including switching to renewables), transportation actions, forestry projects, and $\mathrm{CH}_{4}$ recovery. In 1997, Climate Challenge participants conducted the first market-based trade of 1.75 tons of carbon reductions from Niagara Mohawk Power Corporation. The carbon reductions were exchanged for 25,000 tons of $\mathrm{SO}_{2}$ allowances from Arizona Public Service Company. Niagara Mohawk donated the $\mathrm{SO}_{2}$ allowances to a nonprofit environmental organization to be retired.

Utility participants have embraced the program for several reasons. First, it is thought that strong voluntary participation resulting in real improvement in GHG emissions may effectively negate the need for regulated emissions caps. Second, as credit for voluntary early action proposals are introduced and possibly enacted, participation in the program may yield future credits for emissions reduction measures taken now. Third, improvements in operating efficiency and other measures to reduce GHG emissions often result in significant cost savings for the utility. Finally, the participants are able to use their participation as a good neighbor marketing and public relations boost.

Climate Challenge currently has 124 participants among electric utilities and their subsidiaries. DOE estimates that the currently reported commitments from these utilities will result in carbon emission reductions of more than 47.6 million tonnes of carbon equivalent in the year 2000.

\section{Climate Wise}

The Climate Wise Program, a government-industry partnership sponsored by the EPA, DOE, and state and local government officials, focuses on supplying technical assistance to private sector companies in implementing emission reduction measures to position them for potential future emission regulations. To participate, companies must sign a partnership agreement, deliver an action plan that outlines specific energy efficiency and pollution prevention measures within 6 months, and report results each year. Climate Wise assists participants with collecting emissions data and creating action plans, identifying possible regional resources through state and county programs, and estimating energy savings and GHG emissions reductions. Climate Wise also offers a variety of business and peer exchange workshops and opportunities to get involved in other government industry partnerships, such as EnergyStar, Waste Wi\$e, and MotorChallenge.

\section{The Oregon Climate Trust}

The OCT was developed as a result of a groundbreaking law enacted by the state of Oregon in 1997. House Bill 3283 was the first state-level legislation to present a meaningful measure to control $\mathrm{CO}_{2}$ emissions. The bill required all new energy facilities built in the state to implement measures to avoid, displace, or sequester a portion of their $\mathrm{CO}_{2}$ emissions in an amount equal to $17 \%$ less $\mathrm{CO}_{2}$ than the least-polluting plant operating in the United States (for gas-fired plants). New plant developers may choose to meet this obligation by contributing funds to a qualified nonprofit that in turn invests in carbon reduction or sequestration projects.

The OCT was set up as a qualified nonprofit that meets the requirement of House Bill 3283, with the sole purpose of investing in carbon offset projects. The OCT's first priority is to effectively meet the requirements of the law, but additional objectives include promoting and undertaking projects that offset emissions from other sources and offering education programs to increase the general understanding of climate change in the state.

The trust will seek to develop and invest in projects and new technologies that reduce or offset carbon emissions. The OCT is already actively engaged in identifying a range of activities that it will invest in to contribute to its portfolio of projects. 


\section{New Jersey's Sustainability Greenhouse Gas Action Plan}

In April of 2000, Governor Christine Todd Whitman of New Jersey announced an ambitious goal to reduce the state's GHG emissions by $3.5 \%$ below 1990 levels by 2005, 3 years before the Kyoto Protocol deadline. The announcement is significant, not only as an act of environmental commitment, but also as a direct act of state commitment toward the goals of the Kyoto Protocol, independent of any federal mandate or even U.S. participation in the treaty. New Jersey's plan calls for "no regrets" strategies including measures and technologies that are already readily available and have proven to pay for themselves in the short term.

\section{Other Voluntary Emissions Trading Activities}

Several additional programs, described below, may or may not include emissions credit trading, but are thought to have a potential impact on the wind industry.

Although the EPA's emissions trading programs are primarily focused on achieving the NAAQS in nonattainment areas, some states already in compliance with the NAAQS have developed voluntary emissions trading systems and marketbased incentive programs for renewable energy and energy conservation programs. These types of programs are primarily focused on using the market to encourage emissions reductions in anticipation of future clean air mandates.

For example, Michigan is currently developing a voluntary, open-market Air Emissions Trading Program for VOCs and all criteria pollutants except ozone. The program allows all stationary area and mobile sources to earn ERCs by reducing what is required to comply with an existing emission standard based on historical operations.

The program more or less blends the concepts of offset trading and allocation programs, in that the ERCs earned can be used to offset new emissions at another source, through a process called emission averaging, or they can be traded or sold in a local market. However, because it is a voluntary program, an emission budget is not divided among sources and sources are not required to hold allocation permits equal to their total emissions at the end of the year. In addition, the ERCs earned in the program cannot be used to meet compliance with other emissions regulations in Michigan, such as New Source Performance Standards, Maximum Achievable Control Technology standards, National Emission Standards for Hazardous Air Pollutants, and Best Available Control Technology for Toxic Air contaminants.

Another program under development at the local level is a voluntary cross-border emissions trading program between the cities of El Paso, Texas, and Ciudad Juarez, Mexico. The program would allow El Paso Electric Company to purchase air ERCs from Mexican companies to expand operations on the U.S. side of the airshed. This would be the first cross-border trading scheme with Mexico. The environment benefits because the utility would need to obtain more credits to offset emissions than current regulations stipulate.

\section{Green Tags}

Because producing renewable energy is generally more costly than generating energy from conventional fossil fuels, the concept that the environmental benefit of renewable energy can be captured and commercialized to offset the additional cost of production has led to the advent of green tags or green certificates programs. Green tags are based on the idea that two distinct products are derived from renewable energy power production-electricity and an environmental benefit. If the environmental benefit portion of renewable energy can be stripped away from and sold independently of the electricity component, renewable energy generators can operate more economically and compete with more traditional energy generators. The electricity from the project is then sold independently of the green tag as standard power. This is the key difference between green tags and green pricing or green power programs. ${ }^{43}$ In a green pricing program, consumers purchase their base electricity and green electricity (assuming they're not buying 100\% green) from the same regulated supplier. ${ }^{44}$ In a green tag purchase, consumers can continue to buy electricity from their existing supplier, but can purchase the green tags in a separate transaction, usually from a

\footnotetext{
${ }^{43}$ Green pricing takes place in a regulated utility context; green power takes place where consumers have a choice.

${ }^{44}$ The green power purchase may be on a separate tariff filed by the supplier and be accounted for separately from the standard electricity purchase.
} 
different supplier. One advantage of green tags over green pricing programs is that buyers can purchase the environmental benefits even if they are not within an area that supports a green pricing or green power program.

BEF sponsors the most developed green tags program in the United States. The program derives the majority of its power from existing renewable energy facilities. The funds generated from BEF's Green Tags program go directly to the development of new renewable energy facilities.

BPA also offers a program, called the Conservation and Renewable Discount, to its wholesale customers, including utilities and certain federal agencies. Beginning in October 2001, BPA will offer a dollar-for-dollar match on what the customer spends on conservation measures and renewable energy during a 5-year rate period up to a capped total per customer equal to 0.05 mills/kWh of the customer's load, through a discount on the consumer's power bills. Customers qualify for the discount by implementing an energy conservation program, through the purchase of renewable energy resources, by making a contribution to BEF, or by purchasing environmentally preferred power from BPA.

\section{PureWind $^{\mathrm{TM}}$}

PG\&E's PureWind program is a strictly voluntary approach to supporting new renewable energy development in regions lacking access to local green energy pricing programs. PG\&E's program falls under a tradable tags element of New York's generation disclosure rules legislation (see discussion on generation disclosure below). Essentially a green tags program that services a specific renewable energy facility, PureWind sells the attributes of renewable energy without actually consigning renewable energy to the purchaser. The first PureWind facility is the Madison Windpower Facility in Madison, New York, an 11.5-MW wind farm that is the largest in the eastern United States. The facility generates wholesale electricity and delivers it to the New York independent system operator grid. For every megawatt-hour of electricity delivered to the ISO, one PureWind certificate is created. Participants can purchase those certificates in whatever quantity of megawatthours they wish to support. Customers own the environmental attributes of the certificates they purchase, including any future emissions credits that may be created under regulatory authorities. PG\&E is targeting large industrial and commercial customers; Kinko's was the first to sign up, committing to $50 \%$ of its statewide electricity demand.

\section{Cleaner and Greener Emission Reduction Credits}

The Cleaner and Greener program was developed by the Leonardo Academy in Wisconsin under state and federal funding to look at the development of a multi-pollutant reporting system. The Leonardo Academy accepts tax-deductible contributions from individuals (and presumably corporations), which it then uses to purchase and retire emission reduction credits of various types. The academy purports to sell these credits to anyone in any location in the United States. The Academy's Web site includes a pollution "calculator" to help a contributor figure out how much pollution they produce and how much it would cost to offset any percentage of multiple of their annual emissions. (See

www.cleanerandgreener.org for more details.)

\section{Green Pricing Programs}

Green pricing programs offer consumers who get their power from regulated, franchised utilities the option of paying a premium for the purchase of clean energy. Green pricing programs have become so widespread that they have essentially created a new market for clean energy. States can include provisions or requirements for green pricing programs under restructuring legislation or as part of revisions to other regulations that apply to utilities, and several states have done so. Utilitysponsored green pricing programs are now available in many U.S. regions; most focus on a single technology or renewable energy source. Although there are vast differences in the programs offered, most have enjoyed greater than expected participation from consumers.

Several good examples of successful green pricing programs focused on wind power can be found all over the country. Some of the more notable programs are Colorado's WindSource and Wind Power Pilot programs, which recently won the largest commitment ever by federal agencies to purchase wind power; the ClearChoice Program in Texas, Minnesota's Wellspring Program, the Green Rate program sponsored by Traverse City Light and Power in Michigan; Oregon's Renewable Energy 
Supply program; and California's Greenergy program.

Green pricing programs currently involve purchase of green energy at a premium but could also be structured to include purchase of credits.

\section{Emission Reduction Credit Registry System}

Many states have voluntary registries and trading programs that have grown out of the New Source Review program (addressed earlier in this chapter). As an example, the Pennsylvania Department of Environmental Protection maintains a voluntary registry system for emissions reductions in $\mathrm{NO}_{\mathrm{x}}$, VOCs, and criteria pollutants. Generators may submit applications for certification for projects that reduce emissions beyond the regulatory requirements as long as the emissions reductions can be recorded and tracked. The quantified emission reductions are assigned ERCs, expressed in tons per year. Registration of the credits in the ERC registry system constitutes certification that the ERCs satisfy all the pertinent requirements and are available for use. ERCs can be used to satisfy NSR emission offset ratio requirements or can be traded or sold. Worth noting is Pennsylvania's program, which contains a directional component about the transfer of credits. ERCs can be transferred from a dirtier area to a cleaner area, but may not be transferred from a cleaner area to a dirtier area. In other words, if ERCs are created outside the fivecounty Philadelphia region nonattainment area, they may not be purchased by any entity within that region. A similar program in New York tracks all ERCs available to sources from New York, Pennsylvania, and Connecticut.

\section{Green-e Program}

As a response to the differences in the quality of programs and the lack of an overarching oversight system, the Center for Resource Solutions has developed the National Accreditation Initiative for green pricing programs. The program's stakeholders (environmental organizations, utilities, and consumer protection advocates) established a set of minimum standards that green pricing programs must meet before they can be accredited. Initially, the program was has been established in just two states, but it has recently been expanded into the Midwest and the East. To date, the organization has recognized three green pricing programs: Wisconsin Electric's Energy for Tomorrow Program, the Tennessee Valley
Authority's Green Power Switch, and Madison Gas \& Electric's (MGE) WindPower program.

The Green-e Program is a certification and verification program for green electricity. The program offers a way for consumers in areas with retail electricity choice options to easily identify clean electricity. Renewable energy generators who voluntarily submit fuel mix data to the Green-e Program can be certified as green by meeting several specific criteria: (1) at least $50 \%$ of their electricity supply must come from renewable sources; (2) the electricity does not contain any nuclear power other than what is contained in the system; and (3) any nonrenewable part of the supply has lower air emissions than the traditional electricity mix has. In addition, the product must contain at least $5 \%$ new renewable electricity after the first year of deregulation, $10 \%$ in the next year, and $5 \%$ each year thereafter until $25 \%$ of the total product content is generated from new renewable energy sources.

Electricity products that meet the above criteria are adorned with the official Green-e logo, certifying that it is a green power product. The Green-e program currently operates in California, Pennsylvania, Connecticut, Massachusetts, and New Jersey and will expand to other states as their electricity markets deregulate.

\section{Generation Disclosure}

Under some restructuring programs, states are requiring utilities to provide information to consumers on the resource mix from which their power is derived. Along with green pricing and accreditation programs, generation disclosure is intended to protect consumers and to allow customers to make informed energy purchase choices.

One example of early generation disclosure legislation is the New England Information Disclosure Project, which is part of a larger, more comprehensive information disclosure research project of The National Council on Competition in the Electric Industry. The program requires that utilities furnish uniform information disclosure for retail electricity sales throughout New England using a label that is informative, succinct, easily understood, and widely available. The NECPUC developed a model rule that outlines the guidelines for commissions developing information disclosure policies in the region. 
The California Energy Commission (CEC) recently enacted the Certificates of Generation pilot program, which requires that suppliers document their generation sources on a "power content" label. Generators submit documentation to the commission using CEC-approved software called Genreport, which then acts as a certificate that specifies the particular generation facilities from which the generator's power is derived. For renewable energy generators, these certificates can be a marketing tool and can also document that they are making accurate claims about renewable resources. The final regulations for the program are still being developed, and several other western states are also considering similar legislation. It is anticipated that within a few years the program could expand to include all the states that belong to the Western States Coordinating Council and may include an element of tradable certificates, similar to green tags.

\section{Generation Performance Standard}

A GPS is essentially an emissions benchmark to be met either by generators or retail suppliers. It is one of a new breed of output-based pollution control mechanisms that set maximum emissions on a unit of weight per kilowatt-hour basis. It is often conceived of in combination with other regulations to help plug loopholes and ensure that emission reduction goals are achieved. For instance, Connecticut's stated rationale for adoption was as a stop-gap measure while the NOx SIP Call was being challenged in the courts. It is intended to be placed on retail suppliers on a portfolio basis (all plants on average).

NESCAUM has supplied a model rule that was proposed largely intact in Connecticut legislation; Massachusetts and New Jersey legislation calls for development of a GPS (New Jersey's is contingent on action in other states). Attributes are defined only as regulated pollutants (not all emissions) and are those related to load obligations in the state. At the end of each reporting period, covered firms must submit load and emissions data using an acceptable methodology. Program administrators then compare those data with the standard(s) for covered pollutants. The state uses a data collection and verification system to match generation and attributes to end users. If the emissions rate(s) of a supplier's portfolio is(are) found in excess of the standard(s), the supplier must reduce the following year's emissions by at least the level of excess. Although credit trading is not explicitly allowed, it could be, if approved by the state. Credits could be generated by coming in below the standard(s) and then could be either kept for future compliance (for a limited period) or sold. The model rule proposes standards for $\mathrm{SO}_{2}, \mathrm{NO}_{x}$, and $\mathrm{CO}_{2}$ (see Table 9.5). Standards for mercury and $\mathrm{CO}$, required by the Connecticut legislation, have been deferred pending data review. Implementation of GPS regulations in Connecticut is contingent on their adoption in neighboring states. Consistent rules among states in the region are expected to reduce regulatory burdens on retail suppliers (particularly those who operate in multiple states), facilitate compliance determination, and help to avoid double counting.

Table 9.5 The NESCAUM Model Rule Standards.

\begin{tabular}{|l|l|}
\hline Pollutant & Pounds per Megawatt-Hour \\
\hline $\mathrm{NO}_{x}$ & 1 \\
\hline $\mathrm{SO}_{2}$ & 4 \\
\hline $\mathrm{CO}_{2}$ & 1,100 \\
\hline Mercury & Deferred \\
\hline $\mathrm{CO}$ & Deferred \\
\hline
\end{tabular}

\section{System Benefits Charges}

Policy makers developed SBCs as a way to collect funds from utility consumers to support various public benefit programs, such as renewable energy and energy conservation initiatives. SBCs are typically imposed as an added fee on electricity usage (generally on a per-kilowatt-hour basis). Like renewable portfolio standards, the policies (see Table 9.6), scopes, eligible technologies, and administrative practices for SBCs differ significantly from one state to another. In the coming decade, something on the order of $\$ 2.8$ billion will be available to support clean energy from SBCs as a result of electric restructuring (Milford 2000). Other estimates show as much as $\$ 3.7$ billion of spending on renewables between 1998 and 2012, which could drive as much as 3,000 new megawatts of renewables by the end of that period (Steve Clemmer, UCS, personal communication, November 2000). SBCs may be the largest source of new funding for wind and other clean energy technologies during the next 10 years. 
Table 9.6. SBC Policies.

\begin{tabular}{|c|c|c|c|c|c|c|}
\hline State & Program & Surcharge & $\begin{array}{l}\text { Total Funding } \\
\text { (million \$) }\end{array}$ & $\begin{array}{l}\text { Date } \\
\text { Enacted }\end{array}$ & $\begin{array}{l}\text { Time } \\
\text { Horizon }\end{array}$ & Notes \\
\hline Connecticut & SBC & & $\begin{array}{l}\$ 14 / y r \text { in } \\
2000 ; \$ 30 / y r \\
2004+\end{array}$ & 2000 & 5 years & $\begin{array}{l}\text { Connecticut Clean Energy } \\
\text { Fund will take primary } \\
\text { equity positions in green } \\
\text { power projects, companies } \\
\text { or projects that build } \\
\text { demand for green power, } \\
\text { and companies that market } \\
\text { clean energy technologies }\end{array}$ \\
\hline California & $\begin{array}{l}\text { Non- } \\
\text { bypassable } \\
\text { distribution } \\
\text { charge }\end{array}$ & & $\$ 540$ & 1998 & 4 years & $\begin{array}{l}\text { Provides } \$ 540 \text { million in } \\
\text { rate subsidies for RE } \\
\text { projects to enable them to } \\
\text { compete with conventional } \\
\text { sources }\end{array}$ \\
\hline Delaware & SBC & & $\begin{array}{l}\$ 1.5 / y r \text { for } E E \text {, } \\
\text { unknown for } \\
\text { RE }\end{array}$ & & & \\
\hline Illinois & $\begin{array}{l}\text { Renewable } \\
\text { Energy } \\
\text { Resources } \\
\text { Trust Fund }\end{array}$ & $\begin{array}{l}\text { Flat fee of } \$ 0.50 \text { per } \\
\text { month residential } \\
\text { and small } \\
\text { commercial; } \\
\$ 37.50 / \text { month large } \\
\text { commercial }\end{array}$ & $\$ 100$ & 1997 & 10 years & $\begin{array}{l}\text { Supports photovoltaic, solar } \\
\text { thermal, wind, small } \\
\text { hydropower, and other } \\
\text { alternative energy projects }\end{array}$ \\
\hline Oregon & & $3 \%$ & & 2001 & & $\begin{array}{l}\text { Associated green pricing } \\
\text { program }\end{array}$ \\
\hline Massachusetts & $\begin{array}{l}\text { Renewable } \\
\text { Energy Trust } \\
\text { Fund }\end{array}$ & $\begin{array}{l}\$ 750,0001998 ; \$ 1 \\
\text { million 1999; } \\
\$ 250,0002000 ; \$ 1 \\
\text { million 2001; } \\
\$ 750,0002002 ; \\
\$ 200,000 \text { thereafter }\end{array}$ & $\begin{array}{l}\$ 150, \$ 45 / y r \\
\text { for } 5 \text { years }\end{array}$ & 1997 & 5 years & $\begin{array}{l}\text { Massachusetts is the first } \\
\text { state to have enacted both } \\
\text { an SBC and RPS }\end{array}$ \\
\hline Montana & $\begin{array}{l}\text { Universal } \\
\text { System } \\
\text { Benefits } \\
\text { Program } \\
\end{array}$ & $\begin{array}{l}\text { Suppliers contribute } \\
2.4 \% \text { of } 1995 \\
\text { revenues to SBC }\end{array}$ & $\begin{array}{l}\text { \$14/yr for EE, } \\
\text { RE, R\&D }\end{array}$ & 1999 & 4 years & $\begin{array}{l}\text { Includes } 17 \% \text { allocation to } \\
\text { low- income assistance and } \\
\text { weatherization program }\end{array}$ \\
\hline New Jersey & SBC & & $\begin{array}{l}\$ 32 / y r \text { from } \\
2000-2007\end{array}$ & & & \\
\hline New Mexico & SBC & & $\$ 4 / \mathrm{yr}$ for $\mathrm{RE}$ & & & \\
\hline Oregon & SBC & & $\begin{array}{l}8.7 / y r, 3 \\
\text { years }\end{array}$ & & & \\
\hline Pennsylvania & SBC & & $\begin{array}{l}\$ 25 \text { over } 5 \\
\text { years }\end{array}$ & & & \\
\hline Rhode Island & SBC & $\$ 2.3$ million/ kWh & $\$ 17 / y r$ & 1996 & 5 years & $\begin{array}{l}\text { Funds support existing } \\
\text { demand side management } \\
\text { programs with small ( } \$ 1 \\
\text { million in 1998) budget to } \\
\text { go toward renewable } \\
\text { energy programs }\end{array}$ \\
\hline Wisconsin & SBC & & $\$ 3 / y r$ & & & \\
\hline
\end{tabular}

Source: Bolinger, Porter, and Wiser (August 2000). 
Table 9-7. Publicly Known $\mathrm{CO}_{2}$ Trades to Date

\begin{tabular}{|c|c|c|c|c|c|c|c|}
\hline Seller & Buyer & $\begin{array}{l}\text { Location } \\
\text { of Project }\end{array}$ & Type & $\begin{array}{l}\text { Quantity } \\
\text { mt = metric } \\
\text { ton }\end{array}$ & $\begin{array}{l}\text { Project } \\
\text { Cost (\$) }\end{array}$ & $\begin{array}{l}\$ / \text { metric ton } \\
(\mathrm{mt}) \text { of } \mathrm{CO}_{2}\end{array}$ & Date \\
\hline $\begin{array}{l}\text { Fondo Bio- } \\
\text { Climático }\end{array}$ & $\begin{array}{l}\text { Fédération } \\
\text { Internationale } \\
\text { de } \\
\text { l'Automobile }\end{array}$ & $\begin{array}{l}\text { Chiapas, } \\
\text { Mexico }\end{array}$ & $\begin{array}{l}\text { Forestry } \\
\text { (conservation) }\end{array}$ & $\begin{array}{l}5,000 \mathrm{mt} \text { of } \\
\mathrm{CO}_{2}\end{array}$ & 50,000 & $\begin{array}{l}\$ 10 / \mathrm{mt} \text { of } \\
\mathrm{CO}_{2}\end{array}$ & $\begin{array}{l}\text { February } \\
1997\end{array}$ \\
\hline $\begin{array}{l}\text { Northeast } \\
\text { Utilities }\end{array}$ & GEMCo & $\begin{array}{l}\text { Groton, } \\
\text { United } \\
\text { States } \\
\end{array}$ & $\begin{array}{l}\text { Renewable } \\
\text { (landfill gas }\left[\mathrm{CH}_{4}\right] \\
\text { to power fuel cell) }\end{array}$ & $\mathrm{n} / \mathrm{a}$ & $\mathrm{n} / \mathrm{a}$ & & July 1997 \\
\hline Costa Rica & $\begin{array}{l}\text { Centre } \\
\text { Financial } \\
\text { Products }\end{array}$ & Costa Rica & $\begin{array}{l}\text { Forestry } \\
\text { (reforestation) }\end{array}$ & $\begin{array}{l}1,000 \mathrm{mt} \text { of } \\
\text { carbon; up to } \\
200,000 \mathrm{mt} \\
\text { of carbon }\end{array}$ & $\mathrm{n} / \mathrm{a}$ & & 1997 \\
\hline $\begin{array}{l}\text { Niagara } \\
\text { Mohawk } \\
\text { Power }\end{array}$ & $\begin{array}{l}\text { Suncor } \\
\text { Energy }\end{array}$ & & $\begin{array}{l}\text { Renewable, } \\
\text { energy efficiency, } \\
\text { fuel switching }\end{array}$ & $\begin{array}{l}100,000 \mathrm{mt} \text { of } \\
\mathrm{CO}_{2} \\
\text { equivalent, up } \\
\text { to } 10 \text { million } \\
\mathrm{mt}\end{array}$ & $\mathrm{n} / \mathrm{a}$ & & $\begin{array}{l}\text { March } \\
1998\end{array}$ \\
\hline $\begin{array}{l}\text { Southern } \\
\text { California } \\
\text { Edison (SCE) }\end{array}$ & $\begin{array}{l}\text { Ontario } \\
\text { Hydro }\end{array}$ & $\begin{array}{l}\text { California, } \\
\text { United } \\
\text { States }\end{array}$ & $\mathrm{n} / \mathrm{a}$ & $\begin{array}{l}10,000 \mathrm{mt} \text { of } \\
\mathrm{CO}_{2}\end{array}$ & $\$ 40,000$ & $\$ 4 / \mathrm{mt}$ of $\mathrm{CO}_{2}$ & 1997 \\
\hline $\begin{array}{l}\text { American } \\
\text { Electric } \\
\text { Power, BP } \\
\text { America, } \\
\text { Pacific } \\
\text { Corp., } \\
\text { Bolivian } \\
\text { government }\end{array}$ & $\begin{array}{l}\text { United States } \\
\text { and Bolivia }\end{array}$ & & $\begin{array}{l}\text { Forestry } \\
\text { (reforestation) }\end{array}$ & $\begin{array}{l}16 \text { million } \mathrm{mt} \\
\text { of } \mathrm{CO}_{2} \\
\text { equivalent }\end{array}$ & $\begin{array}{l}\$ 9.5 \\
\text { million }\end{array}$ & & $\begin{array}{l}\text { March } \\
1998\end{array}$ \\
\hline $\begin{array}{l}\text { Unified } \\
\text { Energy } \\
\text { System }\end{array}$ & Sumitomo & Russia & $\begin{array}{l}\text { Fuel Switching } \\
\text { (coal to natural } \\
\text { gas) }\end{array}$ & $\begin{array}{l}\text { Up to } 10 \\
\text { million mt of } \\
\mathrm{CO}_{2} \text { equivalent } \\
\text { per year }\end{array}$ & $\mathrm{n} / \mathrm{a}$ & & $\begin{array}{l}\text { March } \\
1998\end{array}$ \\
\hline $\begin{array}{l}\text { Zahren } \\
\text { Alternative } \\
\text { Power Corp. } \\
\text { (ZAPCO) } \\
\end{array}$ & $\begin{array}{l}\text { Ontario } \\
\text { Power } \\
\text { Generation }\end{array}$ & $\begin{array}{l}\text { United } \\
\text { States }\end{array}$ & $\begin{array}{l}\text { Renewable } \\
\text { (landfill gas) }\end{array}$ & $\begin{array}{l}2.5 \text { million } \\
\text { mt of } \mathrm{CO}_{2} \\
\text { equivalent } \\
\text { per year }\end{array}$ & $\mathrm{n} / \mathrm{a}$ & & $\begin{array}{l}\text { October } \\
1999\end{array}$ \\
\hline $\begin{array}{l}\text { lowa Farmers } \\
\text { organized by } \\
\text { IGF } \\
\text { Insurance } \\
\text { Company }\end{array}$ & $\begin{array}{l}\text { GEMCo } \\
\text { Consortium } \\
\text { Members (7) }\end{array}$ & lowa, USA & Agriculture & $\begin{array}{l}2.8 \text { million } \\
\mathrm{mt} \mathrm{CO}_{2} \\
\text { equivalent }\end{array}$ & $\mathrm{n} / \mathrm{a}$ & & $\begin{array}{l}\text { October } \\
1999\end{array}$ \\
\hline Transalta & $\begin{array}{l}\text { Hamburgisch } \\
\text { e Electricitats- } \\
\text { Werke AG } \\
\text { (HEW) }\end{array}$ & Germany & $\begin{array}{l}\text { Renewable (wind } \\
\text { power) }\end{array}$ & $\begin{array}{l}24,000 \mathrm{mt} \\
\mathrm{CO}_{2} \\
\text { equivalent }\end{array}$ & $\mathrm{n} / \mathrm{a}$ & & $\begin{array}{l}\text { June } \\
2000\end{array}$ \\
\hline $\begin{array}{l}\text { Switzerland } \\
\text { and EBRD }\end{array}$ & $\begin{array}{l}\text { Switzerland } \\
\text { and Romania }\end{array}$ & & $\begin{array}{l}\text { Energy Efficiency } \\
\text { (district heat } \\
\text { Systems) }\end{array}$ & $\begin{array}{l}140,000 \mathrm{mt} \\
\text { of } \mathrm{CO}_{2}\end{array}$ & $\$ 640,000$ & $\begin{array}{l}\$ 4.57 / \mathrm{mt} \\
\mathrm{CO} 2\end{array}$ & 1998 \\
\hline $\begin{array}{l}\text { ICE (Costa } \\
\text { Rican Utility) } \\
\text { \& EDON } \\
\text { (Dutch } \\
\text { Utility) }\end{array}$ & $\begin{array}{l}\text { Costa Rica } \\
\text { and the } \\
\text { Netherlands }\end{array}$ & & $\begin{array}{l}\text { Renewable (wind } \\
\text { power) }\end{array}$ & & $\begin{array}{l}\$ 4.5 \\
\text { million }\end{array}$ & & $\begin{array}{l}\text { February } \\
2000\end{array}$ \\
\hline
\end{tabular}


Table 9-7. Publicly Known $\mathrm{CO}_{2}$ Trades to Date (continued)

\begin{tabular}{|c|c|c|c|c|c|c|c|}
\hline Seller & Buyer & $\begin{array}{l}\text { Location } \\
\text { of Project }\end{array}$ & Type & $\begin{array}{l}\text { Quantity } \\
\mathrm{mt}=\text { metric } \\
\text { ton }\end{array}$ & $\begin{array}{l}\text { Project } \\
\text { Cost }(\$)\end{array}$ & $\$ / \mathrm{mt}$ of $\mathrm{CO}_{2}$ & Date \\
\hline $\begin{array}{l}\text { State Forest } \\
\text { of New } \\
\text { South Wales, } \\
\text { Australia }\end{array}$ & $\begin{array}{l}\text { Tokyo } \\
\text { Electric } \\
\text { Power }\end{array}$ & Australia & $\begin{array}{l}\text { Forestry } \\
\text { (reforestation) }\end{array}$ & $\begin{array}{l}\mathrm{n} / \mathrm{a}(10,000 \\
\text { hectares of } \\
\text { forest })\end{array}$ & $\begin{array}{l}\$ 18.9 \\
\text { million }\end{array}$ & & $\begin{array}{l}\text { February } \\
2000\end{array}$ \\
\hline Enmax & $\begin{array}{l}\text { Environment } \\
\text { Canada and } \\
\text { Natural } \\
\text { Resources } \\
\text { Canada } \\
\text { (representing } \\
\text { the Canadian } \\
\text { government) }\end{array}$ & $\begin{array}{l}\text { Alberta, } \\
\text { Canada }\end{array}$ & $\begin{array}{l}\text { Renewable (wind } \\
\text { power) }\end{array}$ & $\begin{array}{l}427 \mathrm{mt} \text { of } \\
\mathrm{CO}_{2} \text { from } \\
1997, \text { up to } \\
2,777 \mathrm{mt} \text { per } \\
\text { year until } \\
2008\end{array}$ & $\mathrm{n} / \mathrm{a}$ & & $\begin{array}{l}\text { February } \\
2000\end{array}$ \\
\hline $\begin{array}{l}\text { Star Lake } \\
\text { Hydro } \\
\text { Partnership } \\
\text { (CHI Canada } \\
\text { and Abitibi } \\
\text { Consolidated) }\end{array}$ & $\begin{array}{l}\text { Ontario } \\
\text { Power } \\
\text { Generation }\end{array}$ & $\begin{array}{l}\text { Newfound } \\
\text { land, } \\
\text { Canada }\end{array}$ & $\begin{array}{l}\text { Renewable (hydro } \\
\text { power) }\end{array}$ & $\begin{array}{l}89,912 \mathrm{mt} \text { of } \\
\mathrm{CO}_{2} \text { in } 1999\end{array}$ & $\mathrm{n} / \mathrm{a}$ & & 1999 \\
\hline $\begin{array}{l}\text { Dupont } \\
\text { Canada }\end{array}$ & $\begin{array}{l}\text { Ontario } \\
\text { Power } \\
\text { Generation } \\
\text { (OPG) }\end{array}$ & $\begin{array}{l}\text { Ontario, } \\
\text { Canada }\end{array}$ & $\begin{array}{l}\text { Emissions } \\
\text { Abatement } \\
\text { Equipment }\end{array}$ & $\begin{array}{l}100,000 \mathrm{mt} \\
\text { of } \mathrm{CO}_{2}\end{array}$ & $\mathrm{n} / \mathrm{a}$ & & $\begin{array}{l}\text { Dec. } \\
1999\end{array}$ \\
\hline $\begin{array}{l}\text { Niagra } \\
\text { Mohawk }\end{array}$ & $\begin{array}{l}\text { Arizona } \\
\text { Public } \\
\text { Service }\end{array}$ & $\begin{array}{l}\text { United } \\
\text { States }\end{array}$ & Fuel Switching & $\mathrm{n} / \mathrm{a}$ & $\mathrm{n} / \mathrm{a}$ & & 1994 \\
\hline $\begin{array}{l}\text { Niagra } \\
\text { Mohawk }\end{array}$ & $\begin{array}{l}\text { Arizona } \\
\text { Public } \\
\text { Service }\end{array}$ & $\begin{array}{l}\text { United } \\
\text { States }\end{array}$ & $\begin{array}{l}\text { Interpollutant } \\
\text { switching }\left(\mathrm{SO}_{2}\right. \\
\text { credits for } \mathrm{CO}_{2} \\
\text { credits) }\end{array}$ & $\begin{array}{l}2.5 \text { million } \\
\mathrm{mt} \text { of } \mathrm{CO}_{2}\end{array}$ & & $\mathrm{n} / \mathrm{a}$ & 1996 \\
\hline $\begin{array}{l}\text { BP Amoco } \\
\text { Business } \\
\text { Units }\end{array}$ & $\begin{array}{l}\text { BP Amoco } \\
\text { Business } \\
\text { Units }\end{array}$ & Global & Various & $\begin{array}{l}49,000 \mathrm{mt} \\
\mathrm{CO}_{2}\end{array}$ & $\mathrm{n} / \mathrm{a}$ & & 1997 \\
\hline $\begin{array}{l}\text { BP Amoco } \\
\text { Business } \\
\text { Units }\end{array}$ & $\begin{array}{l}\text { BP Amoco } \\
\text { Business } \\
\text { Units }\end{array}$ & $\begin{array}{l}\text { Global (35 } \\
\text { Transactio } \\
\text { ns) }\end{array}$ & Various & $\begin{array}{l}361,000 \mathrm{mt} \\
\text { of } \mathrm{CO}_{2}\end{array}$ & & $\begin{array}{l}\$ 17-\$ 22 ; \\
\text { average } \$ 20\end{array}$ & $\begin{array}{l}\text { Sept. } \\
1998- \\
\text { Dec. } \\
1999\end{array}$ \\
\hline Costa Rica & $\begin{array}{l}\text { Consorcio } \\
\text { Noruego }\end{array}$ & Costa Rica & $\begin{array}{l}\text { Renewable (hydro } \\
\text { power) }\end{array}$ & $\begin{array}{l}4 \text { million } \mathrm{mt} \\
\text { of } \mathrm{CO}_{2} \text { over } \\
20 \text { years }\end{array}$ & $\mathrm{n} / \mathrm{a}$ & & 1999 \\
\hline $\begin{array}{l}\text { Pacifica } \\
\text { Paper, Inc. }\end{array}$ & $\begin{array}{l}\text { Not yet } \\
\text { identified }\end{array}$ & $\begin{array}{l}\text { British } \\
\text { Columbia, } \\
\text { Canada }\end{array}$ & $\begin{array}{l}\text { Cogeneration, } \\
\text { energy efficiency, } \\
\text { fuel switching }\end{array}$ & $\begin{array}{l}87,000 \mathrm{mt} \mathrm{of} \\
\mathrm{CO}_{2} \text { in } 1998, \\
117,000 \mathrm{mt} \\
\text { of } \mathrm{CO}_{2} \text { each } \\
\text { year after }\end{array}$ & & $\begin{array}{l}\text { US } \$ 3.3 \text { offer } \\
\text { price }\end{array}$ & $\begin{array}{l}1998- \\
2018(20- \\
\text { year } \\
\text { project } \\
\text { life) }\end{array}$ \\
\hline $\begin{array}{l}\text { State Forest } \\
\text { of New } \\
\text { South Wales }\end{array}$ & Pacific Power & $\begin{array}{l}\text { New } \\
\text { South } \\
\text { Wales, } \\
\text { Australia }\end{array}$ & $\begin{array}{l}\text { Forestry } \\
\text { (reforestation) }\end{array}$ & $\begin{array}{l}250,000 \mathrm{mt} \\
\text { of } \mathrm{CO}_{2} \text { over } \\
10 \text {-year } \\
\text { period }\end{array}$ & $\mathrm{n} / \mathrm{a}$ & & 1998 \\
\hline $\begin{array}{l}\text { Shell } \\
\text { Tradable } \\
\text { Emission } \\
\text { Permit } \\
\text { System } \\
\text { (STEPS) }\end{array}$ & $\begin{array}{l}\text { Business } \\
\text { Units of Shell }\end{array}$ & Global & Various & $\mathrm{n} / \mathrm{a}$ & $\mathrm{n} / \mathrm{a}$ & $\begin{array}{l}6-\$ 7 \\
\text { average; as } \\
\text { high as } \$ 14\end{array}$ & $\begin{array}{l}1999- \\
2000\end{array}$ \\
\hline
\end{tabular}


Table 9-7. Publicly Known $\mathrm{CO}_{2}$ Trades to Date (continued)

\begin{tabular}{|c|c|c|c|c|c|c|c|}
\hline Seller & Buyer & $\begin{array}{l}\text { Location } \\
\text { of Project }\end{array}$ & Type & $\begin{array}{l}\text { Quantity } \\
\text { mt = metric } \\
\text { ton }\end{array}$ & $\begin{array}{l}\text { Project } \\
\text { Cost (\$) }\end{array}$ & $\$ / \mathrm{mt}$ of $\mathrm{CO}_{2}$ & Date \\
\hline Belize & $\begin{array}{l}\text { Suncor } \\
\text { Energy }\end{array}$ & Belize & $\begin{array}{l}\text { Forestry } \\
\text { (reforestation) }\end{array}$ & $\begin{array}{l}400,000- \\
600,000 \mathrm{mt} \\
\text { of } \mathrm{CO}_{2} \text { over } \\
\text { 30-year } \\
\text { period }\end{array}$ & $\mathrm{n} / \mathrm{a}$ & & $\begin{array}{l}\text { Dec. } \\
1997\end{array}$ \\
\hline
\end{tabular}

\section{PART III: EXCHANGES AND INTERNET SITES}

Another interesting development in credit trading has been the development of exchanges to support the trading of various types of credits, principally carbon, between any two or more buyers. Most of these involve private market trades. Some of the following are brokers but serve as functional exchanges. This list is indicative and should not be considered exhaustive.

NatSource and Cantor Fitzgerald are two of the principal brokers that also serve as informal exchanges in many ways. The International Petroleum Exchange (IPE) is a London-based entity trying to create a carbon market, as is the World Bank's Carbon Bank. IPE hopes to establish a market for $\mathrm{CO}_{2}, \mathrm{NO}_{x}$, and $\mathrm{CH}_{4}$ emissions credits sometime in 2001. The Sydney Futures Exchange (SFE) is developing an exchange-style trading market for carbon sequestration credits. SFE is initially developing the carbon trading market in association with State Forests of New South Wales. The KEFI-Exchange in Alberta, Canada, is a members-only exchange for Canadian utilities but is expanding beyond carbon and into new markets. CarbonTrade, Inc., is part of a transparent, open exchange market. Emission Reduction Unit Procurement Tender is a governmental exchange run by the Netherlands Ministry of Economic affairs. The exchange buys reductions in GHG emissions generated by certifiable projects in central and Eastern Europe.

In the United States, Environmental Financial Products is funded by the Joyce Foundation and operates in the Midwest. The International Carbon Bank and Exchange (ICBE) in Tampa, Florida, is setting itself up as both exchange and partial backer of credits (utilizing certification and its own financial backing as a partial form of insurance). ICBE also expects to operate on the Internet in the future.

Several firms are beginning to offer on-line exchanges with the hope of being an ongoing matchmaker between buyers and sellers of various types of RECs, principally carbon at the present time. CO2e.com is Cantor Fitzgerald's exchange. Greenonline.com is a Virginia-based firm sponsored by Science Applications International Corporation (SAIC); its goal is environmental exchange on-line. Ecostech.com of New York is a start-up in e-business for the environment. PG\&E National Energy Group sells its PureWind certificates via the Internet to buyers in any market. EZWatt.com, the Web site of the EZ Watt subsidiary of Northern Alternative Energy, will provide one-stop, Internet-based shopping for green power and hopes to add green credit sales or trading in the near future. 


\section{BIBLIOGRAPHY}

Adels, P. (October 19, 2000). Presentation at ASERTTI Fall Meeting on Credit Trading. Bolton Landing, N.Y.: PennFuture.

Alderfer, B. Eldridge, M., and Rivera, S. (June 6, 2000). Integrating Renewable Energy and Clean Air Policy: Working Draft. Competitive Utility Strategies and Resource Catalysts. Draft REPP Paper.

Arn, M. (September 1998, updated October 2000). Multiple Pollutant Emission Reduction Reporting System. Madison, WI: Leonardo Academy. www.cleanerandgreener.org.

Bolinger, M., Porter, K., Wiser, R. (August 2000). Comparing State Portfolio Standards and System-Benefits Charges under Restructuring. A joint study of the Lawrence Berkeley National Laboratory and the National Renewable Energy Laboratory. www.nrel.gov/analysis/emaa/products.html.

California Environmental Protection Agency (Cal/EPA). (May 2000). Emission Reduction Offset Transaction Cost Summary Report for 1999. Sacramento, CA: Cal/EPA.

Carlson, L.A. (1996). NESCAUM/MARAMA NOx Budget Model Rule. Environmental Science Services. Boston, MA: NESCAUM.

Clemmer, S.L., Paulos, B., Nogee, A. (April 2000). Clean Power Surge: Ranking the States. Cambridge, MA: Union of Concerned Scientists.

Clemmer, S.L., Nogee, A., Brower, M.C.; Jefferiss, P. (January 1999). A Powerful Opportunity: Making Renewable Electricity the Standard Cambridge, MA: UCS.

Clemmer, S., Porter, K., Wiser, R. (1999). Emerging Markets for Windpower: the Role of State Policies Under Restructuring. Joint paper written by Lawrence Berkeley National Laboratory, NREL, and UCS. IN Proceedings: Windpower 1999. June 20-23, 1999. Burlington, VT: AWEA.

DOE EREN Network News. (November 15, 2000). “Green Power Companies Offering Flat Rates in California." Available on-line at www.eren.doe.gov/newsletter/archives/2000/nov15_00.html.

EIA. (October 9, 1998). Impacts of the Kyoto Protocol on U.S. Energy Markets and Economic Activity. Washington, DC: EIA. www.eia.doe.gov/oiaf/kyoto/kyotorpt.html.

Emissions Marketing Association and the Environmental Defense Fund. (1999). Emissions Trading Education Initiative: Emissions Trading Handbook. Milwaukee, WI: Emissions Trading Education Initiative.

EPA Office of Air and Radiation. Energy Efficiency and Renewable Energy Set-Aside in the NOx Budget Trading Program. Washington, DC: U.S. EPA. Available at www.epa.gov/spd/state_local_govnt/state_outreach/.

EPA Office of Air and Radiation. (March 1999). Guidance on Establishing an Energy Efficiency and Renewable Energy (EE/RE) Set-Aside in the NOx Budget Trading Program. Washington, DC: EPA.

Federal Trade Commission. (1998). "Guides for the Use of Environmental Marketing Claims". 16 C.F.R. Part 260.

Federal Trade Commission (August 2, 1984), "Policy Statement Regarding Advertising Substantiation Program". Federal Register 49 Fed. Reg. 30999.

Grace, R.C., Wiser, R.H., Abbanat, B. (July 2000). Massachusetts Renewables Portfolio Standard: RPS Accounting \& Verification Mechanisms and Policy Coordination Report, Summary. Report for the Massachusetts Department of Energy Resources (DOER). Boston, MA: DOER.

Guey-Lee, L. (1998). Wind Energy Developments: Incentives in Selected Countries. Washington, DC: U.S. DOE Energy Information Administration (EIA).

Hargrave, T. (June 2000). An Upstream/Downstream Hybrid Approach to Greenhouse Gas Emissions Trading. Washington, DC: Center for Clean Air Policy. 
Holt, E.A., Grace, R.C. (November 1999). Massachusetts Renewables Portfolio Standard White Paper \#11: The Relationship Between RPS and the Market for Green Power. Report for the Massachusetts DOER. Boston, MA: DOER.

Martin, N. "Verification Hitch to Green Market Launch" (Netherlands). (April 2000). Windpower Monthly, 16(04):35.

Milford, L. (October 2000). PRESENTATION Clean Energy Fund Network.

Mǿller, T. “Pressure to Unblock Market” (Denmark). (May 2000). Windpower Monthly, 16(05):26.

NAAG, Environmental Marketing Subcommittee of the Energy Deregulation Working Group. (December 1999). Resolution Adopting Environmental Marketing Guidelines for Electricity. Washington, DC: NAAG.

Nichols, D., Sarnow, H., Cory, K., Rosen, R. (May 1999). Funding for Energy-Related Public Benefits Needs and Opportunities With and Without Restructuring a Report to the Governor's Office of Energy Conservation. A Report to the Colorado Office of Consumer Counsel and the Governor's Office of Energy Conservation. Boston: Tellus Institute.

Pape, A., Raynolds, M. (July 2000). The Pembina Institute Green Power Guidelines for Canada. Alberta, Canada: The Pembina Institute for Appropriate Development.

Rader, N. (April 2000). "Getting It Right and Wrong in the States." Windpower Monthly News Magazine. Volume 16, No. 4.

Rolfe, C. (October 1998). Selling Clean Air: Market Instruments for Climate Protection. Vancouver, B.C.: West Coast Environmental Law Research Foundation.

Tietenberg, T. (1999). Tradable Permit Approaches to Pollution Control: Faustian Bargain or Paradise Regained? IN Kaplowitz, M.D. (ed.). Property Rights, Economics, and the Environment. Stamford, CT: JAI Press, Inc.

Western Regional Air Partnership. (August 2000). Facts about the Marketing Trading Proposal. Denver, CO, and Albuquerque, NM: Western Governors' Association and National Tribal Environmental Council.

Western Regional Air Partnership. (August 2000). Regional Haze Rule Implementation \& Backstop Market Trading Program. Denver, CO, and Albuquerque, NM: Western Governors' Association and National Tribal Environmental Council.

"The Windicator." (January 2001). Windpower Monthly.

"Windpower Shares Soar on Bright Growth Outlook. " October 6, 2000. Reuters.

Wooley, D., and Morss, E.M. The Clean Air Act: Opportunities for Renewable Energy. A report to the National Renewable Energy Laboratory; expected to be posted on NREL's Web site (www.nrel.gov) in the near future. Young, Summer, LLC. Albany, N.Y.

Wooley, D. (February 2000). A Guide to the Clean Air Act for the Renewable Energy Community. Renewable Energy Policy Project (REPP) Issue Brief No. 15. Washington, DC: REPP. www.repp.org.

UCS. (January 1999). A Powerful Opportunity. Cambridge, MA: UCS. p. 30.

UCS. (April 2000). Clean Power Surge: Ranking the States. Cambridge, MA: UCS. p. 5. 


\section{GLOSSARY OF TERMS}

Additionality

Allowance

Attribute

Baseline

Benchmark

Cap and trade

Carbon credit trading

Clean Development Mechanism (CDM)

\section{Closed trading system}

Credit

Emission Reduction
Credit (ERC)

Generation

Performance

Standard (GPS)

Generation disclosure

Green premium

Green pricing or green marketing

Green tag

Greenhouse gas
(GHG)
A rule governing the legitimacy of a given unit of trade or credit. The rule states that credits must be beyond what might be required in the absence of the activity or measure that produced the credit (i.e., one cannot get credit for meeting a standard that is required by law).

A unit of trade created by a governmental mandate as a "right" to emit a certain quantity (usually one ton) of a specific regulated pollutant.

Descriptive or performance characteristics of a particular generation resource. Attributes can include environmental benefits such as emissions offsets or avoidance, as, for example, from wind-generated electricity, and can denote characteristics such as type of resource, date and time of energy generation, location, and other environmental benefits or costs.

The starting point from which certain trading units are measured.

A reference point against which to compare emissions from different technologies.

A closed trading system whereby a ceiling is set on a regulated entity's total emissions of a pollutant within a given jurisdiction and then either held constant or gradually reduced. Regulated entities within that jurisdiction may trade freely with each other in order to meet their own cap.

A voluntary transaction of units of carbon dioxide emission reduction credits between two or more parties.

The instrument as referenced in Article 12 of the Kyoto Protocol treaty whereby units of carbon emission offsets are traded between Annex I (industrialized) and non-Annex I countries, or between countries with capped emissions and countries without capped emissions.

Systems that use defined emissions caps and are limited to identified participants (usually regulated major sources of emissions).

In this report, a vehicle or instrument for the conveyance, trade, or other use of attributes. Often a unit created as a representation of emissions avoidance or offsets that result from a specific project activity and measured against a specific benchmark.

A pollutant-specific unit of trade established under the New Source Review, or offset trading program of the 1990 Clean Air Act Amendments, equal to $1 \mathrm{ton} / \mathrm{yr}$ reduction in emissions for the life of the facility.

A pollution control mechanism, based on an emissions benchmark, which either generators or retail suppliers must meet; a unit of weight per kilowatt-hour.

A requirement under some state restructuring programs, whereby a utility must provide information to consumers on the resource mix from which its power is derived.

An incremental additional cost on a per-kilowatt basis meant to compensate for the additional cost of producing renewable energy.

The practice of offering consumers an option to pay a premium for the purchase of clean energy.

A nontangible product in the marketplace which represents or conveys the environmental attributes from the subject energy generation; i.e., the environmental benefit portion of renewable energy is stripped away and sold independently from the electricity component.

One of several gases that are considered major causes of climate change. Included are carbon dioxide $\left(\mathrm{CO}_{2}\right)$, methane $\left(\mathrm{CH}_{4}\right)$, nitrogen oxides $\left(\mathrm{N}_{2} \mathrm{O}\right)$, hydrofluorocarbons (HFCs), perfluorocarbons (PFCs), and sulfur hexafluoride ( $\left.\mathrm{SF}_{6}\right)$. 
Joint Implementation
(JI)

Kyoto Protocol

Leakage

Market mechanism

Monetize

New Source Review

Nonattainment area

Offset trading

Open trading systems

Particulate matter (PM)

Renewable Energy

Credit (REC)

Renewable Portfolio Standards (RPS)

RPS-REC

Set-aside

Source

State Implementation Plan (SIP)

System Benefit Charge (SBC)
The instrument as referenced in Article 6 of the Kyoto Protocol treaty, whereby $\mathrm{CO}_{2}$ emission reduction projects are implemented, and the resulting carbon offsets may be traded between two or more Annex I (industrialized) countries.

An international treaty, established in 1997 in Kyoto, Japan, which commits participating nations to quantified reductions of $\mathrm{CO}_{2}$.

A situation where the "greenness" of certain renewable energy electricity sources or products is somehow clouded or diminished.

A trading instrument that relies on market forces to establish buyers, sellers, and products for sale.

The process of giving monetary value to a commodity.

The regulation established under the 1990 Clean Air Act Amendments, whereby new sources of pollutant emissions must offset the emissions of neighboring sources in order to achieve no net gain in emissions in a given area.

A specific defined area or region that does not meet the National Ambient Air Quality Standards as defined by the 1990 Clean Air Act Amendments.

The mechanism established under the New Source Review program of the Clean Air Act, which allows trading of emission credits between sources.

Systems, generally voluntary, in which all (or many) sources can participate; credits are earned against benchmarks or historical emissions.

Solid or liquid particles found in the air, which can be directly emitted or can be formed in the atmosphere when gaseous pollutants such as $\mathrm{SO}_{2}$ and $\mathrm{NO}$ react to form fine particles.

A generic term denoting credit derived from renewable energy.

A state or federal level policy, often initiated under restructuring. The standards require that a minimum amount (usually a percentage) of the state's annual electric usage come from renewable energy.

Units of trade created under state RPS that are used to meet portfolio generation requirements.

A pool of emissions allowances that come from within a state's emissions budget and are not distributed to emissions sources, but rather held out specifically for renewable energy and energy efficiency project developers and vendors who implement an eligible project within that state.

A stationary facility or vehicle that emits a pollutant or pollutants.

A broad strategy, required of each state under the Clean Air Act for submission to the EPA. The SIP outlines how the state will control and reduce air pollution within its borders.

State-level policy, often initiated under restructuring, which imposes an added fee on electricity usage to support energy efficiency, renewable energy, and public benefit programs. 


\section{ACRONYMS AND ABBREVIATIONS}

\begin{tabular}{|c|c|}
\hline APX & Automated Power Exchange \\
\hline AWEA & American Wind Energy Association \\
\hline BAAQMD & Bay Area Air Quality Management District \\
\hline BACT & best available control technology \\
\hline BCSE & Business Council on Sustainable Energy \\
\hline BEF & Bonneville Environmental Foundation \\
\hline BPA & Bonneville Power Administration \\
\hline BPU & Board of Public Utilities \\
\hline CAAA & Clean Air Act Amendments of 1990 \\
\hline CDM & clean development mechanism \\
\hline CEC & California Energy Commission \\
\hline CERs & Certified Emission Reductions \\
\hline CFC & chlorofluorocarbon \\
\hline $\mathrm{CO}$ & carbon monoxide \\
\hline $\mathrm{CO}_{2}$ & carbon dioxide \\
\hline CRER & Conservation and Renewable Energy Reserve \\
\hline DER & discrete emission reductions \\
\hline DOE & U.S. Department of Energy \\
\hline DOER & Division of Energy Resources \\
\hline DSM & demand-side management \\
\hline EBI & environmental benefits inventory \\
\hline ECerT & European Renewable Energy Certificate Trading Project \\
\hline EIP & Economic Incentive Program \\
\hline EPA & U.S. Environmental Protection Agency \\
\hline EPAct & Energy Policy Act \\
\hline EPP & environmentally preferred power \\
\hline ERC & emission reduction credit \\
\hline ERCOT & Electric Reliability Council of Texas \\
\hline EREN & Efficiency and Renewable Energy Network (DOE) \\
\hline ERMS & Emissions Reduction Market System \\
\hline ERU & emission reduction unit \\
\hline EU & European Union \\
\hline FERC & Federal Energy Regulatory Commission \\
\hline FTC & Federal Trade Commission \\
\hline GHG & greenhouse gas \\
\hline GIS & generation information system \\
\hline GPS & generation performance standards \\
\hline HB & House Bill \\
\hline ICBE & International Carbon Bank and Exchange \\
\hline IMPACT & Innovative Market Program for Air Credit Trading \\
\hline IPE & International Petroleum Exchange \\
\hline ISO & independent system operator \\
\hline JI & Joint Implementation \\
\hline LAER & lowest achievable emissions rate \\
\hline
\end{tabular}

LAER

lowest achievable emissions rate 


\begin{tabular}{|c|c|}
\hline $\begin{array}{l}\text { MGE } \\
\text { MSW } \\
\text { MW } \\
\text { MWh }\end{array}$ & $\begin{array}{l}\text { Madison Gas \& Electric } \\
\text { municipal solid waste } \\
\text { megawatts } \\
\text { megawatt-hours }\end{array}$ \\
\hline NAAG & National Association of Attorneys General \\
\hline NAAQS National & Ambient Air Quality Standards \\
\hline NARUC National & Association of Regulatory Utility Commissioners \\
\hline NECPUC & New England Coalition of Public Utility Commissioners \\
\hline NEPOOL & New England Power Pool \\
\hline NESCAUM & Northeast States for Coordinated Air Use Management \\
\hline NGO & nongovernmental organization \\
\hline $\mathrm{NO}_{x}$ & oxides of nitrogen \\
\hline NREL & National Renewable Energy Laboratory \\
\hline NSR & New Source Review \\
\hline NWCC & National Wind Coordinating Committee \\
\hline NYSERDA & New York State Energy Research and Development Authority \\
\hline OCT & Oregon Climate Trust \\
\hline OMET & Open Market Emissions Trading Program \\
\hline ОТС & Ozone Transport Commission \\
\hline PG\&E & Pacific Gas and Electric \\
\hline PM & particulate matter \\
\hline PSCO & Public Service of Colorado \\
\hline PUC & Public Utility Commission \\
\hline RE/EE & renewable energy and energy efficiency \\
\hline REC & renewable energy credit \\
\hline RECLAIM & Regional Clean Air Incentives Market \\
\hline REPP & Renewable Energy Policy Project \\
\hline RPS & renewable portfolio standards \\
\hline RTO & Regional Transmission Organization \\
\hline SAIC & Science Applications International Corporation \\
\hline SBC & system benefit charge \\
\hline SCAQMD & South Coast Air Quality Management District \\
\hline SCE & Southern California Edison \\
\hline SFE & Sydney Futures Exchange \\
\hline SIP & state implementation plan \\
\hline SMUD & Sacramento Municipal Utility District \\
\hline $\mathrm{SO}_{2}$ & sulfur dioxide \\
\hline STEPS & Shell Tradable Emission Permit System \\
\hline TNRCC & Texas Natural Resource Conservation Commission \\
\hline UCS & Union of Concerned Scientists \\
\hline UNFCCC & United Nations Framework Convention on Climate Change \\
\hline VER & verified emission reduction \\
\hline VOC & volatile organic compound \\
\hline WRAP & Western Regional Air Partnership \\
\hline ZAPCO & Zahren Alternative Power Corp. \\
\hline
\end{tabular}




\section{Appendix A \\ Sample Database Printout (\#2 of 60 records)}

Complete database available soon at www.nationalwind.org.

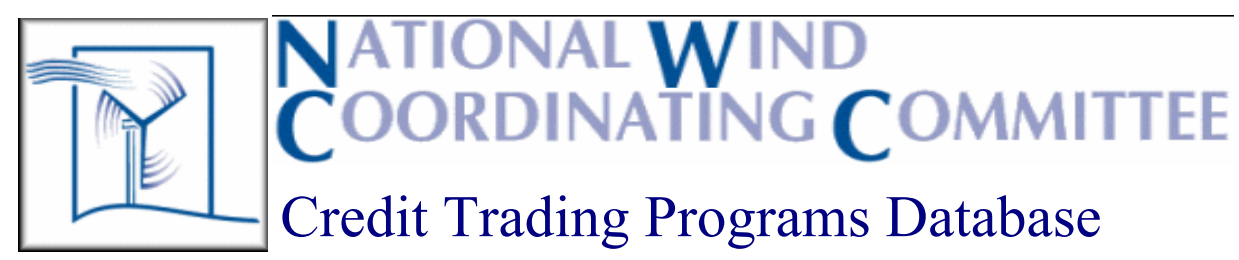

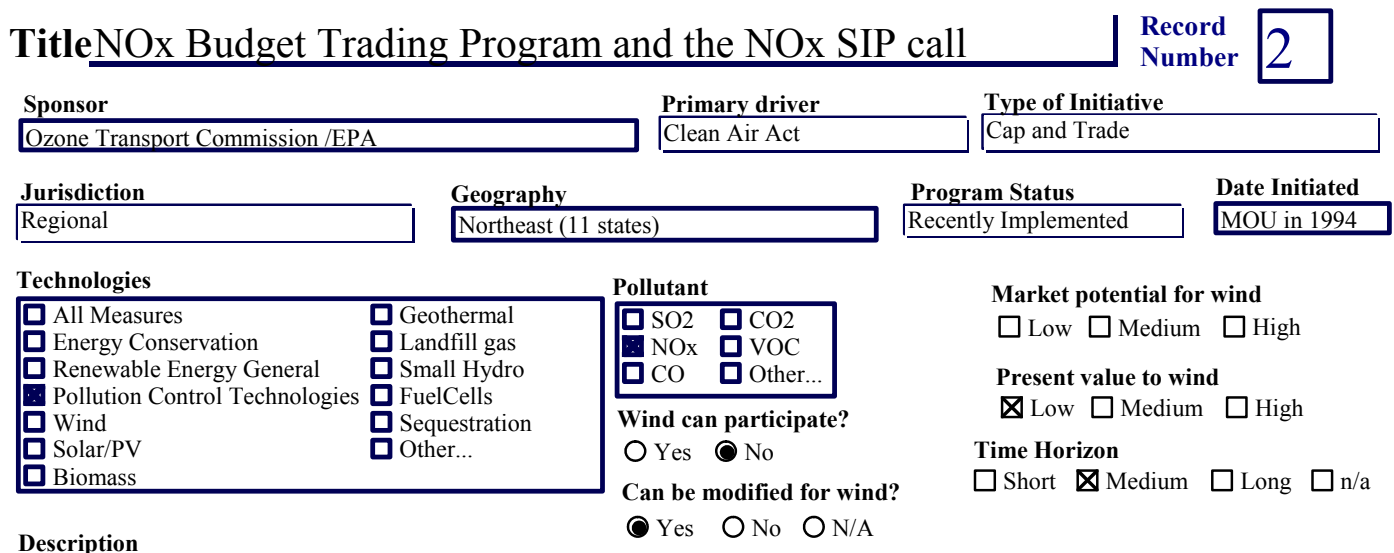

The NOx Budget program was implemented under the clean air act as a means of controling ground level ozone by reducing NOx emissions and affects 11 states and the District of Columbia. The Clean air act sets up the Ozone Transport Commission to oversee and regulate the trading program. OTC states and EPA developed a model rule, which identifies regulatory elements that must be consistant in order to creat an interstate emissions trading program. Each state must develop and adopt rules that are consistant with the model rule. 2 phase program with emission targets for each -- 1st phase beginning May 1, 1999 and the second phase beginning May 1, 2003. States are given maximum autonomy in adopting regulations, provided that the total amount of allowances they allocate do not exceed their NOx budget. The allowance trading system is similar to the EPA's SO2 program (see record \#1). Sources must monitor and report emissions to EPA. Full compliance with the Federal NOx budget trading program is required starting May1, 2003. NOx market prices have been volatile. In 1998 trades were stable in the $\$ 3,000$ per ton range. Then as the first NOx season approached, prices rose to over $\$ 7,000$ per ton. However, current prices have been under $\$ 1,000$ per ton. This program includes an incentive set-aside for energy efficiency and renewable energy. Under the current rule (1999-2002), "incentive" allowances are allocated to all persons who save electricity through the implementation of $\mathrm{E}$ or RE projects. Starting in 2003, this incentive set-aside will be reduced to $5 \%$ of the total allowances from under the cap as part of the Ozon Transport Assessment Group (OTAG) NOx budget program. (see record \#11) In the NOx SIP Call, each of 22 states pluc D.C. are required submit state implementation plans (SIP) to the EPA SIPs can include the installation of reasonably available control technology renewahld

Trading Rules

The OTC implements reductions through a "cap and trade' program. Budget sources are allocated allowances by their state government. Each allowance permits 1 ton NOx during control period. For each ton of NOx discharged in a give control period, one allowance is retired and can no longer be used. Allowances may be bought, sold or traded by any individual, company, etc. like the SO2 program (see record \#1 At the end of the ozone season, emitters have until Dec 31 to balance their books to be certain they have sufficient allowances to cover their emissions. Emitters are able to bank unused allowances for future use. In exchange for unlimited banking, limits are placed on how allowances are withdrawn from the bank under certain circumstances. Specifically, if banked allowances exceed $10 \%$ of the total allocation for a given year; then a withdrawl procedure is applied to the next year. Up to a certain ration of allowances can be withdrawn and used on a 1:1 basis. the remainder of the allowances in the bank must be surrendered on a 2:1 basis.

Contacts
\begin{tabular}{|l|l|l|}
\hline Connecticuit & Phone & Email \\
\hline Delaware & $(860) 424-3027$ & Massachusetts (617) 292-5593 \\
\hline Washington D.C. & $(302) 739-4791$ & New Hampshire (603) 271-1370 \\
\hline Maine & $(202) 287-2437$ & New Jersey (609) 292-6710 Virginia (804) 698-4014 \\
\hline Maryland & $(207) 287-2437$ & New York (518) 457-0631 Pennsylvania (717) 787-4310 \\
\hline
\end{tabular}

Info Sources

www.epa.gov/acidrain/otc/ovrvw

Carlson, Laurel J., "NESCAUM/MARAMA NOx Budget Model Rule", prepared for the NESCAUM/MARAMA NOx Budget Task Force, NESCAUM/MARAMA NOx Budget Ad Hoc Committee, and the Ozone Transport Commissions Stationary and Area Source Committee, May 1,1996 